\title{
REIMAGINING A PLACE FOR GRAMMAR IN LANGUAGE ARTS INSTRUCTION
}

\author{
A Dissertation \\ Presented to \\ The Faculty of the Curry School of Education \\ University of Virginia \\ In Partial Fulfillment \\ of the Requirements for the Degree \\ Doctor of Philosophy \\ by \\ Lauren Burrow Gartland, M.Ed., B.A.
}

December, 2014 


\section{TABLE OF CONTENTS}

$\begin{array}{lll}\text { Page } & \end{array}$

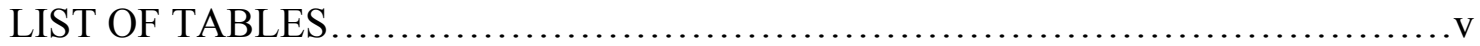

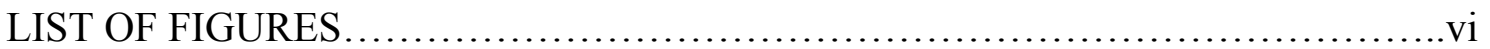

\section{ELEMENTS}

DISSERTATION ABSTRACT

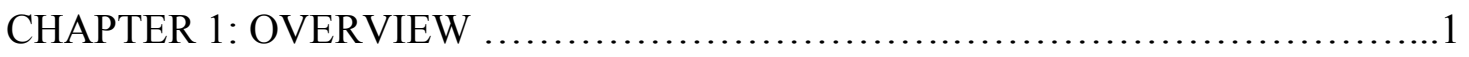

Linking Document: Three Papers on Grammar: An Overview and Orientation References............................................................. 8

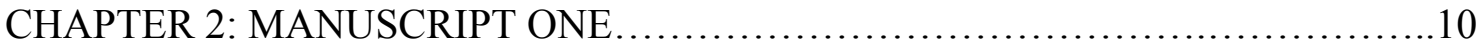

"It Just Flows": Preservice Teachers Grapple with Academic Language

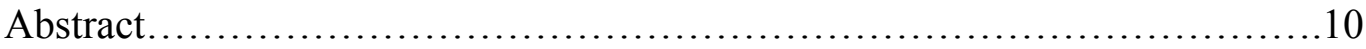

Introduction...............................................................

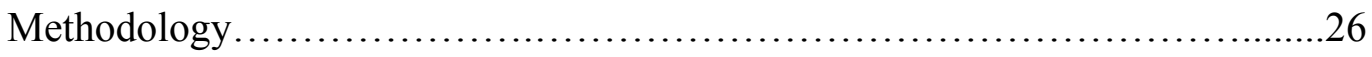

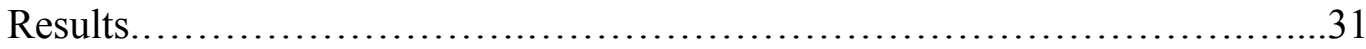

Discussion/Implications.................................................. 41

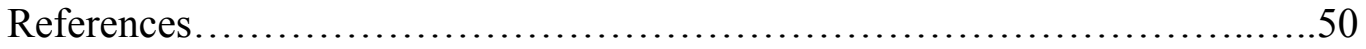

Appendix A. Gibbons (1999) Sentence Document................................56

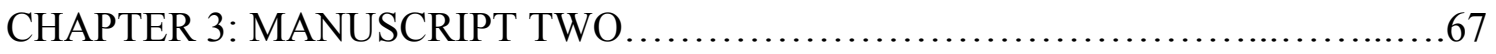

Highlighted History of Grammar Instruction: What Lessons Can We Learn Moving Forward? 


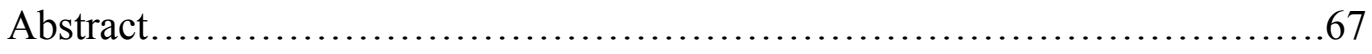

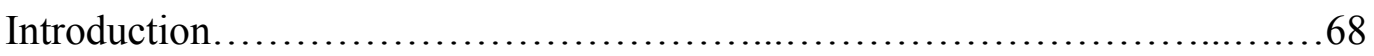

Methodology......................................................... 70

Ancient Grammar Instruction: Citizens, Integrated Curriculum, and Facilitas.....71

Grammar Instruction in England: The Shift from Latin to English...............77

The Rise of Prescriptive Grammar..................................... 82

Prescriptive Grammar's Lasting Legacy in the United States..................90

Recent Rise of National Standards (and the Resurgence of Grammar)..........105

References..........................................................111

CHAPTER 4: MANUSCRIPT THREE..................................... 122

The Histories and Mysteries of Grammar Instruction: Supporting Elementary

Teachers in the Time of the Common Core

Abstract..........................................................122

Introduction........................................................................ 123

What is Grammar?........................................................123

A Brief History of Grammar Instruction.......................................124

Promising Approaches to Grammar Instruction..................................126

Final Thoughts.................................................... 136

References.......................................................................138 


\section{LIST OF TABLES}

\section{Manuscript 1}

Table 1: Researcher Analysis of Gibbons (1999) Sentences ................... 57

Table 2: Codes from Student Explanations...............................61

Manuscript 3

Table 1: Sources for Your Own Grammar Knowledge......................... 142

Table 2: Objectives for Teaching Grammar............................. 143

Table 3: New Ways of Talking About Language.......................... 144

Table 4: Sample Children's Literature for Linguistic Diversity Appreciation...145

Table 5: Informal versus Formal Language Use............................ 146 


\section{LIST OF FIGURES}

Manuscript 1

Figure 1. Looking at Language Complexity....................................... 66 


\begin{abstract}
This three-manuscript dissertation includes a linking document and three manuscripts crafted around the central topic of grammar instruction. The three papers presented herein represent an intellectual journey I began when working as a teaching assistant with University of Virginia preservice Elementary Education students. At that time, I became aware of the students' lack of comfort with grammatical concepts. It has been my goal in this work to ascertain the nature of preservice elementary education students' grammar knowledge, to discover the historical source of their insecurities, and to consider existing pedagogies they can implement to foster greater pedagogical competence for themselves and the young children they will teach. The first paper describes an empirical study I completed to examine preservice students' grammatical knowledge. In that work, I discovered not only that the students had considerable trouble explaining the grammatical features of the targeted sentences, but also that they frequently demonstrated an uneasiness with the task by stating upfront that they were not confident in their grammar knowledge. The second paper presents a highlighted history of grammar instruction. Through the historical documents I reviewed and the studies, books, and papers I read, I determined that many of the untenable pedagogical practices associated with grammar had their origin in the rise of prescriptive grammar during the 18th century. Objections to those practices led to a reduced grammar emphasis in U.S. Schools; that trend has now been reversed with the appearance of the Common Core State Standards (CCSS; National Governors Association Center for Best Practices \& Council of Chief State School Officers, 2010). The third paper is designed to inform a larger, teacher audience of my historical findings as well as practices I reviewed that have the potential to foster children's in-depth grammar knowledge.
\end{abstract}





\section{CHAPTER 1}

\section{Three Papers on Grammar: An Overview and Orientation}

When I was serving as a Teaching Assistant (TA) for EDIS 5300/EDIS 5310 (Language Bloc), I was not only surprised to see how difficult it was for the students to talk about grammar, but to see as well that the topic seemed to induce a great deal of anxiety. Consider, for example, the following passage in E.B. White's (1952) Charlotte's Web:

With her broad bill, the goose pushed the rotten egg out of the nest, while the entire company watched in disgust as the rat rolled it away to eat, and even Wilbur, who could eat almost anything, was appalled. (p. 45)

When we examined this and other similar sentences in White's work, our Elementary Education (ELED) preservice students were preoccupied with the idea of avoiding "run on" sentences; they had difficulty distinguishing between the excellence of White's beautifully crafted, complex sentences, based on his own deep syntactical knowledge and their own experiences having been criticized for producing long, incoherent sentences.

The scholarly papers included in this manuscript-style dissertation represent the journey I took as I sought to confirm my early impressions of our students' grammar knowledge, sought to understand how our students knew so little grammar, and sought to offer at least some minimal support, not just for our students, but also for the many United States teachers who, in light of the Common Core State Standards (CCSS; National Governors Association Center for Best Practices \& Council of Chief State School Officers, 2010), have suddenly been confronted with the need to teach grammar to their own elementary students.

Grammar, of course, is what links these three papers, or to be more specific, it is teachers' grammar instruction that weaves the three papers together. As I sought to discover why the 
Language Bloc students could not intelligibly discuss the varying complexities of sentences their future students might read or speak, I came to understand that something called prescriptive grammar lay at the heart of the students' dilemmas. Prescriptive grammar (PG), as I discuss extensively in the second of my papers (Highlighted History of Grammar Instruction: What Lessons Can We Learn Moving Forward?), is intricately interwoven with the concept of a Standard grammar and its proponents' frequent assertion that there is a single proper way to write and speak. PG has largely dominated grammar instruction since the eighteenth century, and as a result, despite the increasingly multilingual and multidialectal nature of the children in American schools, deeply engrained beliefs about monolingualism (e.g., focusing on "remediating" children's language to match a single correct form of English rather than focusing on ways to expand their linguistic repertoires) continue to plague English-standards reforms (Kibler, Valdés, \& Walqui, 2014). Although there is brief mention of respect for dialect and variation, the CCSS are predominantly focused on America's U.S. children learning a single, valued language, that being Standard English (SE). Although there may be a lack of consensus regarding what SE actually is (Trudgehill, 1999), David Crystal (1994), a leading authority on the English language, has defined SE as "the variety [of English] which is used as the norm of communication by the communities leading institutions, such as the government, law courts, and media" (p. 24).

As I also discuss in my second paper, an emphasis on a SE may be desirable in many ways. To begin, a standardized form of English offers "an essential medium of communication in a diverse world" (Crystal, 2006, p. 93). As Kerswill and Culpeper (2009) have argued, SE “allows people of different walks of life to communicate more easily" (p. 224); without a Standard, issues around clarity and comprehension may arise, and misunderstandings can lead to 
unnecessary conflicts (Bex \& Watts, 1999). Furthermore, more and more scholars have argued that students need instruction in SE because it remains deeply engrained as a source of power and privilege in our society, and students need access to the "standard variety [of English] associated with academic success and upward socioeconomic mobility" (Rickford \& Rickford, 2007, p. 276). In particular, children who have limited access to these grammatical features in their home communities may have fewer opportunities to develop such linguistic knowledge naturally on their own. This group includes English language learners (ELLs), "students whose home languages are other than or in addition to English" (Kibler et al., 2014, p. 436) as well as language minority students (LMs), students who speak English, but a variety that is typically stigmatized in schools.

What has been wrong historically is the pedagogy attached to that Standard. PG pedagogy is not only fraught with a preponderance of skills, drills, and memorization, it is also bound to shame. For hundreds of years, grammar pedagogy has effectively let large classes of children know that their English was (and is) "no good," and that they, as non-SE speakers, were/are also no good. This sense of "no good" was even visible in the data I collected from our UVa students -- "I'm no good at this stuff"; "I don't really get it."

It seemed to me, as I thought of our students, and as I increased my own understanding of grammar pedagogies, that there exists the possibility of escaping from pedagogies that shame students. For example, Myhill, Jones, Watson, and Lines (2013) found statistically significant positive effects for students who received grammar instruction grounded in Carter and McCarthy's (2006) theoretical framework, which focused on grammatical structure (e.g., how words, sentences, and texts are constructed) as well as grammatical choice (e.g., the range of possibilities open to a language user, and how those choices construct meaning). By clearly 
linking how grammatical choices impact an author's intended message, teachers armed with a deep understanding of grammar were uniquely poised to empower students to effectively use language in a variety of different contexts for a variety of different purposes.

As I continued to work my way through the literature, it became clear that scholars and researchers were conceptualizing grammar in very different ways, and as a result, teachers were enacting pedagogies related to grammar in very different ways. Specifically, the differing beliefs about the goals of grammar instruction and how such instruction might benefit students had a huge impact on how teachers enacted grammar instruction in their classrooms. Even more, teachers' own grammatical knowledge was a significant factor in whether or not grammar instruction could improve students' literacy outcomes (Myhill, Jones, \& Watson, 2013).

\section{Dissertation Manuscripts}

Accordingly, my dissertation builds upon the various theoretical conceptualizations of grammar instruction in an effort to 1) better understand the controversies associated with grammar, and 2) consider what directions (if any) hold promise as teachers move to implement the CCSS language standards related to SE grammar. In the following section, I briefly describe each manuscript and end with an explanation of how my work helps to fill current gaps in our literature.

\section{Manuscript One: Preservice Teachers Grapple with Academic Language}

To begin, I conducted a study aimed at understanding how preservice teachers approached the task of explaining "what makes a sentence easy or hard to understand" (Wong Fillmore \& Snow, 2000, p. 30). Their explanations revealed that although they were fairly adept at explaining difficult vocabulary, they had considerable trouble explaining the grammatical features of the sentences that might impact children's comprehension. Many were limited to 
vague language (e.g., "This sentence is too wordy;" This sentence is awkward"), and their comments revealed an intense focus on error-avoidance ("I think this sentence is in the passive voice and I am constantly being told not to write in the passive voice"). In the absence of grammar knowledge, it seemed that large numbers of ELED students were left to rely upon years of limited writing feedback as their only strategy for explaining the potential difficulty of the sentences; further, they frequently demonstrated an uneasiness with the task by stating upfront that they were not confident in their grammar knowledge ("My grammar knowledge isn't the best.").

\section{Manuscript Two: Highlighted History of Grammar Instruction}

In light of the results of my first study, I wanted to better understand the history of how grammar became a topic associated with fear and failure rather than one of empowerment. Accordingly, my second study is a historical review aimed at examining how the goals of grammar instruction (and associated pedagogies) have changed over time. Specifically, I wanted to examine what a long view might reveal in terms of turning away from a focus on erroravoidance to a focus on arming students with a deep sense of language competence. I found that the original goal of grammar instruction was not at all focused on developing a single, correct form of a language (as seen in PG). Instead, ancient scholars promoted grammar instruction in pursuit of facilitas ("the habitual capacity to produce appropriate and effective language in any situation" (Murphy, 2012, p. 38). Their goal (not unlike the CCSS goal) was to prepare students for active citizenship in their society. The multi-method pedagogy of Roman times was specifically designed to develop in students "the deeply-rooted capacity to employ language wherever needed, on whatever subject, in whatever circumstances” (Murphy, 2012, p. 73). Regrettably, as instructional attention shifted from Latin to English, and in light of multiple 
social, cultural, and economical influences, the study of grammar within a highly integrated language arts curriculum tumbled into obscurity, and the prescriptive grammarians' influence

gained prominence. PG's continued emphasis on correctness and error avoidance helps explain our ELED students' comments; long-established PG pedagogies continue to plague grammar instruction even today. I end that paper by arguing that a return to Quintilian's notion of facilitas within a highly integrated language arts curriculum may hold the key to grammar instruction moving forward.

\section{Manuscript Three: Supporting Elementary Teachers in the Time of the Common Core}

Finally, in an effort to disseminate my new knowledge to a broader audience, I designed my final paper as a practitioner piece, aimed at providing teachers some insight to the controversies around grammar as well as some practical suggestions as to how they might approach grammar instruction in their own classrooms. In that work, I addressed teachers' own levels of grammatical knowledge, then specifically focused on pedagogies intended to expand students' linguistic repertoires rather than shaming them for the language of their home communities.

\section{How the Studies Address Current Gaps in Research}

It is my hope that, together, these three manuscripts will begin to fill distinct gaps in the literature on grammar instruction. An important first step in designing instruction begins with a baseline understanding of what students know. My first study addresses this necessary first step by establishing the current state of preservice teachers' grammar knowledge. With these results, we can begin to examine ways to adapt University-level instruction based on existing preservice teachers' needs. My second study provides much needed information about the history of grammar instruction. That study provides the explanation for the results of the first; it is clear 
that many of our ELED students' grammar educations were impacted by historical decisions to abandon grammar instruction. The history I presented not only helps demonstrate how grammar instructions' negative impacts led to its abandonment, but it also provides guidance for reconceptualizing a clear link between deep grammatical understandings and students' ability to use language well. My third and final manuscript is designed to help teachers understand their own lack of grammar knowledge through a quick look at the histories and controversies surrounding grammar instruction and to improve their thinking about grammar instruction by offering them some specific strategies to employ with their own students as they attempt to move away from PG pedagogies and towards grammar instruction that will empower all of America's students. 


\section{References}

Bex, T., \& Watts, R. J. (Eds.). (1999). Standard English: The widening debate. New York, NY: Routledge.

Carter, R., \& McCarthy, M. (2006) Cambridge grammar of English. Cambridge, UK: Cambridge University Press.

Crystal, D. (1994). What is standard English? Concorde (English-speaking Union), 24-26. Retrieved from http://www.davidcrystal.com/?id=4068\&fromsearch=true

Crystal, D. (2006). The fight for English: How language pundits ate, shot, and left. Oxford, UK: University Press.

Kerswill, P. \& Culpeper, J., (2009). Standard English and standardization. In J. Culpeper, F. Katamba, P. Kerswill, T. McEnery., \& R. Wodak. (Eds.), English Language and Linguistics. (pp. 223-243). Basingstoke, UK: Palgrave.

Kibler, A., Valdés, G., \& Walqui, A. (2014). What does standards-based educational reform mean for English language learner populations in primary and secondary schools? TESOL Quarterly, 48(3), 433-453. DOI: 10.1002/tesq.183

Murphy, J. (2012). Roman writing instruction as described by Quintilian. In J. Murphy (Ed.) A Short History of Writing Instruction: From Ancient Greece to Contemporary America ( $3^{\text {rd }}$ ed., pp. 36-76). New York, NY: Routledge.

Myhill, D., Jones, S., \& Watson, A. (2013). Grammar matters: How teachers' grammatical knowledge impacts on the teaching of writing. Teaching and Teacher Education, 36, 7791. Retrieved from http://dx.doi.org/10.1016/j.tate.2013.07.005

Myhill, D., Jones, S., Watson, A., \& Lines, H. (2013). Playful explicitness with grammar: a pedagogy for writing. Literacy, 47(2), 103-111. DOI: 10.1111/j.1741-4369.2012.00674.x 
National Governors Association Center for Best Practices \& Council of Chief State School Officers. (CCSS, 2010). Common Core State Standards for English language arts \& literacy in history/social studies, and technical subjects. Washington, DC: Authors. Retrieved from http://www.corestandards.org/ELA-Literacy/

Rickford, A. E., \& Rickford, J. R. (2007). Variation, versatility, and contrastive analysis in the classroom. In R. Bayley and C. Lucas (Eds), Sociolinguistic variation (pp. 276-296). Cambridge, UK: Cambridge University Press.

Trudghill, P. (1999). Standard English: What it isn't. In T. Bex \& R. J. Watts (Eds.), Standard English: the widening debate (pp. 117-128). London, UK: Routledge.

White, E.B. (1952). Charlotte's web. New York, NY: Harper \& Bros.

Wong Fillmore, L., \& Snow, C. (2000). What teachers need to know about language. ERIC Clearinghouse on Languages and Linguistics. Retrieved from http://eric.ed.gov/?id=ED4443 


\title{
CHAPTER 2
}

\section{Manuscript 1: "It Just Flows": Elementary Preservice Teachers}

\section{Grapple with Academic Language}

\begin{abstract}
The purpose of this study was to examine how well elementary preservice teachers were able to explain the linguistic complexity of varying sentences and to consider what their explanations reveal about their knowledge of academic language factors. Ninety-seven preservice teachers were presented with a series of sentences describing the cause-and-effect relationship between rain and soil erosion and asked to explain what factors might make the sentence easier or more difficult to understand. Drawing from Ravid's (2004) work on linguistic complexity as well as Systemic Functional Linguistics (SFL; Halliday \& Hasan, 1976), we used systematic data analysis (Miles \& Huberman, 1994) to analyze their explanations. Results suggest that the preservice teachers in the study were ill-prepared to discuss academic language features.
\end{abstract}




\section{"It Just Flows": Elementary Preservice Teachers}

Grapple with Academic Language

Recently, the number of studies substantiating the link between student academic language proficiency (also referred to as academic English, advanced literacy, and the language of schooling) and school success has increased dramatically (for reviews see Nagy \& Townsend, 2012; Schleppegrell, 2004; Snow \& Uccelli, 2009). Snow and Uccelli (2009) have explained the relationship:

Indeed, it seems clear that control over academic language is a requirement for success with challenging literacy tasks, such as reading textbooks or writing research papers and literature reviews. As early as the middle-elementary grades, students are expected to learn new information from content-area texts, so failure to understand the academic language of those texts can be a serious obstacle in their accessing information (p.112).

Understanding academic language has been identified as a key obstacle for both struggling readers and English language learners largely because "schooling is primarily a linguistic process, and language serves as an unconscious means of evaluating and differentiating students" (Schleppegrell, 2004, p. 1; see also, Christie \& Martin, 1997, 2007; Unsworth, 2000). In fact, Christie $(1985 ; 1999)$ has referred to the language of schooling as a hidden curriculum. For example, if a child is unfamiliar with the linguistic expectations at school and presents information using features typical of his own oral language, the teacher may judge his speech (or writing) to be unclear or poorly organized (e.g., Michaels, 1981). Over the course of time, a teacher with a limited understanding of the linguistic challenges of academic presentation may unintentionally attribute the child's "confusion" (or apparent lack of reasoning) to a learning 
disability rather than recognizing that the child needs instruction on how to express his knowledge within the parameters of school expectations (Schleppegrell, 2004).

The same is true for reading comprehension. If a child uses her understanding of oral, everyday language as a guide when reading, for example, a scientific text, the child will likely experience less success because the linguistic expectations in the texts will be different (Leu, 1982; Unsworth, 2000). This problem becomes particularly acute as students get older and encounter more lexically and conceptually dense texts (Fang, 2006; Shanahan \& Shanahan, 2008).

Children's difficulty with academic language may be grounded in underdeveloped knowledge of particular lexical (e.g., vocabulary) and syntactic (e.g., how a sentence is structured) features (e.g., Coleman \& Pimental, 2011; Lee \& Sprately, 2010). Teachers, then, must have the ability to help their students develop these linguistic features (e.g., the "secrets" of academic language) from an early age to prepare children for both successful reading comprehension and ultimate school success. A failure to do so disadvantages children both in terms of life and academic achievement (Schleppegrell \& Colombi, 2002; Unsworth, 2000).

The question, then, arises: how well do teachers themselves understand the features of academic language? Or, more importantly, given their need to guide their students' understanding, how well can teachers explain these features? Unfortunately, there is little scholarship that addresses what teachers know about language, and what does exist suggests that they may be ill-prepared to talk about the structures of language that could be problematic for children (Fillmore \& Snow, 2000; Moats, 1994, 2009; Snow, Griffin, \& Burns, 2005). The purpose of the study described in this paper then, was to examine how elementary preservice teachers explain the linguistic complexity of varying sentences and to consider what their 
explanations reveal about their knowledge of academic language factors, factors that may impede both text comprehension and school/life success.

In the review below, we examine literature that addresses not only the linguistic complexity of academic language, but also what is currently known about elementary teachers' knowledge of this phenomenon.

\section{Conceptualizing and Defining Academic Language}

Grappling with the concept of academic language is not easy. To begin, researchers have yet to agree on a formal definition of academic language. In an attempt to create more unity in the field, Nagy and Townsend (2012) have offered the following definition: "Academic language is the specialized language, both oral and written, of academic settings that facilitates communication and thinking about disciplinary content" (p. 47). Although this definition is quite broad, it can serve as a reasonable starting point for examining the differences between everyday language and academic language.

\section{A Closer Look at Everyday Language and Academic Language}

Scholars have characterized the challenges of academic language as consisting not only of unique and rare vocabulary but also of specific grammatical and syntactical structures signaling key relationships in text, features that are typically absent in everyday language (Bailey, 2006; Fang, 2004, 2006; Scarcella, 2003; Schleppegrell, 2004; Snow \& Uccelli, 2009). Although the boundaries between academic language and everyday language are not always clear, these scholars display key differences by comparing and contrasting the characteristics of each. For example, academic language is characterized by the use of a variety connectives (linguistic units that help readers link text ideas across clauses, e.g., whereas, although, therefore), nominalizations (the transformation of a verb to a noun, e.g., investigate to 
investigation), high lexical density (the number of content-specific words per clause), embedded clauses (e.g., the boy who wore the red shirt was his cousin) and passive voice (e.g, the boy caught a fish vs. the fish was caught by the boy). These more complex grammatical features lead towards a detached and authoritative stance and create the effect of presenting more objective information (Fang, 2006; Snow \& Uccelli, 2009). Additionally, these grammatical choices enable authors to create logical links between and among points of information; they also achieve greater overall organization and density of text (Eggins, 2004; Fang, 2004;

Schleppegrell, 2004; Snow \& Uccelli, 2009). In contrast, everyday language is more commonly delivered with low lexical density, a limited variety of familiar connectives (e.g., and, because), in an order that matches the perceived reality, and with considerable redundancy (Christie \& Derewianka, 2008; Snow \& Uccelli, 2009). Not surprisingly, the features of academic language take many more years to develop (Berman, 2008; Olshtain \& Cohen, 2004; Ravid, 2004).

Disciplinary differences. An additional reason that academic language presents a unique challenge is that the grammatical and syntactic features that characterize different disciplines frequently vary. For example, the language used in a historical narrative is often different from the language found in a scientific explanation (Coffin, 2006; Veel, 1997). A historical narrative (e.g., a recount of George Washington Carver's time at the Tuskegee Institute) retells and organizes events with primarily temporal links (Coffin, 2006). In contrast, a scientific explanation (e.g., what causes erosion to occur) must describe both how a sequence of events occurs and why it occurs. So, in addition to linking events as a sequence, the author of a scientific explanation must also include causal links explaining a phenomenon in the physical world (Veel, 1997).

The grammatical features of each discipline serve a specific function in delivering 
specialized knowledge (Christie \& Martin, 2007). For example, Fang (2006) has explained that scientific language has its own socially constructed characteristics that are different from everyday, spoken language, saying,

The language of science has evolved, for functional reasons, from the everyday language of ordinary life in order to meet the needs of scientific methods as well as those of scientific arguments and theories. It contains unique lexicon, semantics, and syntax. (p. 493).

Therefore, students must acquire understanding of generic differences in academic language in order to fully comprehend and ultimately produce texts appropriate to different disciplines. Because language is developmental in nature, attention to these disciplinary differences must occur early to prepare children for success later on in their school careers.

Scientific text. The study described in this paper specifically focused on the academic language found in science texts. Fang (2004) explains, "Students who are not familiar with the specialized meaning-making grammatical resources of science are likely to experience significant difficulties when reading and writing science texts.” (p. 343)

Consider, for example, the two sentences below:

Sentence 1: The soil erosion was caused by the rain.

Sentence 2: It rained so the soil was washed away.

When talking about an observation, a child might say, "It rained so the soil was washed away." But, if he were reading a science textbook, the text would more likely read, "The soil erosion was caused by the rain" (Gibbons, 1999, p. 15). When we compare the sentences, we notice the same actions and events are related in distinct linguistic forms - one everyday speech (sentence 2; although note the presence of the passive, a point to which we return later), the other an 
academic rendition of the same information (sentence 1). The presentation of sentence 1 moves away from a congruent construction of reality (cause preceding effect, see Christie \& Derewianka, 2008) by placing the effect before the cause. This academic rendition is more privileged in school settings. Therefore, the child who can comprehend or produce that sentence will likely experience more success in the classroom than the child who does not understand the linguistic differences between everyday language and academic language and must rely solely upon his understanding of his spoken, everyday language (e.g., sentence 2) to navigate texts (Leu, 1982; Veel, 1997).

\section{Linguistic Complexity}

Work in the field of academic language has provided a depth of understanding related to the differences of academic and everyday language (Bailey, Huang, Shin, Farnsworth, \& Butler, 2007; Christie \& Derewianka, 2005; Fang, 2004, 2006; Scarcella, 2003, Schleppegrell, 2004; Snow \& Uccelli, 2009); the typical presentation of academic language fearures suggests a list vocabulary, a variety of connectives, passive voice, nominalizations, etc. Ravid's (2004) concept of linguistic complexity suggests a more sophisticated, more integrated approach to this presentation. Ravid has defined linguistic complexity in terms of "a lexicon-syntax interface," where lexical items and syntactic constructions "conspire [interrelate] to make a given piece of language more or less complex" (p. 339). We argue that Ravid's model may lead to a more comprehensive view of the increasingly complex and interrelated features of academic language.

Ravid's Linguistic complexity (2004) is composed of two separate, but interrelated components: lexical complexity and syntactic architecture. In the following sections, we explain these components. (Figure 1 provides an overview of the model; Ravid [2004] has been slightly modified to reflect changes in the model as presented by Berman and Ravid [2009]). 
Lexical complexity. Lexical complexity is defined in terms of lexical density and lexical diversity. Lexical density refers to the proportion of content words per clause or sentence; some of these words may be rare or highly technical. Lexical diversity is the term used by Ravid to represent the typical type/token ratio of a text (a measure of vocabulary variation). However, by 2009, she and Berman have reconceptualized lexical diversity to include "a noun scale of semantic-pragmatic abstractness and categoriality" (p. 99). In other words, lexical diversity has been adapted to include the difficulty of the words as well.

To consider these concepts, we return to our two sentences.

Sentence 1: The soil eroded as a result of the rain.

Sentence 2: It rained so the soil was washed away.

Sentence 1 has four content words (soil, eroded, result, rain) in a total of nine words; its lexical density is .444 . Sentence 2 has three content words (rained, soil, washed) in a total of eight words; its lexical density, more typical of oral language, is lower (.375). Perhaps more importantly, as relates to the sentence level, the lexical diversity of the two sentences differs. If we consider the frequency of appearance of words in a lexicon, then sentence 1 consists of words that appear less frequently. "Eroded" and "result" are both more technical and rarer than the words comprising the sentence 2 . The addition of these lexical items increases the lexical diversity of the sentence. Between the increased lexical density and increased lexical diversity, sentence 1 would be more difficult than sentence 2 to comprehend.

Syntactic architecture. Syntactic architecture, according to Ravid (2004), "is defined in terms of several distinct though interrelated factors at differing levels of intra-clausal and interclausal structure" (p. 340). Although Ravid (2004) initially describes syntactic architecture as consisting of three concepts - length, depth, and diversity - her work with Berman (2009) 
suggests a reorganization into two critical concepts -- syntactic length and syntactic density.

Syntactic length refers to the number of words per unit of syntax (phrase, clause, or clause package). For example, the noun phrase, "The quickly eroding cliff," is longer and more complex than the noun phrase "The cliff." Syntactic density consists of syntactic diversity and syntactic depth. Syntactic diversity includes the notion of different types of modifying expressions (e.g., adjectives, post-nominal prepositions, phrases, and relative clauses). It is a function of both number of phrases and number of words per phrase; as it is related to numbers, it is highly related to syntactic length. Syntactic depth refers to the layers of embeddings (e.g., nouns with a prepositional phrases, dependent clauses, etc.) in a sentence. A sentence in which one clause is dependent on another is harder to process than a sentence with two independent clauses linked by a simple additive connective, such as "and” (Nippold, 1998).

To clarify these ideas, consider the following two sentences.

Sentence 2: It rained so the soil was washed away.

Sentence 3: Because it rained, the soil got washed away.

Both sentences make use of the passive. In terms of syntactic diversity, sentence 3 is more diverse because it consists of a dependent (embedded) clause and an independent clause, whereas sentence 2 is less diverse as it consists of two independent clauses. Sentence 3 would also be considered as having greater syntactic depth because of its subordinate, dependent clause, which creates a greater degree of embedding in the sentence. Additionally, sentence 3 would be more difficult for a child to process because the dependent (embedded) clause is presented first. Of note, Irwin and Pulver (1984) found that both third and fifth graders' reading comprehension performance declined when dependent (embedded) clauses with a causal connective (e.g., because) preceded the independent clause. 


\section{The Interrelatedness of Syntax and Vocabulary in Lexical Complexity}

Ravid's (2004) notion of the lexicon-syntax interface is particularly powerful when considering the interrelated nature of academic language features. The following section presents examples of how this model would be applied to specific features of academic language that can be problematic for children.

Connectives: A component of syntactic density and lexical diversity. The specific case of connectives reveals the power of a framework that addresses the interrelatedness of syntax and lexicon. Connectives are particularly important in scientific text because they help explain relationships among text ideas. If children understand how connectives function in a sentence or text, they can potentially use the signals to enhance their reading comprehension (Cain \& Nash, 2011; Crosson, 2010); however, connectives carry abstract meaning and without an understanding of how they function in a sentence, children may be left confused. To add further complication, scientific texts typically rely upon a variety of different connectives (Snow \& Uccelli, 2009). For example, scientific texts can contain: causal connectives (e.g., because, as a result, therefore), which offer explanations; contrastive connectives (e.g., however, conversely, whereas), which signal contradictory information; and spatio-temporal connectives (e.g., previously, next, meanwhile, finally), which provide spatial and temporal links (Fang, 2006). The use of a variety of connectives contributes both to syntactic diversity and to syntactic depth. And, clearly, as connectives remain a source of confusion for university students (e.g., Olshtain \& Cohen, 2004), they also contribute to lexical diversity.

We particularly focus on causal connectives because there is a long history of research demonstrating that children have difficultly processing the causal connectives found in texts (e.g., Cain \& Nash, 2011; Irwin \& Pulver, 1984; Goldman \& Murray, 1992; Perfetti, 1985; Yuill 
\& Oakhill, 1991).

Consider the following three sentences:

Sentence 2: It rained, so the soil was washed away

Sentence 3: Because it rained, the soil got washed away.

Sentence 4: As a result of the rain, the soil got washed away.

Looking at both lexical diversity as well as syntactic diversity, sentence 4 would be more difficult and, in fact, research substantiates this theoretical position (Olshtain \& Cohen, 2004; Schleppegrell, 2009). As discussed earlier, sentences 3 and 4 are more difficult than sentence 2 in terms of syntactic depth (the first clause in both 3 and 4 is embedded) and diversity ( 2 contains two independent clause, while 3 and 4 are more diverse, containing both a dependent and an independent clause). Additionally, the causal connectors, "so" and "because" are typically present in young children's oral language by age 6 (The Corpus of Contemporary American English; COCA; Nippold, 1998); therefore, children are likely more familiar with the constructions and consequently understand the relationship between the rain and the washing away found in sentences 2 and 3. In contrast, the connector, as a result, is not present in in young children's oral language (36 months - 90 months); therefore, it is likely to impede comprehension (COCA; Schleppegrell, 2009).

Grammatical metaphor: A key concept in linguistic complexity. A very helpful construct in the increasing difficulty of texts is the Hallidayan notion of grammatical metaphor (Christie \& Derewianka, 2008; Schleppegrell, 2004). Grammatical metaphor rests upon the notion of congruence in sentence construction, which suggests that sentences are easier to process if they follow the order of perception - the grammatical categories reflect the everyday experience. As Schleppegrel (2004) explains, "Congruent expression refers to the everyday use 
of language, where, in a clause, "things" are in nouns, "happenings" are realized in verbs, “circumstances" are realized in adverbs or prepositional phrases, and relations between elements are realized in conjunctions" (p. 72, emphasis added). In non-congruent sentences, the essential lexical items remain, but their realized form is altered. Congruence is important to note because children tend to prefer a temporal ordering of clauses (Katz \& Brent, 1968). For example, the phrase "The cliff erodes rapidly" is a congruent form, whereas, the phrase "The rapidly eroding cliff...” is an example of a non-congruent form.

Particularly noted in grammatical metaphor is the alteration of verbs to their noun forms, nominalization. These changes affect both syntactic architecture and lexical complexity. Specifically, the use of the grammatical metaphor increases the possibility of a more "packed" sentence, thereby affecting the syntactic depth and diversity. As a consequence, grammatical metaphors along with increased density in sentences may increase the processing time necessary for successful comprehension (Christie \& Derewianka, 2008; Schleppegrell, 2004).

Given the interrelated roles of syntax and lexicon in Ravid's (2004) linguistic complexity, it is important to note that there are times when a nominalization may not necessarily be more rare than its related verb. Here we point to the unique case of "erosion" and "eroded". Work on the grammatical metaphor would suggest that sentence 5 below would be more difficult than sentence 1 , given the presence of the nominalized "erosion" and the passive voice, "was caused by." However, examinations of linguistic corpora indicate that "eroded" is a far more rare word then "erosion" (COCA; ChildFreq; SUBTLEX-US). Then, too, sentence 1 contains the more rare connective "as a result," whereas sentence 5 contains the more frequently occurring verb "cause."

Sentence 1: The soil eroded as a result of the rain. 
Sentence 5: The soil erosion was caused by the rain.

Other syntactic changes also contribute to the concept of grammatical metaphor, such as the downgrading of an independent clause to an embedded, relative clause (Christie \& Derewianka, 2008). The importance of grammatical metaphor in school texts cannot be underestimated. As Christie and Derewianka (2008) assert, "Teachers tend to reward the emergence of non-congruent forms, for it is in these that the abstractions, technical statements and arguments so critical for second education are realized" (p. 25).

Passive voice: A complex component of syntactic architectures. Passive voice is frequently cited as contributing to the difficulty of advanced texts (e.g., Schleppegrell, 2004; Fang, 2004; Snow \& Uccelli, 2009). Employing the passive voice creates changes in congruence, removing the subject (or agent or participant, depending on which form of functional linguistics is utilized) from its expected position at the beginning of the sentence, thus creating a very different theme (the linguistic element that serves as the starting point for the clause, Schleppegrel, 2004). The passive also demotes the previous thematic agent to a component of a prepositional phrase. Through these actions, the syntactic density of the sentence is increased. Not only are there changes in diversity, but there are changes in depth as well. Consider the following sentence:

Sentence 5: The soil erosion was caused by the rain.

The congruent form of this sentence would be "The rain caused the soil erosion." Employing the passive changes the theme from rain to soil erosion. With this grammatical metaphor, the sentence is dramatically more complex. The new theme, a nominalization, can now be deepened by the addition of pre-modifiers and embedded clauses.

Of importance in this study is the fact that science textbooks frequently employ the 
passive voice (see Halliday, 1994 for an interesting speculation on Newton's influence in this area). This passive voice increases the sense of textual authority and scientific objectivity (Christie \& Derewianka, 2008; Schleppegrel, 2004), but it can also complicate the comprehensibility of textbook content.

It is important to note that the presence of the passive voice alone does not make a text less accessible to younger readers. Baldie (1976) and Menyuk (1963) found that children are relatively comfortable with the passive construction by age 6 if the passive voice verbs are actional (verbs conveying physical action, e.g., got washed away). The difficulty with passive voice arises when sentences are written with perceptual, experiential verbs (verbs that denote a subjective experience, e.g., caused as opposed to actional verbs. This lexical phenomenon once again points to the interrelated nature of linguistic complexity.

\section{What Teachers May or May Not Know about Linguistic Complexity}

Although we could not locate any studies examining teachers' knowledge of the concept of linguistic complexity, there is a small body of research examining teachers' linguistic knowledge. Unhappily, though authors may define this term as knowledge of phonemes, graphemes, syllables, morphemes, grammar, and syntax at the word, phrase, sentence, and discourse levels (see Moats, 2009 for a review), within the United States, studies have typically focused on word-level features to the exclusion of sentence- or discourse-level features.

However, the situation in Great Britain is rather different. Energized by a national literacy curriculum that drew increased teacher and student attention to how texts work (DfEE, 1998), various researchers began to examine both preservice and inservice teacher linguistic knowledge (e.g., Cajkler \& Hislam, 2002; Qualifications \& Curriculum Authority [QCA], 1998). In a study of inservice teachers related to the rollout of the new literacy curriculum, QCA 
(1998) had 137 teachers complete a survey. Teachers recognized their difficulties with terminology, particularly as related to sentence structure. While teachers felt knowledgeable about discourse level structures, "this confidence did not extend to phrase, clause and sentence structure either related to reading or in pupils' own writing. Sentence structure was found to be the least systematically covered" by these teachers (QCA, 1998, p. 27).

In addition to the survey, QCA also gave a student writing sample to the teachers for analysis. The authors report that teachers commented far more frequently on punctuation than they did on form or structure, despite teachers' earlier assertions that they comfortably addressed discourse level structures in their teaching.

In Cajkler and Hislam's study, teacher trainees were asked to classify words underlined in a sentence into one of five categories: preposition, noun, verb, adjective, or adverb. They were then to classify 21 words appearing in a recipe into 8 categories; these categories included the new items -- instruction form of verb, infinitive, article, and conjunction. Following this task, the students were to underline all verbs in three sentences, and then to indicate whether those sentences were simple, compound, or complex. In short, these tasks essentially asked students to classify items within existing categories. The researchers found that students were generally successful with the classification of parts of speech, although there were items such as the noun "jump" that were appropriately categorized by fewer than $40 \%$ of the respondents. Regarding the underlining of verbs, the teacher trainees had high accuracy with the exception of the word "got." Type of sentence as well showed considerable accuracy; however, certain participants commented that they would have been unable to think of these sentence-related terms (complex, compound, simple) by themselves. Of interest, some of the participants were interviewed after they had done some teaching. These individuals indicated that teaching had compelled them to 
increase their personal knowledge.

As we have noted, these studies have been conducted in Great Britain. Within the United States, there has been little research that explores what teachers know about how grammar function at the sentence and discourse level. This lack of attention to teachers' syntactic knowledge does not mean that such information is unimportant to researchers. Nagy and Townsend (2012) have proposed a list of questions teachers could ask themselves and their students for assisting comprehension; their questions regarding lexical choices address linguistic complexity as defined in this paper. However, Nagy and Townsend caution their readers that “Any interventions aimed at increasing students' control over academic language presuppose research that still needs to be done on what teachers know and do not know about the language demands of their content areas" (p. 105).

A similar concern for teacher knowledge appears in Fillmore and Snow's (2000) What Teachers Need To Know About Language. In that document, the authors present a list of questions every teacher should be able to answer. In the current study, we address one of their key questions "What makes a sentence or text easy or difficult to understand?" (p. 38). Although the answer Fillmore and Snow supply is limited to the dangers of text simplification (e.g., the process of shortening and simplifying texts for ELLs or struggling students), they highlight upon an important issue, particularly with regard to teacher understanding of the grammatical structures of academic language.

We have opted to focus on the sentence in this paper because it represents the smallest unit of text to which the concepts of linguistic complexity can be applied. A teacher's ability to identify what makes a sentence difficult to comprehend is essential for both reading and writing instruction. In reading instruction, teachers are responsible for selecting texts that match the 
abilities of their readers. They are also responsible for enabling students to grapple with the various aspects of linguistic complexity that may be disabling comprehension. In writing instruction, it is impossible to move students to sophisticated text production unless the teacher can explain how non-congruent forms assist in the constructing of advanced exposition and argument.

We have selected elementary preservice teachers as our target group because we believe that teachers must support children's academic language development from an early age. Equally important in today's schools is the ability to support the developing English of those new to the United States. To be prepared to be effective teachers, they would, then, need to be able to recognize and explain key lexical and grammatical features of academic language before graduation.

The study reported in this paper fills research gaps by describing the current state of certain U.S. preservice teachers' linguistic complexity knowledge. We do this examining how they approach the question posed by Fillmore and Snow (2000, p. 30): "what makes a sentence ... easy or difficult to understand?" In analyzing the explanations preservice elementary teachers offer for their determinations sentence difficulty, we gain insight into the aspects of language elementary preservice teachers note and comment upon; this, in turn, provides insight into their understanding of the features of linguistic complexity. The guiding question for this study was: How do elementary preservice teachers explain factors that make sentences easy or difficult to understand?

\section{Method}

\section{Researcher Stance}

The present study developed from our experience working with elementary education 
preservice teachers in a language arts methods course. We had observed that students were not comfortable examining texts for features of academic language; we sought to better understand what underlay these difficulties so we might ultimately address them. To guide our instruction, we created/adapted a series of preassessments designed to assess students' understanding of written language at both the sentence level and at the text level. This study focuses on the sentence-level preassessment work.

In addition to Ravid's (2004) work, the current study has been largely informed by the framework of systemic functional linguistics (SFL; Halliday \& Hasan, 1976; Halliday \& Matthiessen, 2004), which addresses the grammatical and lexical features of text in terms of social meaning and communication rather than focusing on isolated parts of speech. SFL is concerned with identifying the arrangement of grammatical and syntactical structures across disciplines in an attempt to make text transparent to all learners. This transparency allows all students access to academic content, which are critical to school success (Christie \& Derewianka, 2008; Fang, 2004; Schleppegell, 2004)

Our personal interest in improving preservice teacher preparation as well as our belief that their understanding of the linguistic complexity of academic text is crucial for their future students' success were also present throughout the study.

\section{Participants and Setting}

Archival data collected anonymously from 97 students (93\% female) enrolled in either a five-year Bachelor/Masters of Teaching (B/MT) or a two-year Post-Graduate/Masters of Teaching (PG/MT) teacher education program at a university in the mid-Atlantic region were used in this study. At the time of the study, the B/MT students were in the fourth year of their undergraduate programs and the PG/MT students were in their first year of their teacher 
preparation programs. As a requirement for elementary education licensure, all of the students were enrolled in a language arts method class. The average SAT score for these students was 1279 (Verbal, 657; Math, 622) and the average writing score was 654, indicating above-average reading and writing skills (average national SAT scores for the year these students were admitted were: overall 1057 (Verbal, 504; Math, 533) and Writing, 488; The College Board, http://professionals.collegeboard.com). All participants were English-speaking. In terms of racial and ethnic make-up, they; Caucasian/White (72\%); African American (8\%), Asian (8\%), Hispanic (3\%), non-specified (8\%).

This sample of preservice teachers was a highly able, very well educated group of preservice teachers. We believed that their explanations regarding factors of sentence difficulty would represent a best case scenario for preservice teacher knowledge.

\section{Materials}

As a preassessment for a language arts methods course, we presented the elementary preservice teachers with a document containing a series of sentences taken from one of their textbooks (Gibbons, 1991). We selected the sentences because they express a similar idea -- the cause-and-effect relationship between rain and soil erosion; however, each sentence is presented with slightly different wording, ranging from those representing more oral language-like features to those with more academic, written language features. Gibbons (1991) explained, “The wordings also vary in complexity - some, such as the first example, being very simple, while the later examples involve more complex use of language associated with written texts." (p. 15) For example, the first sentence is fairly simple: It rained, so the soil was washed away (p.15); whereas the last example is more typical of academic language: The soil erosion was caused by the rain (p. 15). 
Creation of an assessment. The created assessment required students to: 1) Identify which sentences would be easiest or hardest for students to comprehend by rank ordering the sentences from 1-6 based on difficulty, 1 being easiest to understand and 6 being the most difficult, and 2) Explain the thinking behind their ordering. We determined that rank ordering the sentences would increase the students' attention to the various features of academic language; however, we were less concerned with the orders they would suggest than with the explanations they would provide. The assessment document (found in Appendix A) contained instructions for how to complete the task with pen or pencil. We piloted this assessment in year one of our study. We found that this methodology produced relevant data in terms of exploring student understanding of the features of written academic text and determined to use the same assessment, unmodified, in year two.

Examination of the assessment's content. To more fully understand the sentences ourselves, we subjected them to our own in-depth analysis prior to analyzing student documents. In addition to the range of oral versus academic features of text, we also sought to determine other aspects of linguistic complexity that might make a sentence easier or harder to understand. To achieve this, we called upon our SFL framework as well as the lexical-syntax interface (Ravid, 2004) as guides. Our initial thoughts on what could be said and on the actual rankings of difficulty appear in Table 1.

\section{Data Collection Procedure}

As noted above, in year one, we piloted our assessment and methodology by distributing the printed assessment document (as described earlier) to 49 elementary preservice teachers. Because we were interested in the class as a whole rather than individual student performance, we indicated that this assessment was to be completed anonymously, with no names written. 
Students were given approximately 20 minutes to complete the task. We found that having them rank order the sentences did in fact compel them to look at the sentences more closely and explain their thinking. Because this methodology produced relevant data, we presented the same task in year two to another set of elementary preservice teachers $(n=48)$ and then examined the combined data (total $\mathrm{n}=97)$.

\section{Data Analysis}

We examined student responses qualitatively using systematic data analysis (Miles \& Huberman, 1994) to determine categories that would capture student ideas of what makes a sentence difficult to understand. Because the goal of this research study was to explore a previously unstudied phenomenon, we employed an inductive coding technique. The first author conducted the preliminary data analyses by reading and rereading all of the preservice teachers' documents in an effort to identify salient patterns. By searching through the corpus data repeatedly, patterns emerged. To fully capture these patterns, the sentences were examined by clauses so that a single sentence could have multiple codes. Through the use of analytic memos, such as the one below, this inductive process led to early codes.

Some students prefer the noun erosion to the verb eroded. They say eroded is harder than erosion: "People might not know that erosion has a verb form." Code=Verb These analytic memos led to subsequent rereadings of the data corpus; by repeatedly rereading the data corpus, disconfirming evidence led to code revision. Through this process, 17 final codes were generated; these appear in Table 2.

Once the categories were qualitatively derived and reviewed for intercoder reliability ( $89 \%$, based on $20 \%$ of total documents), frequency counts for each code were determined to gain a sense of more and less common interpretations of linguistic complexity held by these 
preservice elementary education students. As a final part of the analysis, we placed the codes within the Ravid (2004) framework so we could more clearly see which aspects of linguistic complexity the students most focused upon.

\section{Results}

Students attended to both lexical complexity and syntactic architecture as they explained why one sentence was more difficult than another. Table 2 presents the codes, their definitions, and their frequency of occurrence. As noted above, we have placed the coded data within the Ravid (2004) concepts of linguistic complexity.

\section{Lexical Complexity: A Focus on Diversity}

No students addressed lexical density; however many addressed issues of lexical diversity. Seeking to justify their rankings, 72 (74.2\%) addressed lexical aspects as contributing to the difficulty of the text. In the sections below, we review the lexical aspects noted by students.

Verb versus nominalization. Of the total students who addressed lexical items ("vocabulary") as contributing to the ease with which a sentence could be comprehended, 50 of the 72 students addressing lexical diversity referred directly to the words "erosion" or "eroded" as problematic, although their explanations varied in specificity. Some students spoke generally about the two words together. For example, one student said, 'I think the words 'erode' or 'erosion' would be harder for a kid to understand, so I put them as hardest.” Another student explained, "Rather than using the complex word 'erosion,' these sentences [the ones with 'the soil was washed away'] state what erosion is in common terms (the soil was washed away)."

Other students also expressed that the words "erosion" and "eroded" were more difficult than "washed away," but were provided more detail about the two in their explanations. Seven 
(7.2\%) directly referred to the word "erosion" as being more familiar/common than "eroded" and, therefore, easier to comprehend. Addressing this issue, one student wrote, "A newer term (the verb version [eroded] of the noun [erosion] before) is more challenging." Yet another said, "'Eroded' as a form of 'erosion' could be confusing."

Five students $(5.2 \%)$ discussed the idea of that making the verb "erode" into the noun "erosion" (nominalizing, although they do not use this term) increased the difficulty of the sentence. For example, one said, "Erode (v.) becomes a noun and may be confusing" and another said, "The action 'eroded' is easier to understand than the noun 'erosion'." (Of note: $75.2 \%$ of the students $[n=73]$ ranked the sentence "The soil eroded as a result of the rain" as more difficult than the sentence "The soil erosion was caused by the rain.")

Connectives. Connectives were noted by $39(40.2 \%)$ of the students. A majority of these students ( $\mathrm{n}=31)$ felt that the use of the connective "because" helped clarify the cause-and-effect relationship of soil erosion, whereas, the use of the connective "as a result" was deemed more "complicated" and harder to understand. For example, one student said, "The use of 'because' makes the connection between the rain and the soil getting washed away a little more obvious" while another wrote, "The phrase 'as a result' is more complicated- it means the same thing as 'because', but is much more formal, so children would be less familiar with it." This attention to familiarity can also be seen in this student's explanation:

I took a look at the phrase 'result of' and I thought that younger students wouldn't normally use that in everyday conversation or in writing so then [thought] it could be more difficult for them to comprehend.

Illustrating attention to young readers, another wrote, "I think the phrasing 'as a result' might be less clear than 'because' for a beginning reader." Some students were less descriptive in their 
explanations and simply wrote comments like, “'As a result' gets kind of tricky." Conversely, four students said the phrase "as a result" was more direct and easier to understand than "because” and "so." For example, one student said, "'Because' seems like a less direct way of saying 'as a result of'."

Between the connectives "because" and "so," there was not a clear consensus on which one would be easier for children to understand. Thirteen (13.4\%) of the students said "because" was clearer and more direct than "so," with comments like, "\#2 is similar but it uses the word 'so' instead of 'because' so the cause/effect relationship is less clear,' whereas, seven (7.2\%) students said "so" was easier. For example, one student wrote, "Because the sentence has a very simple transition (so) I think that children would most easily understand what the sentence said. 'Because' is slightly more complex."

Rather than noting the use of the causal connective "as a result", $12.4 \%(n=12)$ of the students focused their attention specifically on the noun "result" and described it as a more difficult term. One student explained, "\#3 [As a result of the rain, the soil got washed away] is a little more difficult just because the word 'result' appears."

Still other students $(n=15,15.5 \%)$ contrasted the word "result" or phrase "as a result" with the verb "cause." They felt that "cause" was more typical of oral language and, therefore, likely more familiar to students than the connective "as a result," even though the verb appeared in the passive voice (was caused by). One of these students wrote, "I think 'was caused by' is easier to understand than "as a result" because it is used more frequently in everyday language." Another wrote, "'Was caused by' seems easier to understand than 'as a result of."” A student referring to "result" rather than the connective "as a result" said, "Since \# 6 [As a result of the rain, the soil got washed away] also uses 'result' I think it would be the most difficult as opposed 
to \#5 which uses the term "caused." The concern with oral/written distinctions appears again below in discussions of syntax.

\section{Syntactic Architecture}

The vast majority of the students $(n=88,90.7 \%)$ referred to the complexity of sentence structure when justifying their decisions on sentence difficulty. Students spoke to issues related to both syntactic density and syntactic length. However the students' descriptions of sentence structure revealed a more complicated picture of their knowledge than did their discussion of lexical features. In this section, we share the results related to syntactic density and syntactic length.

Syntactic density: Diversity in ordering. As students spoke about the syntax of sentences, their comments revealed both understanding and misconceptions. Codes related to diversity in ordering addressed cause-and-effect ordering, placement of connectives, passive voice, and oral versus academic language. Student also revealed misconceptions related to terminology as well as the role of commas in sentences.

Cause-and-effect ordering. Forty-five students (46.4\%) stated that the sentences were easier to understand when the cause preceded the effect, suggesting an attention to the order of events in real-time and a preference for maintaining the cause-then-effect order (e.g., congruence). For example, one student said, "My top 3 choices were made because the sentences have the structure of cause then effect (rain precedes soil erosion)." Another further explained why congruent sentences are easier for young children,

The easier sentences to understand were structured in a simple cause and effect way of writing. It rained so the soil was washed away. That cause and effect way of thinking is very natural and automatic. 
However, of the 45 , only 34 (35.1\%) were able to accurately and consistently rank the sentences in cause-and-effect order. For example, one student who said, "\#3 [The soil getting washed away was the result of the rain] is still cause/effect structure, but again more words and less direct."

Placement of connectives. Whereas some students addressed logical relationships, 24 (24.7\%) of the preservice teachers noted that it was harder to comprehend a sentence when a causal connective ("because" or "as a result") came at the beginning of a sentence rather than in the middle linking the two clauses. One student named the phenomenon, "Reverse order: The sentence starting with 'because' is harder to understand." The explanations placed into this category appeared to address moving the dependent clause to the beginning of the sentence, although only one student explicitly spoke to this point, correctly using the term "clause": "Sentence 2 is, however, slightly more complex than 1 because of the ordering of the clauses: dependent, then independent." All of the other students focused on the position of the causal connective. For example, one preservice teacher said, " $2 \& 3$ are more difficult because the word [because] or the phrase [as a result] that explains the relationship between the rain and the erosion does not come between the two phrases." Another asserted, "Normally, "because" is not found at the beginning of a sentence."

Oral versus academic language. Still others contrasted the syntax of sentences by referring to oral, "everyday" language. This small percentage of students $(\mathrm{n}=12 ; 12.4 \%)$ was able to identify that some of the sentences were more typical of everyday speech and, therefore, easier to understand. One student wrote, "The sentences that I labeled as the three easiest to understand are worded in a way that is closer to everyday speech" and another wrote, " 1 sounds similar to the way people speak, and thus a child would be familiar with the phrasing." 
Passive voice. A small percentage $(\mathrm{n}=12 ; 12.4 \%)$ of the students spoke specifically to passive voice, employing that exact terminology, as a factor related to the difficulty of sentences. Commented one, "Passive voice is one of the hardest structures." However, 7 of the 12 students discussing the passive voice were unable to correctly identify the passive voice in the sentences. One of these students explained, "The passive voice makes it much tougher to understand the meaning of the sentence," but then went on to identify "The soil erosion was caused by the rain" as the sentence that had the most active voice. Another student said, "I personally think active verbs create stronger sentences and are therefore more advanced and difficult than sentences with passive voice," thus demonstrating great confusion related to these linguistic concepts. Of note, although she did not recognize the passive voice, one student indirectly addressed the idea that actional verbs may pose less of an challenge to students in the passive voice when she said, "I chose \#1 [It rained, so the soil was washed away] because there were no difficult words (ex: erosion, eroded) and it was in what I feel like is an 'easy to understand' version of the past tense."

Additional confusions with syntactic terminology. As just noted, not all students were equally successful in their efforts to discuss syntactic phenomena. In all, 19 students (19.6\%) were unable to correctly identify syntactic patterns in any of the sentences. One student wrote, "I ranked the subject-predicate structures as easier than the predicate-subject ones." Another said, "Sentences are easiest to understand when they are not structurally complex. For example, the most simple sentences follow the basic subject-verb-object pattern." (None of the presented sentences follow a subject-verb-object pattern.) In fact, there appeared to be a preoccupation with the subject-verb-object pattern. One of these students asserted, "The first sentence [The soil erosion was caused by the rain] was the 'normal' sentence structure of subject-verb-direct 
object." Even though these students were not able to correctly identify the syntactic patterns of the sentences in the task, one of them was able to suggest the impact of sentence diversity on comprehension: "Many young students may be more accustomed to seeing one type of sentence rather than seeing sentences with varied structures."

Commas and syntactic diversity. While the students described above tended to focus on the words and phrase patterns of sentence structure, $15.5 \%(n=15)$ of the total students focused on punctuation as a component of difficulty, contending that the addition of a comma to a sentence increased its complexity and, therefore, made the sentence more difficult to comprehend. One student, justifying the sentence rankings, wrote, "The next three [sentences] seem slightly more complicated because they had two parts separated by a comma." Another asserted, "The sentences get harder when commas are added." Yet another provided this explanation: "'It rained, so the soil was washed away' is more difficult because of the coma [sic] and word placement." This group of 15 students struggled to express their thoughts on what might make a sentence difficult; their clearest remarks were related to vocabulary.

Syntactic density: Confusion with embeddings. Fifty-five students (56.7\%) appeared to lack an understanding of how the embedding of clauses might impede comprehension. These students addressed that the sentence "The soil getting washed away was the result of the rain," as either "awkward" or "too wordy." However, only 4 of these 55 students were able to correctly isolate the phrase, "the soil getting washed away," as a complicated feature. It is notable that only 2 of the 49 students addressing syntactic density could identify this phrase as a complex noun phrase.

Syntactic Length. In contrast to the many students who commented on syntactic diversity, only 29 (29.9\%) of the preservice teachers addressed syntactic length. These students 
preferred short concise sentences and were concerned with "wordiness." As one preservice teacher commented, "I thought the easiest sentences would be the ones with the shortest and most straightforward wording." Of interest, of the 29 students who asserted that "wordiness" created more difficulty, 11 had also described "as a result" as creating greater comprehension difficulty than "because" or "so" simply because the phrase contained "more words." Another student, linking word choice and sentence length, suggested, 'Using the word 'eroded' for 'washed away' made that sentence more concise and direct. It was easier to understand." Still another remarked, "This sentence ('The soil erosion was caused by the rain') is the easiest to understand because the word 'erosion' simplifies the more wordy and complex phrase 'the soil was washed away'."

Of this group of 29 wordiness-concerned students, three asserted that the sentence, "It rained, so the soil was washed away", was simpler and easier to understand than the sentence, "Because it rained, the soil got washed away", because the first sentence contained fewer words. (For accuracy's sake, we note that both sentences have eight words.) One additional student directly said that s/he specifically focused on word length as a component of sentence length, "I ranked the first two like so because they immediately introduce what appears to be the main point of the sentence, the erosion, while using what appears to be the smallest amount of letters."

Other students $(n=5,5.2 \%)$ also addressed syntactic length without a discussion of "wordiness," some more cogently than others. These students asserted that longer sentences were more difficult to read. One, who had ranked the two shortest sentences as easiest to understand and "As a result of the rain, the soil got washed away" as the most difficult, explained, "It's very hard to decode the whole sentence."

\section{Inability to fully explain linguistic complexity}


Thirty-five students $(36.1 \%)$ made comments about sentences being easier or more difficult to understand but were unable to clearly explain their decisions. For example, one student wrote, "All of the sentences get progressively harder when the structure of the sentence becomes more complex" but was unable to elaborate on the concept of complexity. Another wrote, "The other sentences that were more difficult were the ones where the grammar rules were complicated" but then made no mention of what those grammar rules might be. Most notably, five students reported that they ranked the sentences based on how each sentence “flowed." For example, one student said, "The sentence flows better than the following sentence." And another said, "I put \#1 in front of \#2 because it seemed to flow better and was therefore easier to understand." Even when explaining that s/he had approached the task imagining how s/he would explain the sentences to his or her own students ("For each one I thought to myself how would I explain this to my students?"), this individual still demonstrated difficulty talking about the sentences. One explanation simply read, " $1 \& 2$ were both pretty cut and dry."

Additionally, seven students in this group (7.2\%) simply reported that they could not explain their decisions. As one said,

I ordered the my sentences according to which order I believe it would be the easiest to the most difficult for me to write/come up with, imagining I was an elementary student. But, to be quite honest I have always felt intimidated when it comes to talking about grammar and parts of speech because I really never actually learned all of the structures.

This student, very honest in her explanation, revealed that she was "intimidated" by the task of determining sentence difficulty because she felt unprepared by her previous 
schooling experiences.

\section{Trouble with Terminology}

As is suggested above, these preservice teachers had genuine trouble with expressing their ideas in terminology that would be recognizable by knowledgeable instructors of language arts, as for the two students who identified "because" as a preposition. Here we discuss some of their major problems.

Despite the large numbers of students who addressed sentence structures, only eleven correctly used the word "clause." Five others commented on the "parts" of the sentences. Additional terms used to address clausal concepts included "phrase," "wording," "2 chunks," and sentence arrangement.

When referring to the syntax of a sentence, students also used a variety of terms. Some talked about "sentence arrangement," "sentence construction," and "sentence structure," but only one student used the word "syntax." This comment, "The syntax seems off," referred to the two sentences "Because it rained, the soil got washed away" and "As a result of the rain, the soil got washed away."

We have discussed above student concern with conciseness, or, in their terms, avoiding "wordiness." Additional terms they employed to address this idea included "flows," "straightforward," "direct and to the point," "simple and clear," "a more fluent construction," "a simple plain sentence," "cumbersome," "confusing," "awkward," "convoluted," and "choppy." In general, after producing these descriptors, the students who employed them had nothing further to add to their explanations of how these concepts might impact sentence difficulty.

\section{Discussion}

Before we begin a discussion of our findings, we would like to acknowledge the 
limitations of our study. Although our sample size was suitable (n=97), we only had data from one university program. As noted above, we focused upon this group because they were our own students (convenience), and they represented a highly educated group of preservice students. This choice, however, may certainly limit the generalizability of our results.

Additionally, in creating the assessment task, we could have opted for an approach similar to Cajkler and Hislam's (2002) British study - a very basic identification task focused mainly on parts of speech. But such a task dramatically limits what can be learned in early exploratory research. Then, too, in selecting the sentences from Gibbons (1991), we did not include all known features of the academic language that a student might encounter in a science text. We chose these sentences both because our students would then revisit them in their textbook, providing us an opportunity to return to some of the concepts during our teaching, and because they captured many aspects of linguistic diversity.

Further, as in any study involving a qualitative analysis, our categorization system was informed by the scholars whose work had impressed us. No doubt, others working with this same data set might produce very different codes.

Finally, we assumed that their lack of specificity with regards to linguistic terminology indicated their lack of knowledge. If the students were probed with follow-up interviews, it is possible that they could have had more to say with prompts.

Nonetheless, we believe our data present interesting insights into how elementary preservice teachers approach the task of examining text complexity at the sentence level. Their explanations reveal what they do and do not know about academic language. And they lead us to consider both how these quite able students have come to believe what they do, as well as directing us to consider what should be done about the situation. 


\section{Linguistic Complexity: A Summary of Results \\ Lexical complexity}

Overall, $72(74.2 \%)$ of the students referenced lexical diversity; of these, $50(51.5 \%)$ addressed the words "erosion" or "eroded" in some fashion. The other 22 preservice teachers focused either on the noun "result," the connectives (e.g., "because" regarded as easier than "as a result"), or made general, unelaborated comments about vocabulary being more difficult in one sentence than another. Some of these students $(n=38 ; 39.2 \%)$ attended to the erosion/eroded controversy and either connectives or the noun "result." As noted earlier, no students specifically addressed lexical density.

\section{Syntactic Architecture}

Considerably more students $(n=88 ; 90.7 \%)$ noted sentence structure to address difficulty level than had relied upon vocabulary. The majority of these students $(n=53,54.6 \%)$ focused on syntactic density alone. Others $(n=30,30.9 \%)$ referred both to aspects of syntactic density and syntactic length and five students $(5.2 \%)$ focused solely on syntactic length.

Syntactic density. Students' explanations of syntactic density revealed a great deal of confusion. For the most part, they were not able to accurately and coherently talk about the syntax of the sentences. Within $90.7 \%$ of respondents addressing sentence structure, $35(36.1 \%)$ students could provide no more detailed explanation than, "It just flows better," or "I ordered them based on the grammatical complexity."

In an attempt to give a little more information beyond "It just flows," others $(n=35$, 36.1\%) addressed "wordiness" as a factor in their rankings. These comments did not address lexical density in any fashion. Nineteen (19.6\%) of these students tried but could not correctly identify the syntactic patterns they were discussing. Also noted in the results section were the 
large numbers of students who employed the term "passive voice" but did not fully understand what it meant. Twenty-four students addressed difficulty related to connectives placed at the beginning of sentences. However, only one could accurately state the matter of a dependent clause preceding an independent main clause.

Problematic as well were certain students' constructions of punctuation. In that commas mark increased sentence complexity related to clauses, they can be indicators of an increased difficulty level of a sentence. But, given that only 11 students were able to accurately use the term "clause," it seems quite likely that students had confusion about the relationships between punctuation and grammar.

Syntactic length. Most students who addressed syntactic length $(\mathrm{n}=35 ; 36.1 \%)$ displayed a marked preference for short, concise sentences. Many of them appeared preoccupied with "wordiness." In fact, 11 students said that the connective "as a result" was more difficult because it was "wordier" than the other connectives. These students did not recognize that in addition to being comprised of more words, this adverbial phrase is also more technical and much less commonly heard in oral language.

Concerned with the importance of "simple and clear" sentences, some students asserted that, "The soil was eroded as a result of the rain" and "The soil erosion was caused by the rain" were easier to understand because they were more "direct" and "straightforward." Others specifically asserted that replacing the word "eroded" for "washed away" made the sentence simpler (shorter) and, hence, easier to understand.

Clearly, Ravid's (2004) framework supported presenting a picture of the elementary preservice teacher's abilities to explain linguistic complexity. Considering why the students had the difficulties they did is beyond the framework's capability. It is to those causes that we now 
turn our attention.

\section{Influences (or the Lack Thereof) behind Student Explanations}

As we reflected upon these results, we considered what type of educational experiences might have led to them. We speculate that there could be two key sources for what our students knew and did not know - writing instruction and grammar instruction.

The influence of writing instruction. As we read through the students' comments, we wondered where they had gotten their information on the difficulty. It occurred to us that many of their expressions - wordy, awkward, avoiding passive voice - derived from comments they had received on their own written work. Said one student,

I did not say "The soil erosion was caused by the rain" as the easiest, although I was tempted to, because I think it's in the passive voice and I am constantly being told not to write in the passive voice.

This student's explanation is particularly revealing because not only is she unsure if this sentence is indeed in the passive voice, but she also does not know why the passive tense potentially increases the difficulty of the sentence. She simply knows that she has been told not to use it.

When the preservice students wrote that sentences were "awkward" without a clear indication of why the sentence was awkward, they were relying upon years of unspecific writing instruction that likely focused on error avoidance rather than a building of knowledge about the way the English language works.

It is certainly the case that, beyond high school, university professors are likely to privilege more dense, academic language, so the students who approached the task of determining sentence difficulty no doubt brought these very recent experiences to bear on their decisions. They did not appear to recognize that the feedback they receive on their own writing channels 
them towards an ever increasing academic form, a form that is likely unfamiliar to many children.

Inadequate grammar instruction. Beginning in the 1980s, in large part due to a position paper released by the National Council of Teachers of English (NCTE) and as well as a publication by Graves (1983), grammar instruction and attention to syntactic features disappeared from school curricula (for a review see, Kolln \& Hancock, 2005). Clearly, the results of this study show how hazardous this stance has been, particularly for the classroom teacher, because they are left with a paucity of metalanguage to discuss grammatical choice. Without the terminology and the linguistic knowledge to talk about difficult text, these teachers will neither be able to help their students access complex, academic text or produce it.

The fact that more than a third of the students $(n=35)$ were unable to cogently address any syntactical aspects of sentence difficulty is a cause for great concern. One student commented, "I went by what I thought was the easiest sentence structure. However, my grammar knowledge isn't fantastic, so I marked the numbers based on where I'd get incorrect marks on a paper." Clearly, the limited grammar instruction that afflicts today's K-12 schools is taking a toll. Kolln and Hancock (2005) mockingly describe this conundrum. There is no way of blaming the teacher for not teaching grammar when it has already been proven that teaching grammar is harmful. The fault then lies within the students' failure to somehow soak it up from exposure or from the teacher's non-technical remarks. Or perhaps, because everyone grows at their own pace, that student is simply on a path that will lead them toward maturity somewhere down the road. Unfortunately, some of those students, unschooled in an understanding of grammar, become English teachers in their own right. Even if they have become 
writers not prone to error, they do not carry into teaching a deep grounding in knowledge of the language. Editing student writing becomes more a matter of what "feels right." They don't have the knowledge base necessary to put the quirks of prescriptive grammar into perspective. They don't see a connection between formal choices and rhetorical effect. (p. 26)

In an educational climate where grammar has been devalued, there is little wonder that these capable preservice teachers were reduced to describing sentence differences in terms of their "flow."

Kolln and Hancock's contention that students must "soak up" grammatical knowledge is quite visible in the preservice teachers' discussions of the placement of connectives. They were able to recognize that there was something more difficult about the sentences that began with "because" and "as a result;" there was something that made these sentences harder than the compound sentence featuring the connective "so." But the students could not articulate why; as in the QCA (1998) study of inservice teachers, the word "clause" was seldom mentioned, and there was even less mention of different types of clauses. One student articulated that there appeared to be two "parts" to the sentences, but seemed unable to name these parts "clauses," and was certainly not able to indicate that clauses and their introductory connectives function in the sentences in very specific ways.

\section{What Should Elementary Preservice Teachers Learn}

Considering the results from this study, it is clear that elementary preservice teachers need additional instruction on the concepts of that comprise linguistic complexity and academic language. Although there are numerous areas for improvement, we focus in this section on three that we see as key to successful elementary language arts instruction: grammatical knowledge, a 
more informed view of vocabulary instruction, and greater awareness of the phases of children's writing development.

Grammatical knowledge. Simply put, these students were quite shaky in their grammatical knowledge. We have pondered how best to call our students' attention to grammar. In the absence of strong coverage of academic language in our language arts textbook, we have included readings from books such as Knapp and Watkins (2005) Genre, text, grammar: Technologies for teaching and assessing writing. We have tried using sentence-combining activities, such as those presented in Killgallon and Killgallon's (2000) practice book for elementary teachers. However, we have come to recognize that there is insufficient time in a single language arts methods course to completely develop our students' knowledge. At this point, we are considering modules of instruction that students would have to successfully complete prior to enrolling in their language arts methods course.

Increased understanding of the range of vocabulary. Like many other professors, we have relied upon Beck, McKeown, and Kucan's (2002) three tiers of vocabulary. In particular, we have found its distinction between tier 2 words and the relatively rare words of tier 3 useful for our students. It may be, however, that more attention needs to be paid to the rare words, which Hayes and Ahrens (1988) have shown to be essential to the comprehension of scientific articles.

In our examination of Ravid's work, we noted that in her 2009 chapter with Berman, they had decided to step away from the typical type/token measure of vocabulary towards a semantic scale for nouns. There have been various authors who have suggested scales for vocabulary learning, but it may be that this concept needs to be linked to the frequency with which words appear at various ages in children's vocabulary. Having preservice elementary students work 
with online databases that reveal frequency of word use by age may heighten their recognition of the words that seem concise and precise to them but represent huge hurdles for elementary readers.

Understanding children's writing development. It may be our bias towards SFL, but we believe that Christie and Derewianka's (2008) School Discourse is an essential volume for understanding how children's writing develops. In its present form, it may be too challenging for the preservice student, but without the information it contains, teachers, as we have noted in our results section, may misinterpret children's early efforts towards advanced grammatical constructions, treating them as errors instead of celebrating movement towards more academic language.

\section{Directions for Future Research}

This particular study was designed to examine and describe how one group of elementary preservice teachers at a prestigious university approached the task of explaining what makes a sentence easy or difficult to understand. As should be clear both from our limitations section and from our recommendations for changes in language arts instruction, a great deal of research still needs to be conducted.

As noted, this study was limited to a single population of elementary preservice students. We need to know if these findings would be repeated were we to replicate with students at other institutions, or with secondary preservice students, whose greater content knowledge might lead them to more informed explanations for sentence difficulty. Additionally, it is equally important to determine how classroom teachers themselves explain these concepts.

Armed with an understanding of the current state of knowledge, we can begin to move towards interventions, such as those we have suggested above. We need to determine how we 
can most efficiently move preservice and inservice teachers forward in their understandings of linguistic complexity.

As well, we need content analyses to examine existing language arts textbooks - both those for university level students and for the K-12 population. Do these textbooks present information related to academic language? If so, what do they cover? And how effectively are the concepts addressed? What exactly do children (or preservice teachers) learn from these works?

\section{Conclusion}

This study represents a first effort at describing to what degree preservice teachers are capable of explaining linguistic complexity, the essence of academic language, when presented with a set of sentences. Our findings compel us to agree with colleagues such as Kolln and Hancock (2005) and Martin (2009) who explain that today’s teachers lack knowledge about language, which is essential to children's school and societal success.

It is time for the literacy field to depart from the vilification of grammar. Grammar is no skunk at a party that seeks to improve all students' potential. 


\section{References}

Bailey, A. L. (2006) (Ed). Language Demands of School: Putting academic English to the test. New Haven, CT: Yale University Press.

Bailey, A. L., Huang, B. H., Shin, H. W., Farnsworth, T., \& Butler, F. A. (2007). Developing academic English language proficiency prototypes for fifth grade reading: Psychometric and linguistic profiles of tasks, an extending executive summary. (CSE Technical Report \#720). University of California, Los Angeles. Center for the Study of Evaluation; Center for Research and Evaluation, Standards, and Students Testing, Los Angeles, CA.

Baldie, B. J. (1976). The acquisition of passive voice. Journal of Child Language, 3, pp. 331348.

Beck, I. L., McKeown, M. G., \& Kucan, L. (2002). Bringing words to life. New York: Guilford.

Berman, R. A. (2008). Developing linguistic knowledge and language use across adolescence (pp 347-367). In E. Hoff \& M. Shatz (Eds.) Blackwell Handbook of Language Development. Oxford, UK: Blackwell Publishing doi: 10.1002/9780470757833.ch17

Berman, R. A. \& Ravid, D. (2009). Becoming a literate language user: Oral and written text construction across adolescence. (pp. 92-111). D. R. Olson \& N. Torrance (Eds.), The Cambridge Handbook of Literacy. New York: Cambridge University Press.

Cain, K. \& Nash, H. M. (2011). The influence of connectives on young children's processing and comprehension of text. Journal of Educational Psychology, 103(2), 429-441.

Christie, F. (1985). Language and schooling. In S. Tchudi (Ed.), Language, schooling, and society (pp. 21-40). Upper Montclair, NJ: Boyton/Cook.

Christie, F. (1999). Pedagogy and the shaping of consciousness: Linguistic and social processes. London: Continuum. 
Christie, F., \& Derewianka, B. (2008). School Discourse. London: Continuum.

Christie, F., \& Martin, J. R. (Eds.). (1997). Genre and institutions: Social processes in the workplace and school. London: Pinter.

Christie, F., \& Martin, J. R. (Eds.). (2007). Language, knowledge, and pedagogy: Functional linguistic and sociological perspectives. London: Continuum.

Coffin, C. (2006). Historical discourse: The language of time, cause, and evaluation. London: Continuum.

Coleman, D., \& Pimental, S. (2011). Publishers' criteria for the Common Core State Standards in English language arts and literacy. Grades 3-12. The National Association of State Boards of Education, Council of Chief State School Officers, Achieve, and the Council of Great City Schools.

Crosson, A. C. (2010). Pinpointing the challenging aspects of academic language: Does knowledge of connectives play a special role in the reading comprehension of English language learners and English-only students? (Doctoral dissertation.) Retrieved from ProQuest Digital Dissertations.

Department for Education and Employment (DfEE) (1998) The national literacy strategy: Framework for teaching. London: DfEE

Eggins, S. (2004). An introduction to systemic functional linguistics, $2^{\text {nd }}$ Edition. New York: Continuum.

Fang, Z. (2004). Scientific literacy: A systemic functional linguistics perspective. Science Education, 89, 335-347. DOI 10.1002/sce.20050

Fang, Z. (2006). The language demands of science reading in middle school. International Journal of Science Education, 28, 491-520. doi: 10.1080/09500690500339092 
Fang, Z. (2008). Going beyond the fab five: Helping students cope with the unique linguistic challenges of expository reading in intermediate grades. Journal of Adolescent \& Adult Literacy, 51, 476-487. doi:10.1598/JAAL.51.6.4

Fillmore, L.W., \& Snow, C. (2000). What teachers need to know about language. Washington, DC, ERIC Clearinghouse of Language and Linguistics. Retrieved from http://eric.ed.gov/?id=ED444379.

Gibbons, P. (1999). Learning to learn in a second language. Portsmouth, NH: Heinemann.

Goldman, S. R., \& Murray, J. D. (1992). Knowledge of connectors as cohesion devices in text: A comparative study of native English and ESL speakers. Journal of Educational Psychology, 84, 504-519.

Halliday, M. A. K. (1993). Some grammatical problems in scientific English. In M. A. K. Halliday \& J. R. Martin (Eds.), Writing science: Literacy and discursive power (pp. 69-85). Pittsburgh, PA: University of Pittsburgh.

Halliday, M. A. K. \& Hasan, R. (1976). Cohesion in English. London: Arnold.

Halliday, M. A. K. \& Martin, J. R. (1993). Writing science: Literacy and discursive power. Pittsburgh, PA: University of Pittsburgh.

Halliday, M. A. K. \& Mattheissen, C. (2004). An introduction to functional grammar ( $3^{\text {rd }}$ ed.). London, Arnold.

Hayes, D. P., \& Ahrens, M. (1988). Vocabulary simplification for children: A special case of 'motherese'?" Journal of Child Language, 15, 395-410.

Irwin, J. W. \& Pulver, C. J. (1984). Effects of explicitness, clause order and reversibility on children's comprhension of causal relationships. Journal of Educational Psychology, 76(3), 399-407. 
Katz, E. W., \& Brent, S. B. (1968). Understanding connectives. Journal of Verbal Learning and Verbal Behavior, 7, 501-509.

Killgallon, D., \& Killgallon, J. (2000). Sentence composing for elementary school: A worktext to build better sentences. Portsmouth, NH: Heinemann.

Kolln, M. \& Hancock, C. (2005). The story of English grammar in United States schools. English Teaching: Practice and Critique, 4, 11-31.

Lee, C. D., \& Spratley, A. (2010). Reading in the disciplines: The challenges of adolescent literacy. New York, NY: Carnegie Corporation of New York.

Leu, D. J. (1982). Differences between oral and written discourse and the acquisition of reading proficiency. Journal of Literacy Research, 14, 111-125.

Martin, J. R. (2009). Genre and language learning: A social semiotic perspective. Linguistics and Education, 20, 10-21. doi: 10.1016/j.linged.2009.01.003

Menyuk, P. (1963). Syntactic structures in the language of children. Child Development, 34, 407422

Michaels, S. (1981). "Sharing time": Children's narrative styles and differential access to literacy. Language in Society, 10, 423-442.

Miles, M. B., \& Huberman, M. A. (1994). Qualitative data analysis: An expanded sourcebook ( $2^{\text {nd }}$ Ed.). Thousand Oaks, CA: Sage Publications.

Moats, L. (1994). The missing foundation in teacher education: Knowledge of the structure of spoken and written language. Annals of Dyslexia, 44, 81-102. doi: 10.1007/BF02648156 Moats, L. (2009). Knowledge foundations for teaching reading and spelling. Reading and Writing, 22, 379-399. doi: 10.1007/s11145-009-9162-1

Nagy, W. \& Townsend, D. (2012). Words as tools: Learning academic vocabulary as language 
acquisition. Reading Research Quarterly, 47, 91-108. doi: 10.1002/RRQ.011

Nippold, M. A. (1998). Later Language Development: The school age and adolescent years $\left(2^{\text {nd }}\right.$ ed.). Austin, TX: Pro-Ed.

Olshtain, E., \& Cohen, E. (2004). Logical connectors in Hebrew: How well do eighth graders master them? In D. Ravid \& H. Bat-Zeev Shyldkrot (Eds.), Perspectives on language and language development: Essays in honor of Ruth A. Berman (pp.315-326). New York, NY: Kluwer.

Perfetti, C. A. (1985). Reading Ability. New York: Oxford Press.

Ravid, D. (2004). Emergence of linguistic complexity in written expository texts: Evidence from later language acquisition. In D. Ravid \& H. Bat-Zeev Shyldkrot (Eds.), Perspectives on language and language development (pp. 337-355). Dordrecht: Kluwer

Scarcella, R. (2003). Academic English: A conceptual framework. Santa Barbara, CA:

University of California Linguistic Minority Research Institute. Schleppegrell, M. J. (2004). The language of schooling: A functional linguistics perspective. Mahwah, NJ:

Lawrence Erlbaum. Retrieved from http://escholarship.org/uc/item/6pd082d4\#page-1

Schleppegrell, M. J. (2009). Language in academic subject areas and classroom instruction:

What is academic language and how can we teach it? Retrieved April 12, 2012. Retrieved from www7.nationalacademies.org/CFEPaper_Mary_Schleppegrell.pdf

Shanahan, T., \& Shanahan, C. (2008). Teaching disciplinary literacy to adolescents: Rethinking content-area literacy. Harvard Educational Review, 78, 40-59. Retrieved from http://www.hepg.org/her/abstract/640

Snow, C. E., Griffin, P., \& Burns, S. M. (2005). Knowledge to support the teaching of reading: Preparing Teachers for a Changing World. San Francisco, CA; Jossey-Bass. 
Snow, C. E. \& Uccelli, P. (2009). The challenge of academic language. In D. R. Olson \& N. Torrance (Eds.), Cambridge Handbook of Literacy. New York: Cambridge University Press.

Unsworth, L. (Ed.) (2000). Researching Language in Schools and Communities: Functional Linguistic Perspectives. New York: Cassell.

Veel, R. (1997). Learning how to mean - Scientifically speaking: Apprenticeship into science discourse in secondary school. In F. Christie \& J. R. Martin (Eds.), Genre and institutions: Social processes in the workplace and school (pp. 161-195). London: Pinter.

Yuill, N., \& Oakhill, J. Children's Problems in Text Comprehension: An Experimental Investigation. New York: Cambridge University Press. 


\section{APPENDIX A}

\section{Sentence Sort}

In the space provided, please number the six sentences below from easiest to most difficult to understand. In the space below and continuing on to the back of this page, please explain the thinking for your ordering.

The soil erosion was caused by the rain.

As a result of the rain, the soil got washed away.

Because it rained, the soil got washed away.

The soil eroded as a result of the rain.

It rained, so the soil was washed away.

The soil getting washed away was the result of the rain. 
Table 1

Researcher Analysis of Gibbons (1999) Sentences

\section{It rained, so the soil was washed away.}

Lexical Density $=.375$ (content words: rained, soil, washed)

Lexical Diversity $=$ All words are likely familiar to school-age children

Syntactic Length: 2 clauses, 8 words (total)

Syntactic Density: 2 independent clauses, linked with a simple connective (conjunction) so, which is common in children's early language development

Congruent construction: Cause precedes effect, mirroring real-life events

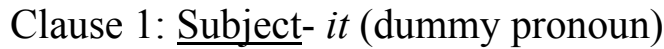

Verb- rained (active, past tense)

Clause 2: Connective- (conjunction) so, common in children's early language, but less direct and carries more than one meaning;

Subject- the soil; verb: was washed (passive voice, but actional decreasing cognitive load for younger children), adverb: away

Summary: Fairly simple sentence construction and unlikely to impede comprehension. Low lexical density and low lexical diversity. Low syntactic length and diversity.

\section{Because it rained, the soil got washed away.}

Lexical Density $=.375$ (content words: rained, soil, washed)

Lexical Diversity= All words are likely familiar to school-age children

Syntactic Length: 2 clauses, 8 words (total)

Syntactic Density: The sentence consists of a dependent (embedded) clause and an independent clause; the dependent, embedded clause is presented before the independent clause (this move preserves the congruence of the sentence, but potentially increases processing time)

Connective: because increases syntactic depth due to demoting an independent clause to a dependent, embedded clause.

Congruent construction: Cause precedes effect, mirroring real-life events

Clause 1: Causal connective (conjunction) because, common in children's early language development

Subject: it (dummy pronoun)

Verb: rained (active, past tense)

Clause 2: Subject: the soil

Verb: got washed (passive voice, but actional decreasing cognitive load for younger children) 


\section{Adverb: away}

Summary: Sentence 2 is slightly more complex than sentence 1 . Both have similar lexical density and diversity as well as identical syntactic length. Sentence 2, however, has greater syntactic density (depth and diversity). The addition of the causal connective "because" demotes the clause to a dependent, embedded clause. Also, the dependent, embedded clause appears at the beginning of the sentence, decreasing comprehensibility (Irwin \& Pulver, 1984).

\section{As a result of the rain, the soil got washed away.}

Lexical Density $=.364$ (content words: result, rain, soil, washed)

Lexical Diversity = as a result is more technical and more difficult (Schleppegrell, 2009); not

likely in children's oral language

Syntactic Length: 2 clauses, 11 words (total)

Syntactic Density: The sentence consists of a dependent (embedded) clause and an independent clause; the dependent, embedded clause is presented before the independent clause (this move preserves the congruence of the sentence, but potentially increases processing time)

Connective: As a result increases syntactic depth due to demoting an independent clause to a dependent, embedded clause. Also, as a result requires the addition of the prepositional phrase of the rain, which increases the syntactic depth and diversity.

Connective: as a result is more technical- neither the phrase as a result nor the word result were present in children's oral language (36 months - 90 months). More typical of written language than oral. (Schleppegrell, 2009)

Congruent construction: Cause precedes effect, mirroring real-life events

\section{Syntactic features:}

Clause 1: Causal connective (adverbial phrase)- as a result, more typical of written language rather than oral Prepositional phrase- of the rain.

Clause 2: Subject- the soil Verb- got washed (passive voice, actional)

Adverb: away

Summary: Although sentence 3 is technically less lexically dense than sentences $1 \& 2$ (due to the addition of "as a result", the sentence length became 11 words rather than 8), the lexical diversity is greater --As a result is more technical and the additional prepositional phrase increases syntactic diversity and depth.

\section{The soil getting washed away was the result of the rain.}

Lexical Density= .364 (content words: soil, washed, result, rain)

Lexical Diversity= result used as a noun rather than as connective

Syntactic Length: Only 1 clause but the lengthy noun phrase the soil getting washed away 
increases the syntactic length (as well as the depth and diversity), 11 words

Syntactic Density: the prepositional phrase of the rain also increased the syntactic density

Non-congruent construction: moving towards a nominalization. Thematic agent (rain) is demoted to a component of prepositional phrase (of the rain)

Note: This sentence represents children's early movement towards grammatical metaphor.

1 Clause: Subject- The soil getting washed away ("getting washed away" modifies "the soil") lengthy noun phrase

Verb: was (past tense, to be verb - verb of abstract relation)

Direct Object: the result (technical vocabulary word)

Prepositional phrase: of the rain

Summary: The syntactic architecture of Sentence 4 makes it more difficult than sentences $1,2, \&$ 3 despite its relatively low lexical density; lexical diversity similar to sentence 3 . The lengthy noun phrase the soil getting washed away increases the syntactic length, as well as depth and diversity. The noun result could also be challenging.

\section{The soil erosion was caused by the rain.}

Lexical Density $=.50$ (content words: soil, erosion, caused, rain)

Lexical Diversity= erosion (technical, although less rare than eroded)

Syntactic Length: 1 clause (8 words)

Syntactic Density: The word erosion represents a nominalization (but four times more common in oral language than the verb erode)

Non-congruent construction: erosion is nominalization. Thematic agent (rain) is demoted to a prepositional phrase (by the rain)

Passive voice- moves from actional passive voice to experiential passive voice (which is harder) but, the verb cause (even though in the passive voice) is more common than connective as a result

1Clause: Subject- The soil erosion ("soil" modifying "erosion")

Verb- was caused (passive voice- moves from actional passive voice to experiential passive voice, which is harder)

Prepositional phrase: by the rain

Summary: Highest lexical density of all sentences. Non-congruent due to addition of nominalization. The noun erosion is also more difficult than the verb, eroded. Thematic agent (rain) is demoted to component of a prepositional phrase. Less syntactic depth than 6 .

6. The soil eroded as a result of the rain.

Lexical Density $=.444$ (content words: soil, eroded, result, rain)

Lexical Diversity= eroded and result are both technical and more rare words, increasing the lexical diversity of the sentence 
Syntactic Length: 1 clause, 9 words (total)

Syntactic Density: Greater depth than 5 (as a result of the rain)

Non-congruent

Lexical features: Greater syntactic density (depth and diversity) in addition to increased lexical density and lexical diversity. Erode not present in children's oral children's language (aged 36 months to 90 months)

1 Clause: Subject- the soil

Verb- eroded (active, past tense)

Causal connective- as a result (not typical in oral language; more typically found in advanced science text)

Prepositional phrase: of the rain

Summary: Lexical density of sentence .44 is lower than sentence 5 , but the lexical diversity is increased. Erode is not present in children's oral language (36-90 months); as a result is also more technical and more difficult than because or so. The noun erosion is also four times more common in oral language than the verb eroded. The sentence is also rendered in a non-congruent form, increasing the complexity of the syntactic architecture. 
Table 2

Codes from Student Explanations.

\begin{tabular}{|c|c|c|c|c|c|}
\hline Features & ERODE & $\#$ & $\%$ & Students say the & "People mightngthplesw that \\
\hline \multicolumn{4}{|c|}{ Lexical Complexity (Vocabulary) } & noun erosion is & erosion has a verb form (eroded)." \\
\hline \multirow{5}{*}{$\begin{array}{l}\text { Lexical } \\
\text { Diversity: } \\
\text { Difficulty } \\
\text { of words }\end{array}$} & $\begin{array}{l}\text { VOC } \\
\text { (general) }\end{array}$ & 7 & 7.2 & $\begin{array}{l}\text { Any reference to } \\
\text { than to the verb. } \\
\text { vocabylary making a } \\
\text { eroded } \\
\text { senteneegsier }\end{array}$ & $\begin{array}{l}\text { "I started nympering with wh, wat } \\
\text { erosion could be confusing." } \\
\text { seemed like the easiest }\end{array}$ \\
\hline & EROSION & $\begin{array}{l}7 \\
2\end{array}$ & $\begin{array}{l}74 . \\
2\end{array}$ & $\begin{array}{l}\text { sentenee easter or } \\
\text { mominatization: } \\
\text { students deutt to } \\
\text { underts describe } \\
\text { undend. }\end{array}$ & $\begin{array}{l}\text { "Erode (v.) becomes a noun and } \\
\text { may be confusing." }\end{array}$ \\
\hline & $\begin{array}{l}\text { VOC } \\
\text { (erosion/eroded) }\end{array}$ & 6 & 6.2 & $\begin{array}{l}\text { Sow the termerosion } \\
\text { Student specifically } \\
\text { 1s more abstract than } \\
\text { refers to eroded and } \\
\text { the verb eroded. } \\
\text { erosinn as ineregsino }\end{array}$ & $\begin{array}{l}\text { "The action eroded is easier to } \\
\text { understand thord erode or the noun erosion. } \\
\text { erosion would be hard for a kid to }\end{array}$ \\
\hline & & $\begin{array}{l}5 \\
0\end{array}$ & $\begin{array}{l}51 . \\
5\end{array}$ & $\begin{array}{l}\text { the difficulty of a } \\
\text { sentence. }\end{array}$ & $\begin{array}{l}\text { hardest." } \\
\text { "Rather than using the complex } \\
\text { word erosion, the easier sentences } \\
\text { state what erosion is in common } \\
\text { terms (the soil washed away)." }\end{array}$ \\
\hline & $\begin{array}{l}\text { VOC } \\
\text { (result) }\end{array}$ & $\begin{array}{l}1 \\
2\end{array}$ & $\begin{array}{l}12 . \\
4\end{array}$ & $\begin{array}{l}\text { Students reference } \\
\text { "result" as a more } \\
\text { technical vocabulary } \\
\text { word. }\end{array}$ & $\begin{array}{l}\text { "\#3 is a little more difficult just } \\
\text { because the word result appears." } \\
\text { "\#3 and \#4 step up notch to } \\
\text { include the word result to convey } \\
\text { causation. }\end{array}$ \\
\hline \multirow[t]{3}{*}{$\begin{array}{l}\text { Lexical } \\
\text { Diversity: } \\
\text { Difficulty } \\
\text { of words } \\
\text { \& } \\
\text { Diversity } \\
\text { of usage }\end{array}$} & CONNECTIVE & $\begin{array}{l}3 \\
9\end{array}$ & $\begin{array}{l}40 . \\
2\end{array}$ & $\begin{array}{l}\text { Students state that } \\
\text { they ranking the } \\
\text { sentences based on } \\
\text { the difficulty of the } \\
\text { connective (because, } \\
\text { so, or as a result) } \\
\text { used in the sentence. }\end{array}$ & $\begin{array}{l}\text { "I felt that as a result of was more } \\
\text { difficult to understand than } \\
\text { because or so." } \\
\text { "Because the sentence has a very } \\
\text { simple transition (so) I think that } \\
\text { children would most easily } \\
\text { understand what the sentence said. } \\
\text { Because is slightly more } \\
\text { complex." } \\
\text { "I think the phrasing 'as a result' } \\
\text { might be less clear than because } \\
\text { for a beginning reader." }\end{array}$ \\
\hline & WCB/AAR & $\begin{array}{l}1 \\
5\end{array}$ & $\begin{array}{l}15 . \\
5\end{array}$ & $\begin{array}{l}\text { Students state that } \\
\text { the verb "to cause" } \\
\text { is more common } \\
\text { (and easier to } \\
\text { understand) than "as } \\
\text { a result" (even } \\
\text { though the verb is in } \\
\text { the passive voice) }\end{array}$ & $\begin{array}{l}\text { I think caused by is easier to } \\
\text { understand than as a result } \\
\text { because it is used more frequently } \\
\text { in everyday language." } \\
\text { "Was cause by seems easier to } \\
\text { understand than as a result of." }\end{array}$ \\
\hline & ERODE & & & $\begin{array}{l}\text { Students say the } \\
\text { noun erosion is }\end{array}$ & $\begin{array}{l}\text { "People might not know that } \\
\text { erosion has a verb form (eroded)." }\end{array}$ \\
\hline
\end{tabular}




\begin{tabular}{|c|c|c|c|c|c|}
\hline \multicolumn{6}{|c|}{ Syntactic Architecture } \\
\hline $\begin{array}{l}\text { Overall } \\
\text { Syntactic } \\
\text { Architecture }\end{array}$ & $\begin{array}{l}\text { STR } \\
\text { (general) }\end{array}$ & $\begin{array}{l}8 \\
8\end{array}$ & $\begin{array}{l}90 . \\
7\end{array}$ & $\begin{array}{l}\text { Students talk about } \\
\text { ordering the } \\
\text { sentences based on } \\
\text { the complexity of } \\
\text { the sentence } \\
\text { structure. }\end{array}$ & $\begin{array}{l}\text { "All of the sentences get } \\
\text { progressively harder when the } \\
\text { structure of the sentence becomes } \\
\text { more complex." } \\
\text { "The more complex the grammar, } \\
\text { the higher the number." } \\
\text { "The other sentences that were } \\
\text { more difficult were the ones where } \\
\text { the grammar rules were } \\
\text { complicated." } \\
\text { "I put the } 5^{\text {th }} \text { sentence as the } \\
\text { easiest [it rained so the soil was } \\
\text { washed away] because I thought it } \\
\text { most closely resembled the } \\
\text { simplest form of the sentence." }\end{array}$ \\
\hline \multirow[t]{5}{*}{$\begin{array}{l}\text { Syntactic } \\
\text { Density }\end{array}$} & $\begin{array}{l}\text { EQMMA- } \\
\text { USE }\end{array}$ & $\begin{array}{l}1 \\
5 \\
\end{array}$ & $\begin{array}{l}15 . \\
5\end{array}$ & 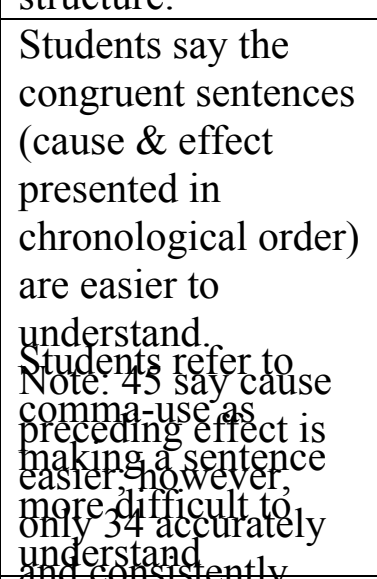 & 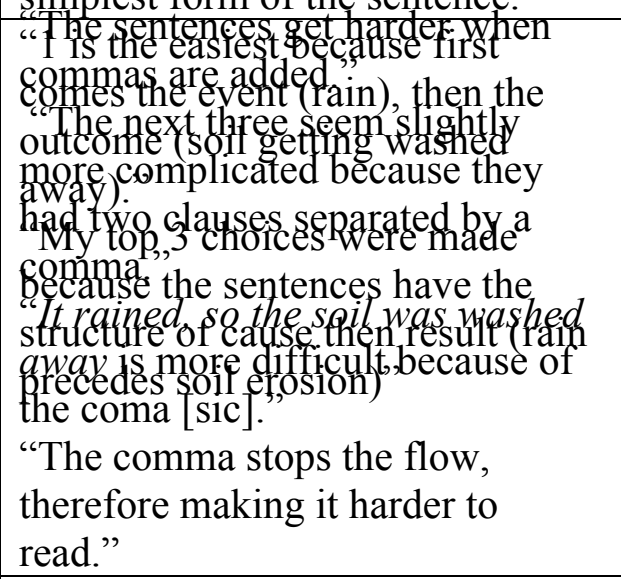 \\
\hline & $\mathrm{ACD} / \mathrm{EL}$ & $\begin{array}{l}4 \\
5\end{array}$ & $\begin{array}{l}46 . \\
4\end{array}$ & $\begin{array}{l}\text { Academic versus } \\
\text { ranked the sentences } \\
\text { conversational }\end{array}$ & $\begin{array}{l}\text { "I ordered it based on what } \\
\text { sounded most like conversational }\end{array}$ \\
\hline & ORDER & $\begin{array}{l}1 \\
2\end{array}$ & $\begin{array}{l}12 . \\
44\end{array}$ & 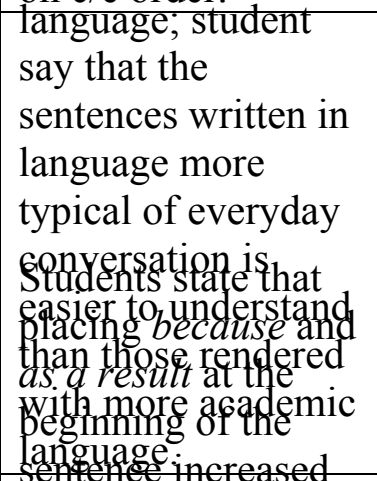 & 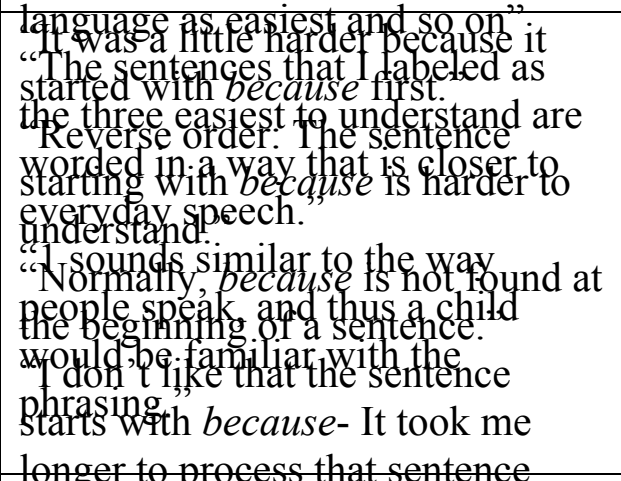 \\
\hline & PASSIVE & 4 & 7 & Studepeftedity. that & $\begin{array}{l}\text { strussive, yoice is one of the } \\
\text { structure. }\end{array}$ \\
\hline & $\begin{array}{l}\text { SYN } \\
\text { PATTERNS }\end{array}$ & $\begin{array}{l}1 \\
2\end{array}$ & $\begin{array}{l}12 . \\
4\end{array}$ & $\begin{array}{l}\text { passive voice as less } \\
\text { direct (or harder to } \\
\text { comprehend) than } \\
\text { active voice), but } \\
\text { cannot accurately } \\
\text { identify the passive }\end{array}$ & 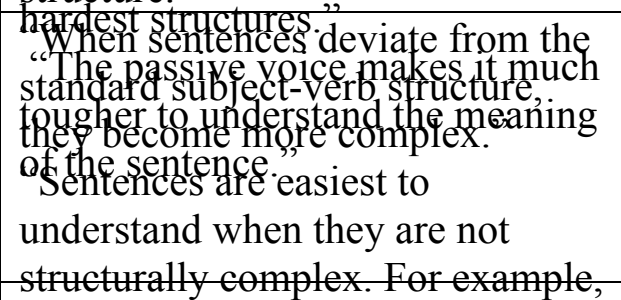 \\
\hline
\end{tabular}




\begin{tabular}{|c|c|c|c|c|c|}
\hline & & & & $\begin{array}{l}\text { voice in the } \\
\text { sentences. }\end{array}$ & \\
\hline $\begin{array}{l}\text { Syntactic } \\
\text { Density: } \\
\text { Confusion } \\
\text { with } \\
\text { embedding }\end{array}$ & $\begin{array}{l}\text { AWKWARD } \\
\text { /WORDY-6 }\end{array}$ & $\begin{array}{l}3 \\
7\end{array}$ & $\begin{array}{l}38 . \\
1\end{array}$ & $\begin{array}{l}\text { When referring to } \\
\text { the sentence, "The } \\
\text { soil getting washed } \\
\text { away was the of the } \\
\text { rain" students refer } \\
\text { to the sentence as } \\
\text { awkward, confusing, } \\
\text { or too wordy. } \\
\text { Wordy: (14 said } \\
\text { both awkward and } \\
\text { wordy; } 10 \text { said } \\
\text { wordy; } 13 \text { said } \\
\text { awkward) }\end{array}$ & $\begin{array}{l}\text { "This is simple enough to } \\
\text { understand, but awkwardly } \\
\text { worded." } \\
\text { "Too many words!" } \\
\text { "Excessive words!" } \\
\text { "Sentence } 6 \text { is very long and run } \\
\text { on with the words all jumbled up." }\end{array}$ \\
\hline $\begin{array}{l}\text { Syntactic } \\
\text { Length }\end{array}$ & $\begin{array}{l}\text { WORDY/ } \\
\text { CONCISE }\end{array}$ & $\begin{array}{l}3 \\
5\end{array}$ & $\begin{array}{l}36 . \\
1\end{array}$ & $\begin{array}{l}\text { Students either say } \\
\text { that shorter/more } \\
\text { concise sentences } \\
\text { are easier to } \\
\text { comprehend OR that } \\
\text { "wordy" sentences } \\
\text { are harder to } \\
\text { comprehend. } \\
\text { ( } 17 \text { referred to only } \\
\text { to "The soil getting } \\
\text { washed away } \\
\text { sentence;" } 12 \\
\text { referred to other } \\
\text { sentences; and } 6 \\
\text { referred to both } \\
\text { sentence } 6 \text { and made } \\
\text { other comments. }\end{array}$ & $\begin{array}{l}\text { "I though the easiest sentence } \\
\text { would be the one with the shortest } \\
\text { and most straight-forward } \\
\text { wording." } \\
\text { "\#5 (As a result of the rain, the } \\
\text { soil got washed away) seems like } \\
\text { there are a lot of unecessary [sic] } \\
\text { words." } \\
\text { "Using the word 'eroded' for } \\
\text { "washed away' made that sentence } \\
\text { more concise and direct. It was } \\
\text { easier to understand." }\end{array}$ \\
\hline $\begin{array}{l}\text { Inability to } \\
\text { explain } \\
\text { syntactic } \\
\text { architecture }\end{array}$ & $?$ & $\begin{array}{l}3 \\
5\end{array}$ & $\begin{array}{l}36 . \\
1\end{array}$ & $\begin{array}{l}\text { Students say one } \\
\text { sentence is easier } \\
\text { than another, but } \\
\text { cannot explain why. } \\
\text { Also: Students say a } \\
\text { sentence is easier } \\
\text { because it "flows" } \\
\text { but can't explain } \\
\text { why. }\end{array}$ & $\begin{array}{l}\text { "Not too difficult to understand } \\
\text { but in my opinion not the easiest." } \\
\text { I put \#1 in front of \#2 because it } \\
\text { seemed to flow better and } \\
\text { therefore was easier to understand. } \\
\text { "The sentence just flows better } \\
\text { than the following sentences." } \\
\text { "The wording in this sentence is } \\
\text { cumbersome." }\end{array}$ \\
\hline
\end{tabular}


"IT JUST FLOWS" 
Figure 1. Looking at Linguistic Complexity

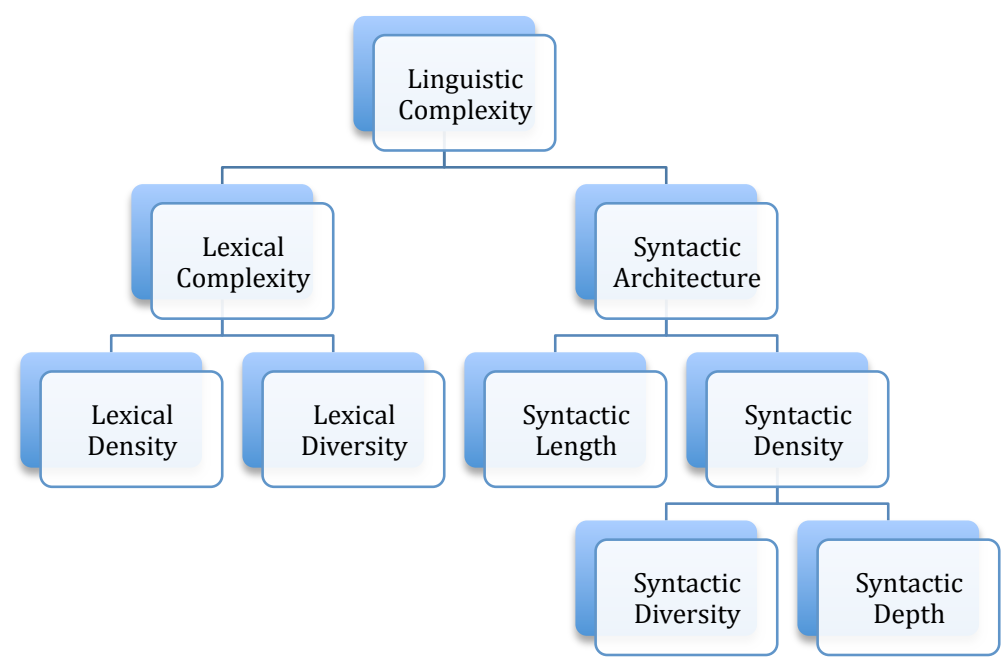




\title{
Chapter 3
}

\section{Manuscript 2: Highlighted History of Grammar Instruction: What Lessons Can We Learn} Moving Forward?

\begin{abstract}
This paper presents a highlighted history of grammar instruction. Beginning with pedagogies in ancient Rome, I trace the appearance of grammar instruction in England from Aelfric's Latin grammar with notes in English though the rise of prescriptive grammar instruction in the late 1700's. I then follow the impact of Murray's (1795) grammar text on grammar instruction in the United States from the 1800's until the 1960's, when key American professional organizations advocated the cessation of grammar teaching. In the final sections of this paper, I consider today's most current policy documents in light of my historical findings, ultimately suggesting that ancient Roman pedagogy may offer much to today's instruction.
\end{abstract}


Highlighted History Of Grammar Instruction: What Lessons Can We Learn Moving Forward? After decades of absence in most public schools, grammar instruction is reappearing in the national curricula of many Anglophone countries, particularly in England, Australia, and the United States. Specifically, in the U.S., The Common Core State Standards (CCSS; National Governors Association Center for Best Practices \& Council of Chief State School Officers, 2010), which have been adopted in 43 states, bring renewed interest to teaching "the conventions of standard English [SE] grammar and usage when writing or speaking" (CCSSI, n.d., "Conventions of SE", para 1). Although critics maintain that over 50 years of research indicate that traditional grammar instruction does not improve students' literacy development, particularly their writing performance (Braddock, Lloyd-Jones, \& Schoer, 1963; Graham, McKeown, Kiuhara, \& Harris, 2012; Graham \& Perin, 2007; Hillocks, 1984; Hillocks \& Smith, 2003), Myhill and Watson (2014) suggest that "there are signs of an emerging consensus that grammar may be important in developing learners' understanding of how language works and, specifically, how grammar choices are significant in shaping and constructing meaning” (p. 53). In fact, more and more researchers are now arguing that grammar is "absolutely central to the study of language" (Crystal, 2006, p. 89) and suggesting that it is incumbent upon teachers to provide explicit grammar instruction because "to deny children access to it [SE grammar] is to deny them equality of social and economic opportunity" (Clark, 2001, p. 1; see also Bailey, 2006; Delpit, 2002; Schleppegrell, 2007).

Though the renewal of interest in grammar instruction brought about by various standards is not entirely unwelcome, Myhill and Watson (2014) have cautioned that the CCSS documents, in particular, appear to lack a well-articulated rationale for why grammar instruction may be important for students. Initial efforts to examine the CCSS have revealed similar concerns. Troia 
and Olinghouse (2013) conducted a quantitative content analysis of the CCSS Writing and Language Standards and reported that while the renewed attention to grammar is not necessarily problematic in itself, the lack of a clearly articulated purpose for why such instruction is included may result in a return to "a traditional, decontextualized approach to teaching grammar (i.e., using worksheets, diagramming sentences, studying parts of speech)" (p. 347). Without clear insight into why the re-introduction of grammar is important for students, it may appear that the only two choices for teachers are traditional grammar practices or no grammar at all (Clark, 2001).

Rather than rehashing the same debates for or against grammar instruction, Myhill and Watson (2014) assert that the field needs to shift its attention toward new, more coherent conceptualizations for the role of grammar instruction in student learning and to explore pedagogies that may help students. Because grammar instruction has historically occupied a central position in education, beginning as early as ancient Greece and Rome, it is possible that there is much to learn from history in terms of how different theoretical frameworks have helped (or hindered) students in their efforts to become more efficient and effective language users.

Such a historical review is essential when considering the ideas and practices related to grammar instruction. Understanding how grammar came to be highlighted as an integral part of a student's education provides insights regarding where current practices come from, how they developed, and why they are (or are not) effective in helping students. In addition, dialogues and debates around current controversies often have historical underpinnings (frequently unknown and unrecognized) that can provide the perspective needed to evaluate new attempts to define the goals of instruction related to language and grammar. Therefore, an understanding of the history of grammar instruction can provide perspective as the international English language arts field, 
propelled by new policy documents, moves forward to reintroduce grammar into school instruction. Accordingly, the purpose of this paper is to examine how the goals (and associated pedagogies) of grammar instruction have changed over time and to consider what lessons might be learned from that history as efforts to implement new policies move forward.

\section{Method}

For this review, I have followed recommendations for historical research offered by Stahl and Hartman (2004) and Monaghan and Hartman's (2000), using both primary sources (e.g., grammar textbooks; language arts methods textbooks) and secondary sources (e.g., historical reviews) to answer the following questions: (1) How have the goals of grammar instruction changed over time? (2) How have the pedagogies related to grammar instruction changed over time? (3) Which lasting ideologies related to grammar instruction have influenced school pedagogy? (4) In light of such influences, what cautions must be considered with the implementation of the new grammar emphasis?

Because my research revealed an extensive field, I determined that in this work, I would highlight key aspects of grammar instruction, beginning in ancient Rome and ending with today's efforts to reintroduce grammar. Because I wanted to provide readers with a comprehensive look at how grammar instruction has changed over time, and how those changes have affected pedagogy, I chose to offer an overview rather than providing an in-depth focus on a single time period or a single aspect of grammar instruction. Consequently, this paper is divided into five sections. In the first, I describe how grammar was conceptualized and taught in ancient Rome, highlighting grammar instruction as an integral part of a deep study of language. In the second, I describe how the shift from Latin to English impacted grammar instruction. In the third, I trace how the need to regularize and legitimatize the use of English ultimately led to a 
diminished conception of grammar. In the fourth, I describe how the inherited beliefs about grammar from England impacted grammar instruction in the United States, and then examine how the influence of rule-based grammar instruction has wax and waned over time. Finally, in the fifth, after briefly addressing today's CCSS, I offer suggestions on what we might learn from this history moving forward.

It is important to note here that none of these ideas is new to the field; in fact, many prominent scholars have covered various periods of grammar instruction extensively. My purpose is to bring these important scholarly insights back into conversations in light of the widespread adoption of new educational policies; these conversations are particularly important as the field moves to support both preservice and inservice teacher training during implementation.

\section{Ancient Grammar Instruction: Citizens, the Integrated Curriculum, and Facilitas}

The overall goal of education for Greek and Roman citizens (remembering that many in these societies were not citizens) was to prepare children and young adults for active participation in society by helping them develop a strong a command of language (Murphy, 2012). Language expertise (and thus language education) became highly valued in the ancient city-states of Greece and Sicily when the division of land among "commoners" (p.786) created increasing legal disputes. To successfully argue their cases in courts and to play a role in society, these new citizens would need persuasive language skills (Nelson \& Kinneavy, 2003) because, as Murphy (2012) explained, citizenship in the democratic Greek city-states, and later in the Roman Empire, “demanded a high level of communicative skill from its citizens" (p. 37).

Given the Greco-Roman realization that strong communication skills were crucial to a healthy, functioning society, education, as it evolved in ancient Rome, focused on the 
development of facilitas, "the habitual capacity to produce appropriate and effective language in any situation" (Murphy, 2012, p.38). Habituation (engraining a habit of excellence in students' language use) was the key to success, and the goal was not mere competence, but eloquence (Abbott, 2012; Christiansen, 2003).

Facilitas was achieved through the detailed study of rhetoric (the study of effective speaking and writing; Nelson \& Kinneavy, 2003). The concept of rhetoric has changed considerably throughout history, but ancient rhetorical studies stressed an ability to understand how language worked in oral and written communication along with the personal proficiency to apply the affordances of these language resources in one's own speaking and writing (Corbett \& Connors, 1999). The following sections offer insight into how grammar instruction was approached as a key aspect of rhetoric within a highly integrated language arts curriculum, all with the overall goal of developing facilitas.

\section{The Elements of Ancient Rhetoric}

Roman rhetoric, as explained in Rhetorica ad Herennium (author unknown, 86 BCE, see Corbett \& Connors, 1998; Murphy, 2012; Nelson \& Kinneavy, 2003), consisted of five major canons; to understand these best, it is helpful to keep today's process writing in mind (see also The Quintilian Progression by Edmund Henderson as described in Bloodgood, 2002). Invention addressed the creation/assembly of ideas that could make a convincing case (prewriting). Arrangement addressed the organization of these ideas (focus/drafting). Style attended to the best words and sentences for the expression of these ideas (drafting/revision). Memory provided mechanisms (mnemonics, visual images) for remembering how to produce oral text (no analogous aspect in writing process). And, finally, Delivery spoke to the presentation of textmodulation of voice, gestures, and facial expressions (publication). 


\section{Studies with the Grammaticus}

Before students could move to advanced rhetorical studies with their rhetor (teacher of rhetoric), they spent years studying with their grammaticus (teacher of grammar), through a curriculum largely based on the careful analysis of the best authors of the time (Murphy, 2012), sharing a pronounced similarity to another of today's writing instructional aspects - the mentor text. And although there was a distinction between the grammaticus and the rhetor, grammar instruction was inextricable from the study of rhetoric in pursuit of facilitas. Quintilian, whose Institutio Oratorio (95 A.D.) provides us considerable insight into Roman education, believed that grammar exercises were "so foundational that students must be taught its precepts directly, especially in the earliest stages" (Murphy, 2012, p. 53). This early attention to the precepts (the rules governing language use) was indeed considered foundational to instruction; however, Quintilian asserted that such rules should not be followed slavishly (Christiansen 2003). Instead, these rules served as "guides rather than commandments" (Murphy, 2012, p. 53). Furthermore, the notion of a precept included both grammar and rhetoric; the two were almost inseparable (Murphy).

Exemplary (mentor) texts. Quintilian also emphasized that effective grammar instruction was not possible without attention to both the productive aspects of language (e.g., speaking and writing) and the receptive aspects of language (reading and listening; Murphy, 2012). Quintilian noted the importance of this integration, contending that reading (of exemplary texts) provided both ideas and language for the production of students' written texts by providing them models to imitate/follow (Christiansen, 2003). Likewise, oral presentation -- recitation (chiefly of exemplary texts, but also of students' own writing) -- provided opportunities for 
listening, laying the foundation for that critiquing of speech so essential to citizens' active participation in Roman society.

Toward that end, children read, wrote, spoke, and listened to a variety of exemplary texts on a daily basis within an exceptionally integrated language arts curriculum, as their teacher, the grammaticus, addressed the language choices authors and speakers made that contributed to the overall impact of the text's message. In particular, the grammaticus demonstrated for students "how the author made good or bad choices" (Murphy, 2012, p. 55) in pursuit of their intended message. In this way, students focused on both content and form (Corbett \& Connors, 1999). Reflecting on the pedagogical practices typical of that time, Abbott (2012) suggested that the grammar studies of Roman education should best be seen "an integrated curriculum of oral and written composition combined with literary criticism" (p. 150). From the perspective of ancient times, Dionysios Thrax, author of 100 C.E.'s most popular Roman grammar book, suggested that grammar was "an experimental knowledge of the usages of language as generally current among poets and prose writers" (emphasis added; cited in Haussamen, 2000, p. 6). With these definitions of grammar and the overall goal of facilitas, it makes sense that Quintilian would contend that the precepts were guides rather than commandments.

Imitation: A method of study. In an effort to provide teachers with a systematic program of instruction, Quintilian recommended that schoolmasters integrate grammar instruction in reading, writing, speaking, and listening activities through a uniform method of study known as Imitation, applicable both to elementary and advanced students once they knew the basics of reading and writing (Christiansen, 2003). The sequence of learning activities provided teachers with a great deal of support and guidance, therefore, the following section describes the details of the pedagogy associated with grammar instruction in pursuit of facilitas. 
Imitation: The sequence of learning activities. As indicated above, the overall pedagogical recommendations that Quintilian carefully detailed for the grammaticus largely focused on exemplary texts. Quintilian's use of what today are termed mentor texts was absolutely critical to the study of grammar because it helped students to distinguish between sophisticated and immature texts and encouraged them to become critical explorers of texts (Christiansen, 2003). In fact, Murphy (2012) noted that the one of the overall objectives of Imitation was "to accustom the student to what we would today call a 'close reading' of text" (p. 55). This 'close reading' helped students build up a copia (an abundance of syntactical forms and ideas drawn from reading and listening) to be used to further their own communicative goals (Nelson \& Kinneavy, 2003). The sequence of how these exemplary texts were to be taught is described below.

Studies began with read alouds of histories and poetry emphasizing delivery, which required students to take on "the character of the speaker" (Christiansen, 2003, p. 70). This reading led to the next step, text analysis, in which every possible decision made by the writer related to organization of ideas and word choices (including figurative language) was examined. This text analysis work, explained Murphy (2012), led to "a high degree of linguistic sensitivity in the students" (p. 57).

Students then memorized exemplary texts, providing future access to "the best words, phrases, and figures [of speech]" (Quintilian, cited by Murphy, 2012, p. 58) at any point in their own productive efforts. Quintilian considered memorization particularly important for the young, affording them "an intimate acquaintance with the best writings" that would enable them to "carry their models with them and unconsciously reproduce the style of the speech which has been impressed upon the memory" (Quintilian, cited by Christiansen, 2003, p. 71). Once texts 
were memorized, students moved to paraphrasing, first to increase their attention to structure (they might be told to retell beginning in the middle or even at the end of a tale), and second to develop their own speaking style. Even the youngest students were to retell fables from Aesop; texts naturally became more complex as children advanced through school.

Next students engaged in transliteration activities - from Greek to Latin (and vice versa), from poetry to prose (and vice versa), from long texts to shorter summaries, from a grand style to plain (and vice versa). Such exercises gave students a "keen awareness of language" (Murphy, 2012, p. 59). At this point, students were asked to orally present either their paraphrasing or their transliteration, sometimes read aloud, sometimes from memory. Finally, there were corrections (and praise) given for this presentation, offered by both teacher and peers. Correction, explained Quintilian (see Murphy, 2012), was seen to be good for all in developing proper habits of mind, but was to be provided in a context of students' future presentation improvements.

Overall, children were actively engaged in what was clearly a highly integrated language arts curriculum, in which children engaged in grammar study in pursuit of "the deeply-rooted capacity (Quintilian's word is facilitas) to employ language wherever needed, on whatever subject, in whatever circumstances" (Murphy, 2012, p. 73). Toward that end, grammar instruction was not merely an additional subject to cover, but designed to compliment a wellintegrated, carefully designed language arts curriculum (e.g., no exercise was ever completed for a single purpose). The grammaticus led students incrementally through this highly-coordinated, integrated sequence of learning activities, in which "Grammar was fully realized in language itself - in fluid, flexible, lively, ever-changing, emotional, beautiful, stylish, graceful language performance" (Glenn, 1995, p. 10). Aimed at producing a habit of language that would enable 
students to be successful, productive citizens, such that "the letter of the alphabet becomes years later a stirring oration in the Roman Senate" (Murphy, 2012, p. 73), it was an effective system.

\section{The Legacy of Quintilian's Grammar Instruction}

Although we may see echoes of this pedagogy today, Murphy (2012) cautioned, "the full power of their use resides in their interrelation to each other, and in their place in a proven sequence" (emphasis added; p. 73). Indeed, while particular aspects of Quintilian's curriculum are visible throughout history, the overall coherence of the system eroded, particularly in light of the massive social, cultural, and economical changes of Western society. Specifically, the study of rhetoric and grammar became increasingly fragmented, and the highly integrated nature of the language arts curriculum dissolved (Abbott, 2012; Murphy, 2012). Evidence of this fragmentation can be seen as early as the $6^{\text {th }}$ century, in Priscian's grammar, which devotes itself only to proper pronunciation of Latin and descriptions of syntax. As a result, the educational goal of facilitas to enable active citizenship was ultimately lost and eventually replaced with much narrower goals for grammar instruction.

\section{Grammar Instruction in England: The Shift from Latin to English}

Following the dissolution of the Roman empire (449 AD or BCE), grammar instruction continued to have a fundamental place in education, and Latin, which remained the lingua franca, was both the linguistic goal and medium of instruction as Roman influence spread throughout Europe. In England, the various English vernaculars (the variety of language spoken by people in a particular country or region) held low status, so it was the "grammar" schoolteacher's responsibility to teach "the understanding, speaking, reading, and writing" of Latin (Gwosdek, 2013, p. 29). Accordingly, textbooks were only written in Latin. 
However, as more and more English-speaking students pursued Latin as a second language, teachers found themselves having to explain the forms and structures of Latin in English. As a result, grammars (textbooks used to teach grammar) began to use vernacular forms of English for this purpose. In fact, Aelfric's Grammar (987), written during the Anglo-Saxon period in which Old English was spoken, appears to be first grammar that used English to explain Latin grammar features to students (Gwosdek, 2013).

The publication of Aelfric's grammar encouraged teachers to reference grammatical differences between Latin and English, thus helping students to understand their own language better (Gwosdek, 2013). At first, this attention to English vernacular was considered a diversion (particularly given the wide variety of English dialects spoken at that time), but as the practical need for effective communication increased along with England's burgeoning commerce, the status of English began to shift. The following section describes how the shift from learning Latin to an increased interest in learning English ultimately resulted in the first English grammar, William Bullokar's (1586) Pamphlet for Grammar (as cited in Dons, 2004).

\section{Confusions around Grammar Instruction Begin}

Following Aelfric's grammar, additional authors created Latin grammars with English explanations. Although this made sense from a pedagogical approach, the creation of multiple English-language Latin grammars became problematic as the English language varied dramatically from one community to another. To begin, the Angles, Saxons, and Jutes each brought their differing Germanic dialects to England. Crystal (2006), reviewing Old English texts, noted "there were five main dialect areas in England" (p. 4); each had its own pronunciations (evident in their spelling), vocabulary, and grammar. As a result of these 
variations, English-language Latin grammars often contained conflicting information, creating considerable confusion in terms of grammar instruction (Gwosdek, 2013).

Although there were efforts to standardize English to address these confusions (e.g, King Alfred's West Saxon dialect gained prominence as a standard form in the late ninth century), the English language, in light of numerous invasions, would continue developing on its own accord. Most notably, the Norman invasion (1066) introduced both vast new vocabulary and a chaos of spellings (cwens in Old English would transform to queens, Crystal [2006], p. 7), moving Old English into Middle English (Kerswill \& Culpeper, 2009).

Despite the continual upheaval of wars, the courts of England promoted increased literary productivity, with Chaucer's Canterbury Tales as the best-known work of that period (late 1300's). The Tales themselves speak to the changing status of English, as well as to a critical new bifurcation of the language: a dialect of upper class language contrasted with a variety of dialects held in less esteem and spoken by those of inferior stature (or as Chaucer termed it, knayvyssh speche; Crystal, 2006, p. 9). This bifurcation of English - the privileged versus the vernacular - would ultimately come to undergird grammar instruction. (Incidentally, Chaucer himself would lament the varied spellings of his hand-copied works, [Crystal].)

Impact of the printing press. Whereas there was no real consensus on a standard form of English before the fourteenth century, the fifteenth century marked a period in which "London English" gained prominence as a standard because more and more writings (e.g., literary texts, contracts, legal documents) were produced London English than in any other dialect (Fries, 1940). Such writings tended to be produced in London English because William Caxton, who introduced the printing press to England in 1476, was primarily concerned with rapidly producing texts for a demanding, literate, upper class British society (Kerwill \& Culpeper, 2009; 
Yates \& Kenkel, 1999). Caxton faced the challenge of deciding which of the English varieties would appeal to the largest (paying) audience, and his audience had opinions of their own on correctness in English. (This included Lady Margaret of York, sister to King Edward IV, who insisted that Caxton amend his English to her standards [Crystal, 2005]). As a result of the printing press, the cost of books was greatly reduced, and more and more people became interested in learning to read and write in English, thus increasing the status of English, in particular London English.

King Henry endorses Lily's Grammar. The creation of the printing press also impacted the content of grammars. Whereas grammars were previously limited to handwritten copies, the advent of the printing press led to the wide distribution of grammars; however, even though London English had become the preferred standard for written work, the content of grammars continued to vary widely (Gwosdek, 2013). In fact, in 1540, King Henry VIII realized that the variation seen in the published grammars might pose challenges for students, so he called for 'certein lerned men mete for suche a purpose, to compile one brief, plaine, and vniforme grammar' in order to avoid the harm done to the children's education due to the diversity of grammars and teaching methods" (Gwosdek, 2013, p. 110). Beginning in 1542, King Henry VIII, and later his son, Edward VI, would require all teachers to use Lily's Grammar (Lily, 1540), eventually leading to the title, "The King's Grammar."

The King's goal was to ensure that "every pupil at grammar school had to use the same textbook and learn the same rules that had to be taught according to the same teaching method" (Gwosdek, 2013, p. 111), one of the first efforts towards English education standards. Although Henry's effort to reform and standardize the teaching of Latin grammar was understandable, Lily's Grammar focused mostly on the lower levels of the common Latin curriculum. For 
example, a section of Lily's Grammar reflects a biproduct of the 'Grammarian War' (15191521), in which William Horman (schoolmaster and grammarian) argued for the use of imitation of excellent authors in pursuit of good Latin (a la Quintilian) while Robert Whittington and John Skelton argued for the drilling of grammatical rules (Gwosdek, 2013). The Whittington/Skelton impact can be seen in the introduction to Lily's Grammar highlighting "the eighte partes of speche: the nowne, pronowne, verbe, participle, aduerbe, conuiction, preposition, interiection," these categories themselves having appeared in Priscian's grammar nine centuries earlier (Robins, 2013).

Given the Kings' promotion of Lily's grammar, and given Lily's adherence to the Whittington/Skelton stance, the overall breadth of grammar instruction began to narrow in focus, and the corresponding pedagogies reflected this shift by becoming more rigid, more focused on the correct application of the rules as opposed to the concept of grammar in Roman times as an experimental knowledge accompanied by flexibility in the application of precepts. Furthermore, the royal endorsement of Lily's grammar limited the publication of other grammars, thus further restricting teachers to Lily's approach to grammar instruction (Gwosdek, 2013).

The expanding English language. Despite King Henry VIII's best efforts to provide stability to grammar instruction, he could not control the overall language itself. People continued to speak in different accents and dialects and write with different spellings and grammatical forms. And even though the total number of grammars declined, more and more written English texts (e.g., mythic tales, popular stories, poems, phrasebooks, and devotional pieces) appeared. In fact, there was an emerging sense among many that English lacked the necessary words to present certain ideas (Gwosdek, 2013). This perception led to the burgeoning of loan words, particularly from Greek and Latin, culminating in a noted period of coinage, the 
Elizabethan era (Kerswill \& Culpeper, 2009). Fascinatingly, Shakespeare himself was responsible for introducing at least 1,700 new words-accommodation, impartial, inauspicious, savagery (Crystal, 2010, p. 42) to name just a few. As a result of the influx of new words as well as the rapid changes occurring to the English language, many in England would contend that their language was "out of control" (Crystal, 2006, p. 60), its texts bloated with "ornateness and eloquence" (p. 61).

\section{The English Grammar Tradition is Born}

The dramatic changes to the English language, along with the recognition English itself had practical value in terms of overall communication and commerce, resulted in an increased interest in the English language. In fact, in 1586, William Bullokar published his Pamphlet for Grammar, which represented an important shift in formal grammar instruction. For the first time, the purpose of a grammar text was not to teach Latin; rather, it was to teach English. One of Bullokar's main goals was to demonstrate that English was as rule-bound as Latin, and worthy of study itself (Dons, 2004). Attempting to codify the regularities of the English language, Bullokar based much of his work on Lily's Grammar (Gosdwek, 2013). As a result, his English grammar was largely based on Latinate rules and, thus, set the precedence for the need to validate English through a Latin foundation (Dons, 2004). The interest in English grammars would only intensify as the practical need for command of the English language increased; this, in turn, would eventually drastically alter the pedagogy of grammar instruction.

\section{The Rise of Prescriptive Grammar}

In England, the eighteenth century, marked both by a growing merchant class and the Industrial Revolution, would become a period of intense attention to creating a standardized English grammar (Christie, 1993; Ferreria-Buckley, 2012). As Crystal (2006) explained, "There 
was an urgency surrounding the notion of a standard language... and because grammar is common to both spoken and written language, it is of crucial importance when it comes to defining a standard" (p. 95). Furthermore, the grammar one used would immediately let listeners know "who they were talking to. Snap judgments were everything, when it came to social position" (p. 95). And this would matter tremendously in a nation increasingly attentive to socioeconomic status (Fries, 1940). Thus, it became quite important, particularly for the upwardly mobile, to use a grammar associated with the wealthy, upper class, and not what Chaucer would have termed knayvyssh speche.

\section{The Need to Stabilize and Legitimize the English Language}

Given the importance of impressions made by grammatical use as well as the general desire to impose some linguistic stability on English, a number of new grammars devoted solely to English were written, and these texts varied in their approach to language. Whereas many grammarians of the seventeenth century (e.g., Ben Jonson and John Wallis) had argued that it was absurd to apply the inflexible rules of Latin to a living language, insisting instead that a standard should be determined by common usage, the prominent grammarians of the eighteenth century (e.g., Robert Lowth) would argue that correct grammar should follow a strict set of authoritative rules (Christie, 1993; Dons, 2004). In fact, the battle among those who set out validate the legitimacy of English by describing how the English language worked versus those who wanted to legitimize English by modeling it on Latin would set the stage for grammar wars well into the twentieth century.

Specifically, Ben Jonson (1640), in a manner reflective of Quintilian, had argued that great literature (e.g., Chaucer, Gower, and Lydgate) should be the basis for studying English grammar as opposed to grammarians who tried to regularize English on Latin as a model (Dons, 
2004). Writing in 1654, John Wallis would concur: that mastery of the English language was indispensable and the study of Latin-based rules of little help. Instead, he suggested that grammar studies should include the history of how the English language developed. In fact, based on that history, teachers could contrast the major differences between Latin and English, with Wallis arguing that his predecessors had not spent adequate attention delineating such differences: "They all forced English too rigidly into the mould of Latin... giving many useless rules... which have no bearing in our language" (trans. Kemp, 1972, p. 109-111, as cited by Dons, 2004).

Despite these particular $17^{\text {th }}$ century scholarly efforts to describe English as it was actually spoken and written, many other linguistic scholars would later argue that these efforts did not provide enough order and stability to the language. As Lord Chesterfield would declare in 1754, "it must be owned that our language is at present in a state of anarchy" (as cited in Crystal, 2006, p. 75). The urgency to standardize English in terms of vocabulary, spelling, and grammar resulted in the publication of numerous dictionaries, grammars, and pronunciation manuals.

Of all the eighteenth century grammarians, Robert Lowth, in1765, provided the most systematic approach to syntax. By that time, the study of grammar had been relegated to wordlevel features, specifically concerned with the proper use of words, correct spelling, examining roots and origins, or "for identifying the 'rules' by which words worked in the construction of language" (Christie, 1993, p. 76). Unlike his contemporaries who believed English to be too simplistic to warrant the study of syntax, Lowth additionally addressed sentence-level features; however, his attention was limited to the application of Latinate syntax onto English. His pursuit of correct language use was dogmatic, and no one's language use was sheltered from criticism; 
Lowth would find fault with "the language of Shakespeare, Milton, Dryden, Pope, Addison, Swift and others" (Crystal, 2006, p. 108), while he himself would introduce one of English's very long-lasting grammatical plagues: preposition stranding, or the rule that English sentences were never to end in a preposition.

Grammarians like Lowth would later be described as prescriptive because they imposed a "prescription" of rules to English, in the same way a medical prescription is provided for the unwell or diseased. They believed that the application of Latinate rules to English would rid it of all of its particular vernacular problems and impose some linguistic order to the chaotic language (Applebee, 1974; Clark, 2001; Kerswill \& Culpeper, 2009). Because Latin was chiefly taught as a written language by that time, the prescriptive grammarians believed that it represented a set of linguistic norms that were unchanging and "pure" (Woods, 1985, p. 6). The overall goal of grammar instruction then was to rid English of "the barbarous usages of the uneducated" (Woods, 1985, p. 6) and fix the 'flawed' language of the working class children and adults (Applebee, 1974; Clark, 2001; Kerwill \& Culpeper, 2009). In short, knayvyssh speche would no longer be acceptable.

\section{Criticism of the Prescriptive Grammarians}

In many ways the prescriptive grammarians' search for English standards was understandable. As Crystal (2006) has explained, there is nothing inherently wrong with the idea of a linguistic standard because it is helpful in terms of creating "an essential medium of communication in a diverse world" (p. 93). Likewise, Kerswill and Culpeper (2009) have argued that a standardized form of English "allows people of different walks of life to communicate more easily" (p. 224). Without a standard, issues around clarity and comprehension arise, and misunderstandings can lead to unnecessary conflicts (Bex \& Watts, 1999). 
The problem most scholars had with the prescriptive grammarians was that they believed in the notion of a universal grammar, or the belief that adherence to Latin represented a state of grammatical perfection, which led to the belief that any deviation from Latin would result in a substandard degradation of English sentences (Bex \& Watts, 1999; Clark, 2001; Haussamen, 2000). As a result, Latinate English grammar led to many rules that constrained expression (e.g., sentences should not end with prepositions) and further reinforced the belief that one form of English was inherently superior to others (Clark, 2001; Haussamen, 2000). Even more damaging was the belief that good language became associated with good behavior, leading to dangerous social implications that often resulted in discrimination (Watts, 1999). Clark (2001) explained:

The form specified is not simply a definition of the 'common' language but a 'standard ' to be reached. Any usage not adhering to it [Latinized English] in either writing or speech was thus 'lazy' and 'full of errors', corresponding in turn to aspects of people's behavior. Language was thus thought to mirror the thoughts of the mind. Since standard English was the 'proper', 'correct', and 'superior' form of language, it appeared logical that those who spoke and wrote it were, therefore, 'proper', 'correct', and 'superior' citizens. (p. 31)

Therefore, from a prescriptive grammarian's perspective, proper English grammar was not only privileged above all others in terms of skills related to speaking and writing, but it also became associated with a set of societal values, which ultimately led to moral judgments based on the way people spoke and wrote (Bex, 1999; Christie, 1993; Clark, 2001; Woods, 1985).

Ultimately, the prescriptive grammarians' influence would overshadow that of others, and the goal of studying English shifted from describing how written English worked to the design and application of a prescriptive set of rules so that the English might speak their native 
tongue properly and correctly (Watts, 1996; Milroy \& Milroy, 1998). Christie (1993), examining these changes, noted, "the quality of the grammar textbooks declined generally, as did the practices for teaching grammar over all” (p. 86).

\section{PG's Impact on Pedagogy}

Given the presumed superiority of SE and the corresponding moral and behavioral implications, teaching correct English quickly became a central educational goal in British schools (Clark, 2001). However, as Applebee (1974) aptly captured, "the shift of grammatical studies from the classics to English involved a shift from a method of teaching a foreign language to one of correcting a native one" (pp. 6-7). Because of the overwhelming influence of the prescriptive grammarians, language instruction in schools was not focused on when different usages were appropriate to different settings - that is, teaching children to recognize and understand the consequences of the grammatical choices they made. Instead, schools, particularly elementary schools, became a place to "fix" children's language use and to eradicate "vulgar" dialects (Ferreira-Buckley, 2012, p. 180). In many cases, dialects were even banned in schools (Christie, 1993). And by fixing children's language use, teachers could assure themselves that they were molding well-behaved, compliant citizens (Christie, 1993).

To teach correct and proper English, teachers turned to popular grammars, believing that memorizing grammar rules was the remedy for what many prescriptive grammarians described as children's "deplorable use of English" (Fries, 1940, p. 18). Lindley Murray, whom Applebee (1974) described as "the father of English grammar" (p. 7), authored what would become the most influential grammar text of the nineteenth century (Crystal, 2006; Woods, 1985). Although Murray was "not a highly original author" (Tchudi, 1967, p. 25) and liberally copied Lowth's 1765 work (Crystal, 2010), his grammar, first published in 1795, was the first to be written for 
use in a school setting (Haussamen, 2000). Unlike Dionysios Thrax, the author of Rome's most popular grammar book in $100 \mathrm{CE}$, who had suggested grammar was "an experimental knowledge of the usages of language as generally current among poets and prose writers" (emphasis added; cited in Haussamen, 2000, p. 6), Murray $(1795 ; 1968)$ defined grammar simply as "the art of speaking and writing the English language with propriety" (p. 1). His text featured twenty-two grammatical rules, many of which continue today; his first rule was "A verb must agree with its nominative case, in number and in person: as, 'I learn;' 'though art improved;' 'The birds sing'” (Murray, 1805, p. 126).

The standard pedagogy for learning Murray's grammar was “definition, drill, and memorization" (Beckham, 1938, p. 35), all grounded in the belief that if children could simply memorize the rules of correct grammar, they would (miraculously) become good writers and speakers. Murray himself presented only two methods for grammar improvement- practicing the rules through false syntax (the correction of incorrect sentence constructions) and parsing (analyzing a sentence into parts of speech). Noted Tchudi (1967),

At no point in the text is the student required to compose an original thought... Murray clearly took it for granted that if the student could recite the rules, correct examples of false syntax, and parse dexterously, the art of correct speaking and writing had been taught and the job of the grammarian was completed (p. 31). Elementary schools for English-speaking children, then, became focused on teaching highly-specified language skills, and PG activities served that purpose well because they had very little to do with promoting effective language use. As Christie (1993) explained, Elementary school, conceived primarily for the poor, was intended to produce generations of sober, law-abiding and industrious workers. It did not aim to produce 
independent persons, capable of developing and sustaining arguments and opinions on their own (p. 87).

Thus, dominance of PG instruction in schools was particularly damaging for children living in poverty (often the children of immigrants). Rather than encouraging children to develop their expressive language skills, grammar instruction became a means of managing large numbers of children by requiring them to be orderly and quiet, disciplined and silent (Christie, 1993).

As a result of these changes, the Roman conception of grammar instruction (intimately linked with rhetorical studies), designed to develop facilitas with all forms necessary for active citizens of society, faded into obscurity (Woods, 1985). By the time grammar instruction had been firmly positioned as a school subject in schools in the nineteenth century, those opposing the prescriptive grammarians (e.g., concerns over Lindley Murray's list of rules) had become less prominent; this "received tradition" of PG instruction was firmly established and would last well into the twentieth century (Christie, 1993). Christie would lament, "It was a debilitating tradition of English teaching at best" because it "shut out systematic concern for the manner in which language worked to build meaning" (p. 77).

In conclusion, although standards for English were needed for "mutual intelligibility" (Bex \& Watts, 1999, p. 3), the prescriptive grammarians' efforts to control the language resulted in an exceptionally narrow concept of grammar. The goal of grammar instruction, once in pursuit of facilitas, was reduced to teaching children to speak and write not with power but correctly. Furthermore, the standard pedagogy, described as "pure drudgery for the teacher as well as the student," (Beckham, 1938, p. 35) embraced isolated activities. Rather than encouraging students to learn how to use different grammatical constructions for different purposes to convey their ideas, whether in writing or in speaking, or to consider an author's craft as they critically 
analyzed text, the PG activities were designed to teach correct speaking and writing in limited ways.

\section{PG's Lasting Legacy in the United States}

As Pinker (1994) has aptly observed, "once introduced, a prescriptive rule is very hard to eradicate, no matter how ridiculous" (p. 387). Not surprisingly, the prescriptive tradition of teaching grammar made its way from England to the United States, almost immediately establishing a strong foothold (some might say stranglehold) in American pedagogy. And in reaction to such a "dysfunctional, error-focused" approach to language instruction (Kolln \& Hancock, 2005, p. 21), in the second half of the twentieth century, grammar instruction would simply disappear from schools. In this section, I will describe how PG became so popular in U.S. schools during the nineteenth century. Then, I will describe how PG's influence would wax and wane over the years, until the 1960s when educators, unable to further tolerate PG pedagogy, rejected grammar instruction altogether.

\section{Nineteenth Century: The Art of Speaking and Writing Correctly}

In the early part of the nineteenth century, learning English in American elementary schools (also referred to as "grammar" schools) was best explained as "reading as memorization and writing as handwriting or copying; it was unconcerned with originality, self-expression, or even understanding" (Schweiger, 2010, p. 536). And PG was firmly established at the center of the language curriculum, leading to what Leonard (1962) came to call, The Doctrine of Correctness in English usage from 1700-1800. In fact, Lyman's (1922) research examining school curricula and grammars in American schools before 1850 concluded that the concept of grammar was defined simply as the art of correct speaking and writing. The associated pedagogies of the prescriptive grammarians' exercises were especially appealing to teachers 
during this time because students could work independently, and teachers could "attend to other problems" (Woods, 1985, p. 8). Furthermore, it was believed that drills in grammar instruction had the power to discipline the mind (Woods).

The emphasis on teaching minimal levels of language and literacy only intensified as new voices entered into public schools. Although many of the ideals associated with the founding of the United States were grounded in the diversity of its people, Americans inherited a way of thinking about language from England that was deeply rooted in a focus on monolingualism, the notion that one language, specifically one variety of English (SE), represented the most "correct" form of communication (Milroy, 1999). An increasingly diverse school population may in fact have hardened this stance. Connors (1986) has argued that the United States school system's obsession with grammatical correctness can be explained by a cultural and class-based linguistic anxiety that developed as a result of the increasingly large numbers of diverse students in public classrooms. Furthermore, much like the goal of teaching English seen in England, many educators did not believe the "poorer rank of people" should be given opportunities to participate in the new government (Dierks, 2010, p. 268). Dierks noted that even venerated educators such as Noah Webster advocated for "a new system of education above a baseline of mere literacy, yet below a threshold of knowledge, agency, and participation, never mind any potential for leadership" (p. 268).

Between the years of 1820 to 1870 , over 7.5 million immigrants came to the United States, nearly doubling the population in the country. The rapidly increasing numbers of children entering schools ensured that by the mid-to-late nineteenth century, schools no longer represented a homogenous discourse (Russell, 2002). And because these students came from 
diverse backgrounds, they had a variety of ways of expressing themselves, which, in turn, alarmed those desirous of maintaining linguistic order (Bordelon, Wright, \& Halloran, 2012).

The elite colleges and universities were particularly unhappy and began to require entrance exams in an attempt to put pressure on elementary and secondary teachers to better prepare students' their writing abilities (Nelson \& Calfee, 1998). These exams included a written portion requiring each candidate to "write a short English composition, correct in spelling, punctuation, grammar, and expression" (Applebee, 1974, p. 30). Additionally, these colleges and universities commenced teaching entry-level composition classes themselves; however, rather than recognizing that the problem lay in students' poor conceptualizations of a broader view of language, these institutions oversimplified the problem in terms of mechanical correctness (Bordelon et al., 2012; Nelson \& Calfee, 1998). The expectation was that grammar (specifically, PG) was to be attended to in the elementary schools and possibly high school, whereas at the college level, the focus of entry-level composition classes was on remediation of any existing deficiencies (Kolln \& Hancock, 2005).

Thus, attention to PG and its pedagogies (e.g., parsing and false syntax) remained deeply entrenched in schools at all levels, focusing on a rigid set of rules for the enforcement of superficial aspects of syntax and punctuation. As a result, students became more concerned with error avoidance, resulting in a diminished capacity to compose well (Cox, 1885). Lamented Cox, "we cleave to formal correctness, and forget the more effective elements of natural and beautiful speaking and writing" (p. 182)

\section{First Attempt at Standards and the Progressive Era}

To further address the ever-increasing complaints about college students' writing skills, as well as to promote some consistency among the nation's schools, the National Education 
Association (NEA), in 1982, created The Committee of Ten and commissioned this group to write what would later be considered the United States' first attempt at national standards (Applebee, 1974; Gold, Hobbs, \& Berlin, 2012). Although the Report of the Committee of Ten (NEA,1894) was primarily designed to address concerns related to the secondary school curriculum, it had a lasting impact at every level of schooling, particularly written composition in the elementary grades (Nelson \& Calfee, 1998).

Specifically, the 1894 Report specified that the teaching of composition begin in third grade, far earlier than typical practice of the day. Writing in the elementary grades had typically focused on penmanship, spelling, and isolated grammar activities. If composition skills were covered (and it was not a given that they would be addressed at all), they were typically delayed until secondary school (Nelson \& Calfee, 1998). Encouraging third grade elementary teachers to teach English composition was a radical idea at the time. The Committee also attempted to contextualize grammar instruction by linking it with both reading and writing; however, the Committee (1894) possibly misstepped, suggesting that "a student may be taught to speak and write good English without receiving any special instruction in formal grammar" (p. 89). Rather than suggesting alternative pedagogies where grammar instruction might nest within an integrated curriculum, the Committee simply rejected isolated grammar instruction.

Elementary teachers, then, were to reduce the time spent on formal grammar exercises and if grammar was to be addressed, it was to be "incidental" (NEA, 1894 p. 89) to expression, the presentation of ideas in speaking and writing. Toward that end, the Report also encouraged elementary teachers to allow a child "to furnish his own material, expressing his thoughts in a natural way" (p. 88). This represented a major shift in pedagogical thinking at the elementary level. Previously, it was believed that schools were designed to teach obedience and submission; 
but the Report of the Committee of Ten marked "a concession to student interest and innovation that was the hallmark of the newly emergent child-centered progressive elementary education" (Gold et al., 2012, p. 236). The interest in honoring children's expression along with studying grammar (albeit "incidental") within the context of an integrated language arts curriculum marked an important shift away from the isolated, prescriptive pedagogies typical of the time. However, simply rejecting prescriptive pedagogies in favor of incidental learning ultimately led to the loss of a systematic approach to grammar instruction.

\section{PG Pedagogies Rejected, but Nothing to Replace It}

The public response to the Committee of Ten's1894 report was mixed. While recommendations for teaching English in elementary school reflected the new progressive and child-centered philosophy of education, recommendations addressing secondary schools remained subject-centered (Nelson \& Calfee, 1998). In terms of secondary instruction, again, the Report attempted to place grammar instruction in context by linking it back to reading and writing instruction; however, at the secondary level Report suggestions heavily focused on correctness: "The formal teaching of grammar should aim principally to enable the pupil (1) to recognize the parts of speech, and (2) to analyze sentences both as to structure and syntax" (p. 89), activities clearly linked to PG. Failing to provide a rationale for including these particular practices, the Report did, however, recommend that routine parsing and the correction of false syntax should be avoided. In general, the tension between the two opposing ideas - teaching English within an integrated, child-centered approach versus focusing on basic skills in a divided, subject-centered approach - would characterize most of the pedagogical controversies throughout the twentieth century.

Questioning the Place of PG Instruction: 1896-1950 
Happily for many educators, new ideas about pedagogy were coming from Europe, and English began to "blossom into a broader and richer subject by 1900" (Beckham, 1938, p. 6). This "broader and richer" approach to language is reflected in the turn-of-the-century methods textbooks for teachers. Such stances would also find support in the emerging research tradition of the early 1900's

PG questioned in teachers' methods textbooks. Evidently coining the term, languagearts (in this case hyphenated), Hinsdale (1896) indicated that his goal in Teaching the LanguageArts: Speech, Reading, Composition was to

State fully and indicate clearly the principles that underlie all practical language culture, whether it assume the form of speech, reading, or composition - what I have ventured to call language-arts. (p. 4)

He defined the language-arts as speaking, reading, and writing, concluding that these three elements represented tools in developing knowledge in other subjects (e.g., history, science). Hinsdale's integrated language arts curriculum is important to note, but nested within his integrated curriculum, Hinsdale highlighted an arguably more important insight, one clearly breaking from the past - namely, that teaching composition (both written and oral) should be in pursuit of effective expression, above and beyond correctness. Stated Hinsdale, "It is now generally admitted, at least by competent authorities, that the 'Lindley Murray view of grammar' is mainly false and that the subject, taught in the traditional way, has small practical value" (p. 2). Teachers, suggested Hinsdale, had an obligation to explicitly teach children how to write and speak well, rather than simply expecting it of them; however, in rejecting PG, he followed the Committee of Ten Report -- grammar was to be addressed incidentally during language arts instruction. Unhappily, Hinsdale provided little guidance for enacting incidental instruction. 
Hinsdale's text was followed by Chubb's (1902) The Teaching of English in the Elementary and Secondary School and Carpenter, Baker, and Scott's (1903) The Teaching of English in the Elementary and Secondary School, both of which were reprinted through the 1920s (Applebee, 1974). Chubb, like Hinsdale, criticized Murray's grammar and emphasized the importance of "freeing ourselves from the tyranny of Latin models" (p. 209), insisting that teachers instead focus on "a grammar that deals with the actual facts of the English tongue" (p.

The following year, Carpenter et al. (1903) also decried formal grammar instruction, largely criticizing the "rote-work" pedagogy and stressing the emerging understanding "that much of the subject was not in reality English grammar at all, but Latin grammar badly fitted to the English" (p. 145). Dividing English studies into "language, grammar, literature, rhetoric, and composition" (p. 35) did not make sense; instead, they asserted, each element should be included in an integrated English course. Like Hinsdale (1896) and Chubb (1902), they stressed that grammar should be taught "indirectly and progressively" (p. 35).

Generally speaking, then, educators began to reject PG pedagogies in favor of a broader, contextualized approach to grammar instruction and the expression of ideas; however, in the absence of concrete ideas for incidental, indirect, or progressive grammar pedagogies, teachers tended to either continue with existing grammar practices or simply stopped teaching it altogether.

The scientific movement: Challenging prescriptive beliefs quantitatively. As a growing number of scholars and educators recognized that PG had limited practical value, a movement to explore pedagogies that might enhance children's speaking and writing skills began to emerge (Fries, 1940). These ideas gained additional momentum in the early twentieth century as efforts to apply scientific measurement to educational practice rose in popularity (Nelson \& 
Calfee, 1998). Employing quantitative approaches, scholars were able to challenge the prescriptive grammarians' belief that memorizing grammar rules led to effective English communication (Fries, 1940; see also Lyman [1922] for a list of studies). Among the most influential studies, Hoyt (1906) challenged the place of PG pedagogies (e.g., parsing, memorizing parts of speech) in the elementary school setting, arguing that such activities were not suitable for elementary-age children. In the end, his findings suggested, "the absence of any relation between knowledge of English grammar and the ability to either write or to interpret language” (pp. 17-18). Although, Kolln (1981) would later call many of such studies' conclusions into question, they are important to note in terms of the scholarship guiding education at the beginning of the twentieth century.

These new beliefs and confirmatory studies supported a shifting grammar pedagogy, specifically, "grammatical items were taught only as they would directly affect student performance" (Tchudi, 2010, p. 133; see also Fries, 1940). This shift is also reflected in the 1917 "Hosic Report" (so named for its editor; also referred to by its shortened title, "Reorganization of English").

The reaction against English grammar arose from the knowledge that the formal work in the subject that was being done was of small practical value... A sane attitude toward the teaching of grammar would seem to be to find out what parts and aspects of the subject have actual value to children in enabling them to improve their speaking, writing, and reading to teach these parts according to modern scientific methods, and to ignore any and all portions of the conventional school grammar that fall outside of these categories. (p. 37) 
Although the stage seemed set for a movement away from PG, progress was slowed by studies designed to determine which aspects of grammar had value for students. Unfortunately, rather than focusing on how grammar pedagogies might enhance students' ability to use language effectively, these studies remained fixated on correctness (albeit, correctness in context), focused on children's non-SE (Fries, 1940).

Moreover, the majority of teachers continued to rely heavily of classroom textbooks for instruction. Although the methods textbooks designed for teachers rejected PG and its pedagogies, Donsky (1984) reported that the classroom textbooks designed for elementary children published from 1900-1959 still promoted these pedagogies: "those nineteenth century die-hards, grammar and sentence construction, plodded unerringly along, oblivious to changing time and educational currents" (p. 797). Furthermore, she noted that the increasing numbers of immigrant children in schools led to fears (echoing the previous century) that "the English language was on the verge of total corruption" (p. 797). Consequently, teachers were called to join the "crusade" in "the battle against slang or jargon, particularly as presented by the worst offenders of good speech - the comic books and the radio" (p. 798). Thus, PG remained firmly in place.

\section{0-2010: Grammar is Ultimately Abandoned}

Efforts in the early part of the twentieth century to reconnect grammar with meaning had, for the most part, failed, and PG pedagogies maintained their strong place in the curriculum. As Kolln and Hancock (2005) explained, "Nothing changed in K-12 classrooms until Fries' structural linguistics of the 1950s and Chomsky's generative-transformational grammar of the 1960s came to the scene" (p. 14). New efforts to integrate grammar into the language arts curriculum, focusing on teaching children to use language effectively, gained popularity in the 
middle of the century, but again the movement stalled. And when PG reappeared, the reaction was to simple remove grammar entirely from schools. As Squire (2003) would conclude, "the excesses of the new freedom defeated itself' (p. 10). In this section, I explore these developments in greater depth.

The arrival of new English pedagogies. The fifties and sixties did indeed represent what Gold et al. (2012) called a "panacea" for grammar instruction (p. 246). Educators began to focus on structural linguistics, in hopes that learning about sentence structures would enable students to master grammar (Gold et al.).

Charles Fries (1952), one of the most influential of structural linguists, sought to describe English language structures based upon its use by native speakers, thus directly challenging previous PG notions (Hillocks \& Smith, 2003). Breaking PG ties enhanced distinctions between grammar and usage, two terms that had been considered synonymous since the eighteenth and nineteenth centuries (Kolln \& Hancock, 2005). Fries (1952) demonstrated that usage is actually dynamic (rather than stable) and that at any given time, usage is "not uniform for all its educated users" (p. 20). Given this understanding, he focused on English speakers' various grammatical choices for conveying meaning (P. Fries, 2010).

In that same year, NCTE's (1952) publication, The English Language Arts, repopularized interest in an integrated language arts curriculum: communication was to be the heart of the curriculum (Smith, 1953; Squire, 2003).

The Commission realized that the arts of reading, listening, and expression are constantly interrelated. Communication is always a two-way process. One person speaks; another listens. One person writes, another reads. In pursuit of any problem, one is likely to do all four - especially in the classroom - to read about 
what is germane to the problem, to talk or write about what he has read, to listen to other peoples ideas on the subject under discussion. (Smith, p. 77)

The publication was immensely popular, selling out in its first month, largely due to its emphasis on "less exercise-doing and more actual expression of ideas in speech and writing" (Smith, 1958, p. 319). The Commission's (1952) decision to promote the term language arts instead of English further resulted in a dramatic increase in the number of elementary teachers who joined NCTE, thus amplifying their voice in pedagogical conversations (Alvermann, 2010).

The publication's (1952) chapter on grammar additionally received special commendation from the Modern Language Association (MLA) because it emphasized that grammar instruction "must shift in emphasis from the laying down of negative rules to the development of positive insights" (Commission for the English Language Arts [NCTE], 1952, p. 278). The stance that "pupils must be taught to observe and understand the way in which their language operates today for all the various needs of communication" (emphasis added, pp. 278279) reflected an abandonment of PG pedagogy for grammar pedagogy as Quintilian had seen it -- grammar knowledge in the pursuit of effective communication. In fact, rather than continuing to define grammar as speaking and writing correctly, the Commission (1952) defined it as "(a) the description of the formation of English sentences, including the relationships of words, phrases, and clauses to each other; and (b) the explanation of choices in the inflectional forms which still survive in modern English" (p. 284). Teachers were to look for opportunities within a fully integrated curriculum that would enhance students' understanding of how language operates in texts.

This call for more integration among the language arts, as well as the study of language and grammar grounded in linguistic choice contrasted to strict rule enforcement, gained 
momentum in the 1950s and 1960s, leading to a number of pedagogical advances in grammar instruction, particularly at the sentence level. Connors (2000) described three major sentencebased activities that began in the 1960s, all of which gained empirical support. He began by describing Francis Christensen's A Generative Rhetoric of the Sentence, which taught students to modify simple sentences by adding clauses or phrases (e.g., appositives) in pursuit of longer, more mature and compelling sentences. Christensen was certain that if students "become sentence acrobats" and "dazzle by their syntactic dexterity" (p. 160), they were bound to become good writers. According to Connors, although several scholars would offer anecdotal evidence that Christensen's approach was effective in improving the quality of students' writing, it was not until 1978 that Faigley designed and executed a scientific study demonstrating that Christensen's methods did indeed have a measurable, significant effect on the quality of students' writing.

Connors (2000) next described the return of imitation studies seen in ancient Rome. Corbett (1965) led this movement, in which students were to copy passages and then imitate the patterns used by the author. According to Corbett (1971), the goal was not for students to slavishly follow model sentences, but instead "to achieve an awareness of the variety of sentence structures of which the English language is capable" (p. 249). Interestingly, Connors reported that Hake and Williams (1977) found that students in their imitation group wrote stronger expository prose with fewer mistakes than the students using sentence-combining approaches.

Finally, Connors (2000) reviewed the long history of sentence combining, beginning with Rose's (1983) One Hundred Years of Sentence Combining, then describing the method's popularity from 1976-1983. In concluding his article, Connors described how the burst of 
activity in sentence-level work in the sixties eventually "lost currency" (p. 119), as I will discuss in the following section.

PG returns. Regrettably, the momentum surrounding sentence-level work within a more fully integrated language arts program was doomed almost from the start. Following World War II, public education's conservative critics argued that schools should be subject-centered, not child-centered, focused on developing strong academic skills (Nelson \& Calfee, 1998). The launch of Sputnik in 1957 supplied "instant credibility to these charges, providing concrete evidence to many that the United States technological dominance was being eclipsed" (Gold et al., 2012, p. 248). Schools and their child-centered, integrated language arts pedagogies were culpable, the march towards contextualized grammar instruction was halted, and pedagogy returned to "separate components of a subject-centered curriculum" (Nelson \& Calfee, 1998, p. 23). As one might expect, the subject-centered curriculum, with its back-to-basics orientation once again returned PG pedagogies to schools.

One other cause, according to Kolln and Hancock (2005), may have been the influence of Noam Chomsky's 1957/1965 generative-transformative grammar on school grammar pedagogy. Although Chomsky repeatedly warned his enthusiasts that his generative-transformational theoretical model was not designed as a model for people to follow, it nonetheless made its way into grammar texts (Hillocks \& Smith, 2003; Kolln \& Hancock, 2005). Teachers found it confusing and hard to teach, and as a result they returned to traditional grammar texts still grounded in prescriptivist, Latin-based grammar, such as John Warriner's English Grammar and Composition (Kolln \& Hancock, 2005).

Grammar disappears. In reaction to the emphasis on the skill-based teaching seen in the back-to-basics movement, many scholars began to argue that grammar and sentence-level work 
was tedious and dehumanizing (D’Agnelo, 1973; Johnson, 1969; Moffett, 1968). Connors (2000) lamented that despite great gains made in grammar pedagogies and the numbers of empirical studies demonstrating the power of sentence-level pedagogies, the uninformed belief that these methods did not improve student writing widely affected classroom practice.

The movement away from sentence-level work gained additional ground after NCTE's Research in Written Composition (The Braddock Report; Braddock, Lloyd-Jones, \& Schoer, 1963) pronounced that grammar instruction had a "negligible... or even harmful effect" (p. 37) on student's writing performance. Further stressing that grammar instruction should be rejected, the Dartmouth Conference of 1966 effectively sounded "the death knell" (Hillocks \& Smith, 2003, p. 729) for grammar instruction as "many educational jurisdictions in the USA, the UK, Australia, New Zealand, and Canada moved to exclude formal grammar teaching from the English curriculum" (Myhill \& Watson, 2014, p. 42). Teachers from both the U.S. and Great Britain had met in Dartmouth to discuss the problems they faced in teaching English. But, as Muller (1967) described, when the American teachers presented their grammar pedagogy, "Disaster struck... It looked just as dreary as the old exercises in grammar. The British were appalled by it; they wanted to know how some of these ghastly exercises could be considered humanistic" (p. 72). American teachers quickly realized the limitations of the back-to-basics movement as the British presented "a model for English instruction which focused not on the 'demands' of the discipline but on the personal linguistic growth of the child" (emphasis added, Applebee, 1974, p. 229). With a focus on fostering personal growth in children, memorization and rote learning fell firmly from favor; however, once again, there seemed no new pedagogies to take its place. 
Providing even further evidence that grammar instruction required major changes, NCTE published a resolution in 1968 (largely in response to the 1963 Braddock Report and the 1966 Dartmouth Conference, but also based on new work in sociolinguistics): teachers were to recognize the legitimacy of children's home languages and dialects. Because PG had historically promoted the use of a single, correct SE grammar in pursuit of speaking properly as a good, well-behaved American, scholars and educators alike began to recognize how detrimental such an elitist tradition could be for students, particularly those who spoke a variety of English that deviated from the so-called standard. Thus, teachers were to reject grammar instruction as "an instrument for presenting grammar of a particular dialect as right or pure or logical or better than others" (as cited in Kolln \& Hancock, 2005, p. 17). Continued the NCTE resolution, "Many English teachers... feel a responsibility to reject approaches to grammar and usage study that support the linguistic imperialism of prescriptive 'school grammars"” (as cited in Kolln \& Hancock, 2005, p. 17).

Although critically and socially important, the resolution led teachers to reject the grammar instruction altogether rather than encouraging the study of grammar in a broader context, deeply informed by the study of language. As a result, teachers became afraid to teach grammar (Kolln \& Hancock, 2005). This turn away from grammar was not limited to teachers; Gold et al. (2012) further contended, "Concerns about grammatical prescriptivism have especially made scholars reluctant to explore writing at the sentence level" (p. 267).

The back-and-forth nature of the call for grammar (typically PG) instruction to the rejection of grammar instruction would continue, but the anti-grammar stance would ultimately prevail during this time. Although it is hard to assign a precise date, Kolln and Hancock (2005) reported that by 1980 grammar instruction had entirely vanished, a conclusion consistent with 
Connors' (2000) report. Its fate was further sealed in 1986, with the publication of Hillocks' Research on Written Composition: New Directions for Teaching; this echoed the Braddock Report, insisting that any teacher who continued with traditional grammar instruction did their students a "gross disservice" (p. 248) and "should not be tolerated" (p. 248).

There have been periodic efforts since the 80 s to revisit grammar instruction, but these have typically hearkened back to turn-of-the-century incidental grammar instruction. Weaver's (1996) Teaching Grammar in Context, the most widely used grammar instruction book, set forward twelve principles for teaching grammar. Specifying that grammar instruction must honor children's home dialects and rejecting isolated grammar activities in favor of an integrated and language-rich curriculum, Weaver's approach had considerable appeal for teachers. Even she, however, would maintain that few grammatical terms were actually needed for grammar instruction. Kolln and Hancock (2005) later argued that the lack of accountability in such an approach resulted in diminished grammar knowledge over time. Ultimately, students failed to “soak up" (p. 25) grammatical knowledge from teachers' vague feedback, and grammar instruction avoidance continued.

\section{The Recent Rise of National Standards (and the Resurgence of Grammar)}

As this highlighted history suggests, grammar studies rise and fall and rise again. Presently, we are in a period of resurgence in English grammar studies; however, as discussed earlier, Myhill and Watson (2014) have contended that the long-standing debate among researchers, teachers, politicians and parents over grammar instruction has not advanced since the early 1960s; consequently, "The same arguments are voiced and re-voiced over time, but with little re-theorization" (p. 53). In light of Myhill and Watson's claim, it is important to consider new national standards that include grammar instruction. Although there are new 
standards in Great Britain (Department for Education [DfE], 2014) and in Australia (Australian Curriculum Assessment and Reporting Authority [ACARA], 2012), I focus in this final section on the United States relatively new CCSS, which reintroduce grammar into English/language arts curricula. Specifically, in light of the highlighted history I have presented, I contemplate how the new reforms offer a potential opportunity to return to a Quintilian-style integrated notion of grammar instruction, but also fail to provide the supports necessary to avert a return to illadvised PG exercises.

\section{CCSS: A Failure to Guide an Integrated Language Arts Curriculum}

CCSS for Language Arts appear to offer an opportunity to reposition language at the heart of the curriculum by including a set of anchor Language Standards; specifically, they remind teachers that reading, writing, speaking, and listening are inseparable (CCSSI, n.d., “Language Anchor Note"). Yet, teachers are not offered any direction on how such instruction would work. For example, the writing standards require children to write opinion pieces in first grade. ("Write opinion pieces in which they introduce the topic or name the book they are writing about, state an opinion, supply a reason for the opinion, and provide some sense of closure" [CCSSI, n.d., "Text Types", para 1].) It seems reasonable to suggest that, in a truly integrated curriculum, students might present their opinions orally as well as in written form (a skill presumably important for societal success), perhaps even prior to writing; however, CCSS speaking and listening standards are focused primarily on being a good group member, not on expressing opinions. ("Follow agreed-upon rules for discussions" [CCSSI, n.d., "Comprehension and Collaboration", para 2].) Without any alignment among the writing and speaking standards, designing grammar instruction related to both would prove challenging for most United States elementary teachers. 


\section{Knowledge of Language, or the Lack Thereof}

In terms of grammar instruction, the Language Anchor Standards require students to use SE correctly and acquire/develop knowledge of language (KOL). However, neither SE nor KOL is ever fully explained in the CCSS (Myhill, Jones, \& Watson, 2013), nor is a clear definition of grammar ever presented. In Appendix A (CCSSI, 2010, Appendix A), the authors describe the recursive nature of grammar development and how grammar knowledge might help students make "appropriate grammar and usage choices in writing and speaking" (p. 29) in addition to using "knowledge of grammar and usage for reading and listening comprehension" (p. 29); however, the CCSS appear to be using the terms grammar and usage almost interchangeably, a practice that hearkens back to prescriptive grammarians (Kolln \& Hancock, 2005). Absent a clear presentation of grammar and usage in the Appendix, teachers will likely then turn to the Language standards themselves for clarification: there they will encounter standards quite heavily focused on correctness and error-avoidance rather than "usage choices" (CCSSI, 2010, Appendix A, p. 29; see also, Myhill \& Watson, 2014).

CCSS never explains how grammar knowledge might contribute to students' KOL (described as an understanding of "how language functions in different contexts, to make effective choices for meaning or style, and to comprehend more fully when reading or listening" [CCSSI, n.d., "KOL”]). Without a clear discussion and given research suggesting acute limitations to current teachers' grammar knowledge (e.g., Gartland \& Smolkin, 2013; Watson, 2013), teachers, and their students, would seem unlikely to succeed in instantiating KOL standards.

\section{The Placement of KOL in the CCSS}


As Crystal (2006) noted, "different usages are appropriate to different settings, and once we are aware of this we can begin to exploit the stylistic contrast involved" (p. 101); those working with contrastive analysis (e.g., Wheeler \& Swords, 2010) as well as some $17^{\text {th }}$ century grammarians would agree. But the CCSS do not introduce this concept of contrast until second grade, when children are finally required to compare formal and informal uses of English. Situating subject-verb agreement (a kindergarten standard) in the context of situation early on (in school we say ___ at home we would say ) as part of KOL would be quite logical. Presently, by the time they reach second grade, children who speak less valued varieties of English will have had two years of being told they do not speak correctly, potentially inhibiting their participation in school conversations (Delpit, 2002; Rickford \& Rickford, 2007). Furthermore, although CCSS authors have stated, Grammar and usage instruction should acknowledge the many varieties of English that exist and address differences in grammatical structure and usage between these varieties in order to help students make purposeful language choices in their writing and speaking (Appendix A, p. 29), the standards themselves do not directly address such language variations until fifth grade. And even then, the standard states, "Compare and contrast the varieties of English (e.g., dialects, registers) used in stories, dramas, or poems" (emphasis added; CCSSI, "Grade 5 KOL”, para 3). So while students will be asked to discuss the language variation seen in literature, they may never have addressed the English variation in their own lives. Again, this puts non-SE speakers at a great disadvantage.

Although the CCSS suggest a link between grammar knowledge and effective communication, that link is never fully explained. Without a clear understanding of how 
grammar knowledge might help students write well-crafted persuasive essays, articulate clear arguments in a group discussion, or analyze an author's craft in a literature circle, teachers may once again return to isolated grammar activities, long-established to be ineffective.

\section{Concluding Thoughts}

In 1902, Chubb wrote, “Among the greater unsettled questions connected with the study of English, none is more unsettled than the Grammar question. What place shall the study of formal English grammar have in our curriculum?” (p. 204). Over 100 years later, the situation is little different. Much of our grammar controversy has been inherited from the eighteenth century prescriptive grammarians; as Gowers (1954) contended, "The old-fashioned grammarian certainly has much to answer for. He created a false sense of values that still lingers" (p. 120). Still, the fault is not theirs alone:

...whatever their virtues and vices, the eighteenth-century grammarians cannot reasonably be blamed for the twentieth century's continuing preoccupation with grammatical correctness; if this is an aspect of their work that has had a longer influence that we might wish, that is not their fault" (Haussamen, 2000, p. 20). Understanding the history around grammar instruction can help us move beyond the debate regarding whether grammar has or has not a place in the curriculum to a more in-depth discussion about how grammar knowledge can enrich students' language use and understanding. However, as history shows, without a clearly articulated path forward, the push for students to learn SE grammar will likely lead teachers to draw upon "out-dated and linguistically untenable, prescriptive attitudes toward language use that associated language with self-evident standards, correctness, and values" (Clark, 2001, p. 120). 
As we attempt to "re-imagine" (Derewianka, 2012, p. 128) how grammar instruction might enable students greater flexibility in their linguistic choices, revisiting the grammar instruction seen in the Roman Quintilian's curriculum holds considerable promise. His instructional system not only represented a fully integrated language arts program-something much favored but rarely achieved - but he also offered ancient schoolmasters (and perhaps us as well) a detailed discussion of supporting such instruction. Regrettably, at present, only disintegrated fragments of Quintilian's excellent, integrated instruction survive, employed by teachers in ways Quintilian likely never intended. Murphy (2012), addressing this point, cited Kelly:

Nobody really knows what is new or old in present-day language teaching procedures. There has been a vague feeling that modern experts have spent their time in discovering what other men have forgotten; but as most of the key documents are in Latin, moderns find it difficult to go to original sources. In any case, much that is being claimed as revolutionary in this century is merely a rethinking and renaming of earlier ideas and procedures. (p. 74)

In closing, I echo the scholars who have called for a return to facilitas, specifically placing explicit grammar instruction into highly integrated language arts programs. Furthermore, I suggest that carefully considering Quintilian's systematic imitation studies instruction, only briefly described in this paper, holds great promise for guiding teachers in the powerful, meaningful, thoughtful instruction of contextualized grammar studies in their own classrooms. Historical knowledge may prove the key to future grammatical success stories. 


\section{References}

Australian Curriculum Assessment and Reporting Authority (ACARA). (2012). Australian Curriculum: English. Version 3.0. Sydney, AU: Australian Curriculum Assessment and Reporting Authority. Retrieved from http://www.australiancurriculum.edu.au/Australian\%20Curriculum.pdf?Type=0\&s=E\&e $=$ ScopeAndSequence

Abbott, D. P. (2012). Reading, writing, and rhetoric in the Renaissance. In J. Murphy (Ed.) $A$ short history of writing instruction: From ancient Greece to contemporary America $\left(3^{\text {rd }}\right.$ ed., pp. 148-171). New York, NY: Routledge..

Alvermann, D. E. (2010). The teaching of reading. In E. Lindemann (Ed.) Reading the past, writing the future: A century of American literacy education and the National Council of Teachers of English (pp. 55-90). Urbana, IL: NCTE.

Applebee, A. N. (1974). Tradition and reform in the teaching of English: A History. Urbana, IL: NCTE.

Bailey, A. L. (Ed.). (2006). The language demands of school: Putting academic English to the test. New Haven, CT: Yale University Press.

Beckham, C. (1938). The history of the teaching of high school English from 1870 to 1900 (Unpublished doctoral dissertation). Stanford University, Palo Alto, CA.

Bex, T. (1999). Representations of English in twentieth-century Britain: Fowler, Gowers and Partridge. In T. Bex \& R. J. Watts (Eds.) Standard English: the widening debate (pp. 89112). New York, NY: Routledge.

Bex, T., \& Watts, R. J. (Eds.). (1999). Standard English: the widening debate. New York, NY: Routledge. 
Bloodgood, J. W. (2002). Quintilian: A classical educator speaks to the writing process. Reading Research and Instruction, 42(1), 30-43.

Bordelon, S., Wright, E. A., \& Halloran, S. M. (2012). From rhetoric to rhetorics: An interim report on the history of American writing instruction to 1900. In J. Murphy (Ed.) A short history of writing instruction: From ancient Greece to contemporary America $\left(3^{\text {rd }}\right.$ ed., pp. 209-231). New York, NY: Routledge.

Braddock, R., Lloyd-Jones, R. \& Schoer, L. (1963) Research in written composition. Urbana, IL: NCTE.

Carpentar, G., Baker, F., \& Scott, F. (1903) The teaching of English in the elementary and secondary school. Retrieved from http://babel.hathitrust.org/cgi/pt?id=nyp.33433069253569;view=1up;seq=9

Carter, R., \& McCarthy, M. (2006) Cambridge grammar of English. Cambridge, UK: Cambridge University Press.

Christiansen, N. (2003). The master of the double frame and other lessons from classical education. In M. Helmers (Ed.) Intertexts: Reading pedagogy in college writing classrooms (pp. 68-96). Mahwah, NJ: Erlbaum.

Christie, F. (1993). The 'received tradition' of English teaching: The decline of rhetoric and the corruption of grammar. In B. Green (Ed.) The insistence of the letter: Literacy studies and curriculum theorizing (pp. 75-106). Pittsburg, PA: The Falmer Press.

Chubb, P. (1902) The teaching of English in the elementary and secondary School. Retrieved from http://books.google.com/books?id=31UiAQAAMAAJ\&printsec=frontcover\&source=gbs _ViewAPI\#v=onepage \&q\&f=false 
Clark, U. (2001). War words: Language, history and the disciplining of English. Oxford, UK: Elservier.

Clark, U. (2010). Grammar in the curriculum for English: What's next? Changing English, 17(2), 189-200. DOI:10.1080/13586841003787332

Common Core State Standards Initiative. (2010). Appendix A: Research supporting key elements of the Standards. Retrieved from http://www.corestandards.org/assets/Appendix_A.pdf

Common Core State Standards Initiative. (n.d.). College and career readiness anchor standards for language. Retrieved from http://www.corestandards.org/ELA-Literacy/CCRA/L/

Common Core State Standards Initiative. (n.d.). English language arts standards, language, grade 5. Retrieved from http://www.corestandards.org/ELA-Literacy/L/5

Common Core State Standards Initiative. (n.d.). English language arts standards, speaking \& listening, grade 1. Retrieved from http://www.corestandards.org/ELA-Literacy/SL/1

Common Core State Standards Initiative. (n.d.). English language arts standards, writing grade 1. Retrieved from http://www.corestandards.org/ELA-Literacy/W/1

Connors, R. J. (1986). Grammar in American college composition: An historical overview. In D. A. McQuade (Ed.), The territory of language: Linguistics, stylistics, and the teaching of composition (pp. 3-22). Carbondale, IL: Southern Illinois University Press.

Connors, R. J. (2000). The erasure of the sentence. College Composition and Communication, 52(1), 96-128. doi:10.2307/358546

Corbett, E.P.J. (1965). Classical rhetoric for the modern student. New York, NY: Oxford Press.

Corbett, E.P.J. (1971). The theory and practice of imitation in classical rhetoric. College Composition and Communication, 22(3), 243-250. DOI: 10.2307/356450 
Corbett, E.P.J., \& Connors, R. (1998). Classical rhetoric for the modern student ( $4^{\text {th }}$ ed.). New York, NY: Oxford Press.

Cox, E. S. (1885). English in American schools. Journal of the Proceedings of the National Education Association, 85, 181-190.

Crystal, D. (2006). The fight for English: How language pundits ate, shot, and left. Oxford, UK: University Press.

Crystal, D. (2010). Evolving English: One language, many voices. London, UK: The British Library.

D’Agnelo, F. (1973). Imitation and style. College Composition and Communication, 24(3), 283290. DOI: $10.2307 / 356855$

Davis, H. (1999). Typography, lexicography and the development of the idea of 'standard English'. In T. Bex \& J.R. Watts (Eds.). Standard English: the widening debate (pp. 6988). New York, NY: Routledge.

Delpit, L. (2002). No kinda sense. In L. Delpit \& J. K. Dowdy (Eds.), The skin we speak: Thoughts on language and culture in the classroom (pp. 31-48). New York, NY: New Press.

Department of Education (DfE). (2014) The National curriculum in England: framework for key stages 1 to 4. London: DfE. Retrieved from: https://www.gov.uk/government/publications/national-curriculum-in-england-frameworkfor-key-stages-1-to-4

Dierks, K. (2009). In my power: Letter writing and communications in early America. Philadelphia, PA: University of Pennsylvania Press. 
Derewianka, B. (2012). Knowledge about language in the Australian Curriculum: English. Australian Journal of Language \& Literacy, 35(2), 127-146.

Dons, U. (2004). Descriptive adequacy of early modern English grammars. Berlin, DE: Mouton de Gruyter.

Donsky, B. B. (1984). Trends in elementary writing instruction, 1900-1959. Language Arts, 61(8), 795-803.

Ferreira-Buckley, L. (2012). Writing instruction in eighteenth and nineteenth century Great Brittain: Continuity and Change, Transitions and Shifts. In J. Murphy (Ed.) A short history of writing instruction: From ancient Greece to contemporary America $\left(3^{\text {rd }}\right.$ ed., pp. 172-208). New York, NY: Routledge.

Fries, C. C. (1940). American English grammar: The grammatical structure. New York, NY: Appleton-Century-Crofts.

Fries, C. C. (1952). The structure of English. New York, NY: Harcourt Brace.

Fries, P. (2010). Charles C. Fries, linguistics and corpus linguistics. ICAME Journal: Computers in English Linguistics 34(7): 89-121.

Gartland, L. B., \& Smolkin, L. B. (2013). “It just flows”: Preservice teachers grapple with academic language. Submitted for publication.

Glenn, C. (1995). When grammar was a language art. In S. Hunter \& R. Wallace (Eds.) The place of grammar in writing instruction: past, present, and future (pp. 9-29). Portsmouth, NH: Boynton/Cook.

Gold, D., Hobbs, C. L., \& Berlin, J. A. (2012). Writing instruction in school and college English: The twentieth century and the New Millennium. In J. Murphy (Ed.) A short history of 
writing instruction: From ancient Greece to contemporary America $\left(3^{\text {rd }}\right.$ ed., pp. 172208). New York, NY: Routledge.

Gowers, E. (1954). The complete plain words. London, UK: HMSO.

Graham, S. McKeown, D., Kiuhara, S. A., \& Harris, K. R. (2012). A meta-analysis of writing instruction for students in the elementary grades. Journal of Educational Psychology, 104(4), 879-896. doi: 10.1037/a0029185

Graham, S., \& Perin, D. (2007). Writing next: Effective strategies to improve writing of adolescents in middle and high schools - A report to Carnegie Corporation of New York. Washington, DC: Alliance for Excellent Education.

Gwosdek, H. (Ed.) (2013). Lily's grammar of Latin in English: An introduction to the eyght partes of speche, and the construction of the same. Oxford, UK: Oxford University Press.

Haussamen, B. (2000). Revising the rules; Traditional grammar and modern linguistics. Dubuque, IA: Kendall/Hunt.

Hillocks, G. (1984). What works in teaching composition: A meta-analysis of experimental treatment studies. American Journal of Education, 93(1), 133-170.

Hillocks, G., Jr., \& Smith, M. W. (2003). Grammars and literacy learning. In J. Flood, D. Lapp, J.R. Squire, \& J.M. Jensen (Eds.), Handbook of research on teaching the English language arts ( $2^{\text {nd }}$ ed., pp. 721-737). Mahwah, NJ: Erlbaum.

Hinsdale, B. A. (1896). Teaching the language-arts: speech, reading, composition. Retrieved from http://babel.hathitrust.org/cgi/pt?id=uc1.\$b263502;view=1up;seq=11

Hosic, J. F. (Ed.) (1917). Reorganization of English in secondary schools: Report by the National Joint Committee on English representing the Commission on the Reorganization of Secondary Education of the National Education Association and the National Council 
of Teachers of English. Washington, DC: GPO. Retrieved from http://www.ncte.org/library/NCTEFiles/Hosic_Report.pdf

Hoyt, F. (1906). Studies in the teaching of English. Grammar: Appendix. The Teachers College Record, 7(5), 29-34.

Johnson, S.T. (1969). Some tentative strictures on generative rhetoric. College English, 31(2), 155-165. DOI: $10.2307 / 374116$

Kerswill, P. \& Culpeper, J., (2009). Standard English and standardization. In J. Culpeper, F. Katamba, P. Kerswill, T. McEnery., \& R. Wodak. (Eds.), English Language and Linguistics. (pp. 223-243). Basingstoke, UK: Palgrave.

Kolln, M. (1981). Closing the books on alchemy. College Composition and Communication, 32(2), 139-151. DOI: $10.2307 / 356688$

Kolln, M., \& Hancock, C. (2005). The story of English grammar in United States schools. English Teaching: Practice \& Critique, 4(3), 11-31.

Leonard, S. A. (1962). The doctrine of correctness in English usage 1700-1800. New York, NY: Russell \& Russell.

Lowth, R. (1765). A short introduction to English grammar. With critical notes. Eighteenth Century Collections Online. Retrieved from http://find.galegroup.com.proxy.its.virginia.edu/ecco/infomark.do?\&source=gale\&prodId $=$ ECCO\&userGroupName=viva_uva\&tabID $=$ T001\&docId $=$ CB3331179757\&type=multi page \&contentSet=ECCOArticles\&version=1.0\&docLevel=FASCIMILE $>$.

Lyman, R. L., (1922). English grammar in American schools before 1850. Chicago, IL: Chicago University Press. 
Milroy, J. (1999). The consequences of standardization in descriptive linguistics. In T. Bex \& R. J. Watts (Eds.) Standard English: The widening debate (pp.16-39). New York, NY: Routledge.

Milroy, J. \& Milroy, L. (1998). Authority in language: Investigation language prescription and standardization ( $3^{\text {rd }}$ ed.). London, UK: Routledge.

Moffett, J. (1968). Teaching the universe of discourse. Boston, MA: Houghton Mifflin.

Monaghan, E. J., \& Hartman, D. K. (2000). Undertaking historical research in literacy. In M.L. Kamil, P.B. Mosenthal, D.P. Pearson, \& R. Barr (Eds.), Handbook of reading research, vol. 3 (pp. 109-121). Mahwah, NJ: Erlbaum.

Muller, H. J. (1967). The uses of English: Guidelines for the teaching of English from the AngloAmerican conference at Dartmouth College. New York, NY: Holt, Rinehard, \& Winston.

Murphy, J. (2012). Roman writing instruction as described by Quintilian. In J. Murphy (Ed.) A Short History of Writing Instruction: From Ancient Greece to Contemporary America ( $3^{\text {rd }}$ ed., pp. 36-76). New York, NY: Routledge.

Murray, L. (1968). English grammar. In R.C. Alston (Ed.) English linguistics, 1500-1800. Leicester, UK: Scolar Press. (Original work published in 1795),

Murray, L. (1805). English grammar: Adapted to the different classes of learners. Hartford, CT: Oliver D. Cooke. (Original work published in 1795). Retrieved from https://archive.org/details/englishgrammara14nurrgoog.

Myhill, D., Jones, S., \& Watson, A. (2013) Grammar matters: How teachers' grammatical subject knowledge impacts on the teaching of writing. Teaching and Teacher Education, 36, 77-91. DOI: 10.1016/j.tate.2013.07.005 
Myhill, D., \& Watson, A. (2014). The role of grammar in the writing curriculum: A review of the literature. Child Language Teaching and Therapy, 30(1), 41-62. doi:10.1177/0265659013514070

National Council of Teachers of English (NCTE), Commission for the English Language Arts . (1952). The English language arts. New York, NY: Appleton-Century-Crofts.

National Education Association (NEA), Committee of Ten on Secondary Education (1894). The Report of the committee of ten on secondary studies, with reports of the conferences arranged by the committee. New York: American Book.

National Governors Association Center for Best Practices \& Council of Chief State School Officers. (CCSS, 2010). Common Core State Standards for English language arts \& literacy in history/social studies, and technical subjects. Washington, DC: Authors. Retrieved from http://www.corestandards.org/ELA-Literacy/

Nelson, N., \& Calfee, R. C. (1998). The reading-writing connections viewed historically. In N. Nelson \& R. Calfee (Eds.), The reading-writing connection (pp. 1-52). Chicago, IL: The University of Chicago Press.

Nelson, N., \& Kinneavy, J. L. (2003). Rhetoric. in J. Flood, D. Lapp, J.R. Squire, and J.M. Jensen (Eds.), Handbook of research on teaching the English language arts (2nd ed., pp. 786-798.). New York: Macmillan.

Pinker, S. (1994). The language instinct: The new science of language and mind. London, UK: Penguin.

Rickford, A. E., \& Rickford, J. R. (2007). Variation, versatility, and contrastive analysis in the classroom. In R. Bayley and C. Lucas (Eds), Sociolinguistic variation (pp. 276-296). Cambridge, UK: Cambridge University Press. 
Robins, R. H. (2013). A short history of linguistics (4 ${ }^{\text {th }}$ ed.). New York: Routledge.

Rose, S. (1983). Down from Haymow: One hundred years of sentence combining. College English, 45(5), 483-491. DOI: 10.2307/376845

Russell, D. R. (2006). Historical studies of composition. In P. Smagorinsky (Ed.), Composition's history: Research on composition, 1983-2003. Urbana, IL: NCTE. (Teachers College Press).

Schleppegrell, Mary J. 2007. The meaning in grammar. Research in the Teaching of English, 42(1), 121-128. Retrieved from http://www.jstor.org.proxy.its.virginia.edu/stable/40171750

Schweiger, B. B. (2010). A social history of English grammar in the early United States. Journal of the Early Republic, 30(4), 533-555.

Scott, F. N., Carpenter, G. R., \& Baker, F. T. (1903). The teaching of English in the elementary and the secondary school. New York, NY: Longmans.

Smith, D. V. (1953). The English language arts: A Link between yesterday and tomorrow. English Journal, 42(2), 72-79. DOI: 10.2307/808689

Smith, D. V. (1958). Re-establishing guidelines for the English curriculum. English Journal, 47(6), 317-338. DOI: $10.2307 / 808587$

Squire, J. (2003). The history of the profession. In J. Flood, D. Lapp, J. R. Squire, \& J. Jensen (Eds.), Handbook of research on teaching the English language arts ( ${ }^{\text {nd }}$ ed.), (pp. 3-17). Mahway, NJ: Lawrence Erlbaum.

Stahl, N. A., \& Hartman, D. K. (2004). Doing historical research on literacy. In N. Duke and M. Mallette (Eds). Literacy research methodologies (pp. 170-196). New York, NY: Guilford. 
Tchudi, S. (1967). The teaching of English composition in American secondary schools, 18501893. (Unpublished doctoral dissertation). Northwestern University, Evanston, IL.

Tchudi, S. (2010). Teaching Language. In E. Lindemann (Ed.) Reading the past, writing the future (pp.125-172). Urbana, IL: NCTE.

Troia, G. A., \& Olinghouse, N. G. (2013). The Common Core State Standards and evidencebased educational practices: The case of writing. School Psychology Review, 42(3), 343357.

Watson, A. (2013). Conceptualizations of 'grammar teaching': L1 English teachers' beliefs about teaching grammar for writing. Language Awareness. 1-15. DOI: $10.1080 / 09658416.2013 .828736$

Watts, R. (1996). Justifying grammars: A socio-pragmatic foray into the discourse community of early English grammarians. In A. H. Jucker (Ed.). Historical Pragmatics (pp. 145-185). Amsterdam, NL: Benjamin

Weaver, C. (1996). Teaching grammar in context. Portsmouth, NH: Boynton/Cook.

Wheeler, R. S., \& Swords, R. (2010). Code-switching: Teaching standard English in urban classrooms. Urbana, IL: National Council of Teachers of English.

Woods, W. F. (1985). The cultural tradition of nineteenth-century "traditional" grammar teaching. Rhetoric Society Quarterly, 15(1-2), 3-12.

Yates, R., \& Kenkel, J. (2002). Responding to sentence-level errors in writing. Journal of Second Language Writing, 11(1), 29-47. DOI: 10.1016/S1060-3743(02)00051-6 


\title{
CHAPTER 4
}

\section{Manuscript 3: The Histories and Mysteries of Grammar Instruction:}

\section{Supporting Elementary Teachers in the Time of the Common Core}

\author{
Abstract \\ The reemergence of grammar instruction in the Common Core State Standards has likely left \\ teachers confused. On the one hand they have been told repeatedly that grammar instruction does \\ not improve student outcomes, and can, in fact, be "harmful" to students. However, on the other \\ hand, many Anglophone countries, including the United States, have re-introduced grammar \\ instruction as an important component of the English language arts curriculum. The purpose of \\ this paper is to help clarify some of the controversies around grammar instruction by providing a \\ brief historical review of grammar instruction. Following, I offer teachers some pedagogical \\ suggestions that will enable them to address grammar in a fun and meaningful way, as opposed \\ to a return the isolated, decontexualized activities that have traditionally plagued grammar \\ instruction.
}


The Histories and Mysteries of Grammar Instruction:

Supporting Elementary Teachers in the Time of the Common Core

Suddenly, the word grammar has reappeared in elementary school teachers'

conversations. The source of this talk is the Common Core State Standards (CCSS; National

Governors Association Center for Best Practices \& Council of Chief State School Officers, 2010), which sets out grade-level expectations for grammar knowledge. The problem is that many teachers are like the preservice teachers with whom I've worked: they're very uncertain of their own grammar knowledge (Gartland \& Smolkin, 2013; see also Watson, 2013). This is not the teachers' or my students' fault; it's the result of years of grammar instruction controversies, in which grammar instruction came to be seen as a "skunk" at the language arts "garden party" (Haussamen, 2003, p. xi). No matter how we got here, many teachers are asking, "How am I supposed to teach this to my students?"

My purpose is first to provide some historical background pertinent to issues of today's instruction and then to provide teachers with pedagogical suggestions that can enable them to escape the "definition, drill, and memorization" (Beckham, 1938, p. 35) pedagogies that have plagued grammar instruction for centuries.

\section{What Is Grammar?}

As Myhill, Jones, Watson, and Lines (2013) suggest, grammar instruction is complicated by "the multiplicity of meanings and connotations that the word evokes" (p. 103). In general, we can say that grammar is a set of rules that explains how a system operates, and in language, this system typically refers to syntax (the arrangement of words and phrases to create well-formed sentences in a language and morphology (the study and description of how words are formed in a language). Grammar can also refer to semantics, the meaning of words and the vocabulary 
choices we employ. In understanding the controversies that surround grammar instruction, it is very important to distinguish between descriptive grammar and prescriptive grammar. Essentially, descriptive grammars present language as it is actually used by speakers and writers of various communities in different settings and contexts, whereas prescriptive grammars describe how people should speak and write (Huddleston \& Pullum, 2005).

Prescriptive grammars privilege Standard English (SE) as the correct variety of English, whereas descriptive grammars characterize SE as one variety of English (albeit an important one), but it is not valued above others. SE is the type of grammar presented in the Common Core because it is the grammar that's associated with "long-term success in public schools, completion of higher education, and employment with opportunities for professional advancement and financial rewards" (Rumberger \& Scarcella, 2000, p. 1). Therefore, adding this type of grammar to children's repertoires can open the door to educational success and socioeconomic mobility. The word adding is where much of the controversy lies. If we can come to view SE as appropriate to employ in particular settings and situations, and other forms as appropriate for other situations, we move away from the idea that there is a single, correct way to speak and write. And we move into the realm of descriptive grammars; this recognition of the legitimacy of other dialects will be the key to successful grammar instruction.

\section{A Brief History of Grammar Instruction}

Before prescriptive grammars arrived on the educational scene in the late 1700's, scholars such as Wallis in the mid-1600's were focusing on descriptive grammars with the idea of contrasting Latin with English (Dons, 2004). Others thought students would learn English grammar best by studying what we would think of as great mentor texts (e.g., Jonson, 1640). But these positions would be overwhelmed as prescriptive grammarians gained prominence. Such 
grammarians (e.g., Lowth, 1762) wanted to recast English in a Latin syntax. Their goal was to enable English speakers and writers of all classes to produce a single correct form, even if they had introduced some new rules in their Latinizing process that had little bearing on the English language, such as the rule that forbids ending a sentence with a preposition.

By the late 1700's prescriptive grammarians had also designed a pedagogy they believed would best serve their goals. Students would memorize grammar rules; they would parse sentences into their various parts of speech; and they would engage in exercises related to false syntax, that is, changing isolated sentences with "incorrect" syntax into the standard form.

However, by the late 1800 's, educators had determined that this isolated, drill-oriented pedagogy was not achieving its goals. Methods textbooks for teachers specifically stated that such pedagogies should be avoided; unfortunately, they did not supply a well-articulated replacement pedagogy. Most often, they suggested that grammar should be taught as needed by students - in short, "incidentally" (Chubb, 1902, p. 214). As a result, teachers were left in a quandary. They could struggle to determine what incidental teaching might be, or they could simply use the textbooks available to them, textbooks that embraced prescriptive grammar pedagogies. Such texts held sway into the 1950's.

By the mid twentieth century, research that had clearly demonstrated that the isolated drill pedagogy was ineffective in enabling children to speak and write with SE. In the 1960's, textbook publishers were ready to experiment with functional grammars and transformational grammars in their textbooks, but the underpinnings of these linguist-derived grammars were difficult for many teachers. During this time there was also a growing awareness of the negative impact of prescriptive grammar on children whose home communities did not emphasize SE. By the late 1960's, organizations such as the National Council of Teachers of English (NCTE) 
would suggest that teachers should "reject approaches to grammar and usage study that support the linguistic imperialism of prescriptive 'school grammars"” (as cited in Kolln \& Hancock, 2005, p. 17). Consequently, grammar instruction in schools virtually disappeared, with the consequence that many teachers today have had no firm grounding in this important language arts component.

Therefore, in light of today's Common Core standards, teachers face an impressive charge. On the one hand, there is an emerging consensus among researchers that teachers have a social responsibility to provide all of their students with access to SE grammar. On the other hand, such instruction, supplied by teachers insecure in their own grammar knowledge, must also foster an appreciation of language variation (rather than a disdain for it). In other words, teachers are tasked with providing children with "opportunities to take control of their language choices as they interact in different social situations with others who speak in diverse dialects" (Cheatham, Armstrong, \& Santos, 2009, p. 8).

\section{Promising Approaches to Grammar Instruction}

Given the new emphasis on SE grammar in the CCSS, coupled with the fact that many teachers have never received grammar instruction themselves (see Table 1 to begin building your knowledge), teachers may feel they have little choice but to move to worksheets representing prescriptive grammar pedagogy (Troia \& Olinghouse, 2013). In fact, more and more research indicates that teachers who are confident in their own grammar knowledge tend to "foster classroom climates which nurture effective grammatical conversations" (p. 89) whereas teachers who feel anxious or insecure about their own grammar knowledge tend to overly focus on rules and enact prescriptive grammar exercises in their classroom (Myhill, Jones, \& Watson, 2013). In the upcoming sections, I present three principles that reflect current scholarship on implementing 
grammar instruction "deeply informed by a disciplined study of language" (Kolln \& Hancock, 2005, p.22) as opposed to a return to "the older, dysfunctional, error-focused, Latin-based school grammar" (p. 22).

\section{Principle 1: Integrate Grammar Instruction into the Overall Language Arts Curriculum}

In addition to increasing their own grammar knowledge, teachers must consider how they will integrate grammar instruction within their overall language arts curriculum. A common myth around grammar instruction is that it is only relevant to writing; however, grammar history (Gartland, 2014) indicates that as early as ancient Greece and Rome, grammar instruction occupied a central position in all language arts instruction. Quintilian (35-95 CE), a Roman rhetorician, emphasized that attention to the productive aspects of language (speaking and writing) was not possible without also considering the receptive aspects of language (reading and listening; Glenn, 1995; Murphy, 2012). Likewise, Schleppegrell and Colombi (2002) have argued that it is not enough for students to understand the complex grammatical features they encounter in their reading and listening; they must also be supported to use such language in their own speaking and writing.

Today's renewed interest in including grammar instruction within a well-integrated language arts curriculum is also apparent in the CCSS Language Anchor Standard:

The inclusion of Language standards in their own strand should not be taken as an indication that skills related to conventions, effective language use, and vocabulary are unimportant to reading, writing, speaking, and listening; indeed, they are inseparable from such contexts. (Common Core State Standards Initiative, n.d., "Note," para 1) 
Therefore, CCSS offers an opportunity to return to the more broadly focused approach to grammar instruction. As Clark (2010) suggests, "a curriculum for grammar is not easily reducible to textbooks or 'we mustn't forget the grammar' bolt-on exercises" (p. 198), but instead should be thoughtfully integrated into the overall language arts curriculum. In other words, grammar instruction is not meant to replace important time spent reading, writing, and speaking; it is meant to complement and be infused in such instruction.

\section{Principle 2: Develop Clear Objectives for Grammar Instruction}

In keeping with the notion that grammar instruction should represent a complementary piece of a highly integrated language arts curriculum, Derewianka (2011) presents a list of objectives for grammar instruction (see Table 2) that can guide both teachers and students as they engage in linguistic exploration within their language arts curriculum. Derewianka (2011) has clearly linked grammatical form (how grammatical features are structured; e.g., how different verb tenses are formed, how an embedded clause works) with meaning (how our linguistic choices create certain meanings, an array of possibilities from which we can choose). For example, her fifth objective of having a "shared language for teaching and learning about the main features of the English language" requires teachers to attend to form (e.g., parts of speech, placement of phrases) in order to develop a grammatical metalanguage; however, the objectives additionally encourage students to consider how those forms affect meaning, thereby assisting students in critically analyzing texts and making appropriate grammatical choices in their own language use. Myhill and Watson (2014) have further emphasized the interrelated nature of grammatical form and meaning when they point out that "grammatical terminology is simply the tool that facilitates language investigation and analysis" (p. 54). They explain that it is not only important for students to know what a passive construction is (e.g., the boy caught a fish vs. the 
fish was caught by the boy), but they must also understand how a passive construction changes the way the information is presented (e.g., the agent of the action is moved to a less direct position, often designed to present information in a more detached, authoritative, and objective manner).

In guiding teachers to consider the relationships between grammatical form and meaning, Derewianka (2011, p. 2) also offers a list of questions teachers might consider when thinking about grammar instruction:

- What range of meanings do verbs express?

- How can my choice of nouns affect the meaning of the text?

- How can I use certain types of adjectives to express my opinion about something?

- Which grammatical features are involved in skills such as classifying, defining, describing, generalizing, exemplifying?

- Which linguistic features can help me produce a text that is coherent and cohesive?

- How do grammatical patterns change from text to text? Why and with what effect?

- How does context affect the kinds of grammatical choices made? (Derewianka, 2011, pg. 2)

Clearly, these questions represent a movement toward grammatical choice and critical analysis, rather than a list of rules stating what is and is not acceptable. Using Derewianka's (2011) objectives as a guide can help teachers to offer a more respectful approach to grammar instruction, one that empowers students to become more contemplative, effective language users.

\section{Principle 3: Experiment with Specific Classroom Activities}

In this section, I present two specific approaches - contrastive analysis and sentence combining attached to mentor texts. Each is research-supported and historically grounded for use in an integrated language arts curriculum.

Contrastive analysis. Perhaps one of the most promising pedagogies/activities for effective grammar instruction can be seen in contrastive analysis (CA) -- the systematic study of languages that examines linguistic similarities and differences between two languages. As noted 
earlier, this approach predates the prescriptive pedagogies and was designed to foster a deeper understanding of how languages work. Sometimes referred to as a means to help students engage in code-switching, CA has long been an important pedagogical tool for second language acquisition (i.e., Lado, 1957).

Rickford and Rickford (2007) contended that CA encourages linguistic versatility by helping students to switch from vernacular dialects (e.g., African American English [AAE], Hawaiian Creole, and Southern Mountain English) and other languages (e.g., Spanish, Mandarin) to SE. They suggested that CA works also with "other variant words, rhyme schemes, poetic forms, and narrative styles, allowing it to mesh smoothly with existing language arts curricula" (p. 284).

CA has not only been successful in expanding children's grammar knowledge and language repertoires (Fogel \& Ehri, 2000), but also represents a popular strategy among many teachers because it explicitly teaches SE while also honoring the diverse linguistic resources that children bring to the classroom. Rather than forbidding children's non-SE dialects, teachers who use CA are able to build on what children already know about language and leverage those resources to their advantage (Cheatham, et al., 2009). In fact, Rickford and Rickford (2007) argued that

There are several advantages to using contrastive analysis to help vernacular speakers acquire the standard variety, including the fact that it appears to have worked everywhere it was tried and evaluated, at least more so than alternative approaches that ignore or disparage the vernacular (p. 280).

They also noted that children who were taught contrastive analysis not only improved their writing performance, they also made greater gains in their reading scores. 
Inside the elementary classroom. The most popular work with CA at the elementary grades can be seen in Wheeler and Swords (2010) exemplary work in which a sociolinguist, Wheeler, and an elementary school teacher, Swords, worked together to help students learn to effectively "code-switch" from informal to formal English, with an emphasis on AAE to SE. Drawing from both their experience and research, they show teachers how to "lay down the red pen and use successful strategies - contrastive analysis and code-switching - for teaching Standard English grammar in linguistically diverse classrooms" (p. vii).

Because the overall goal of code-switching is to equip students with an awareness of how their grammatical choices impact the messages they are trying to communicate, there is less emphasis on the use of drills; the authors recognize that simply correcting errors does not teach students grammar, and can, in fact, lead students to withdraw from classroom participation. In particular, understanding that children's non-SE English is neither incorrect nor deficient, but rather appropriate to certain situations and not to others, is critical to the success of codeswitching lessons. Toward that end, Wheeler and Swords (2010) are careful never to talk about what is "right or wrong" when referring to how students speak or write. Table 3 offers an illustrative guide to help teachers be mindful about how they talk about language use in their classrooms.

After teachers develop a repertoire of ways to discuss grammar with students, Wheeler and Swords (2010) point out the non-SE aspects of their students' speaking and writing. Wheeler and Swords note that these "errors" are actually often based on the "cadences, rhythms, and patterns they've [the children] used at home in their neighborhoods from birth" (p. vii). By identifying these non-SE patterns, teachers can begin designing instruction comparing the English their students actually use with formal academic English (or SE), and in turn, help 
expand the students' grammar knowledge. Rather than replacing a child's dialect with SE, teachers can facilitate “children's growing sociolinguistic awareness to use language appropriately for different situation, for emphasis, and with different audiences" (Cheatham, et al 2009, p. 9).

Pedagogical strategies. A helpful way to encourage children's appreciation of language variation can be to introduce children's literature that validates a variety of dialects (see Table 4 for suggestions). During such a read-aloud, teachers can focus on how the author's language choices contribute to the overall purpose of the message.

After building an understanding/appreciation of language variation, while also identifying key grammatical contrasts to examine, teachers can then create a code-switching lesson, such as considering the use of the apostrophe $s$ ('s) in speech or writing. Some students (e.g., native Mandarin, AAE speakers) tend to delete the apostrophe $s$ in both their spoken and written language based on their language or vernacular patterns (i.e., we went to my aunt house; a giraffe neck is very long). Upon identifying this pattern in their students' communications, teachers could then create a code-switching T-chart comparing formal and informal use as shown in Table 5.

After collecting about four to six examples from students, teachers would underline the contrasting pattern, then ask students to identify the informal and formal patterns. Once children have an opportunity to consider the differences, teachers would guide them through some other examples, eventually releasing them to independent practice.

Teachers can create numerous opportunities for students to apply their ever-expanding understanding of grammar and "language repertoires" (Corson, 2001, p. 87). Children could practice speaking and responding to the new linguistic patterns they are learning by working as 
partners with written teacher-presented sentence frames. For example, one child might ask, "Where will you go after school?" and the partner could respond by completing the sentence frame, "After school, I will go to 's house." Teachers might also give children the opportunity to share some sentences from their own writing. Additionally, teachers can encourage children to try out their new understanding of SE grammatical forms in puppet shows or other dramatic play activities (Cheathum et al., 2009).

$\mathrm{CA}$ is a promising approach to grammar for teachers, particularly given that the approach encourages teachers to customize their lessons to the needs of their own students. In this way, both teachers and students become empowered to talk about grammatical choices in a meaningful way, one that is respectful of the language children bring to school.

Sentence combining and mentor texts. Sentence combining (SC) is a popular approach to grammar instruction, which some researchers (e.g., Rose, 1983) suggest can be seen in Quintilian's ancient Roman language arts instruction and which appeared in American instruction about 100 years ago. Gaining research-based prominence in the 1960's (see Saddler, 2012), SC teaches students how to develop more effective sentences by examining how short, choppy sentences might be combined to create a more mature, complex sentence. At the simplest level, a child who consistently writes short, simple, and unvaried sentences (e.g., My cat has orange fur. My cat is soft.) can use SC exercises to work toward a more complex and sophisticated sentence (e.g., My cat has soft, orange fur). Over 50 years of research demonstrates the effectiveness of SC for the development of more sophisticated writing (Saddler, 2012).

Sentence composing: An important variation. Building on SC, Killgallon and Killgallon (2000) presented a modification, sentence composing (SCO), an approach to teaching SC along with the use of exemplary children's literature as mentor texts for students to examine and 
imitate (another strategy associated with Quintilian). In their introduction, the Killgallons quoted Francis Christensen as they explained why SCO is a helpful and valuable pedagogical resource: "I want them [students] to become sentence acrobats, to dazzle by their syntactic dexterity" (p. vii). The Killgallons then highlighted Christensen's call for the integration of literature, writing, and grammar.

What I am proposing, carries over of itself into the study of literature. It makes the student a better reader of literature. It helps him thread the syntactical mazes of much mature writing, and it gives him insight into that elusive thing we call style. (p. vii)

Like Quintilian's Roman language arts pedagogy, Christensen's and the Killgallons' notion of integrated language arts focuses not only on writing but also on the critical analysis of text. By carefully examining how esteemed authors use language in mentor texts, Quintilian's students developed a bank of resources from which they could draw to create their own engaging and effective sentences (Murphy, 2012). The pedagogies associated with this integrated approach to grammar instruction, both in Quintilian's time and now, represent a much broader notion of grammar instruction than the narrowly focused prescriptive grammar pedagogies that highlighted rules and corrections.

The emphasis seen in both SC and SCO is on sentence structure or form, but a byproduct is often content improvement, particularly when teachers help students make connections between authors' grammatical choices and meaning through engaging activities. Killgallon and Killgallon (n.d.) have explained, "students like the 'puzzle' aspect of unscrambling sentences, coming up with an effective arrangement of the scrambled sentence parts." And unlike most 
textbook or worksheet exercises, in which there is typically just one correct answer, SC activities typically have more than one "correct" answer.

Pedagogical strategies. As an example of how SCO works, Killgallon and Killgallon (2000) used E. B. White's writing in Charlotte's Web as a model. In one exercise, students are presented with the following sentence components:

As the rat rolled it away to eat; With her broad bill; Who could eat almost anything; The goose pushed the rotten egg out of the nest; And even Wilbur ... was appalled; While the entire company watched in disgust. (p. 117)

After students have constructed their own sentences based on the components, the teacher presents E. B. White's actual complex sentence: "With her broad bill, the goose pushed the rotten egg out of the nest, while the entire company watched in disgust as the rat rolled it away to eat, and even Wilbur, who could eat almost anything, was appalled" (Killgallon \& Killgallon, 2000, p. 117).

As another example, teachers might choose to highlight more mature grammatical features, such as the use of adverbial clauses to enhance descriptive writing. Killgallon and Killgallon (2000) suggest that teachers first offer a definition (adverbial clause: the sentence part that give details about the main event in the sentence; as clauses they both contain a subject and verb) and then immediately present activities using mentor texts for students to engage with that feature. Here, they use sentences from Charlotte's Web to provide students with practice identifying adverbial clauses. Note how they've italicized the clauses in the second presentation.

The barn was pleasantly warm in winter when the animals spent most of their time indoors, and it was pleasantly cool in summer when the big doors stood wide open in the breeze. 
The barn was pleasantly warm in winter when the animals spent most of their time indoors, and it was pleasantly cool in summer when the big doors stood wide open in the breeze. (Killgallon \& Killgallon, 2000, p. 115)

After identifying adverbial clauses in multiple quality works of children's literature and discussing how these enhance the author's message/writing, teachers might offer scaffolded opportunities for students to practice adding adverbial clauses to their own writing. For example, after students have read Katherine Applegate's (2012) The One and Only Ivan, teachers might encourage them to create a sentence that includes an adverbial clause to describe some aspects of Ivan's existence in his cage, with White's sentences as a model. This work might begin with students working in small, collaborative peer groups before their own independent efforts.

A similar strategy is to for teachers to ask students to locate a sentence in The One and Only Ivan where they experienced a strong emotional response. After the students have located the sentence, teachers can have them consider how Applegate used the structure of that sentence to evoke their emotional response. By appealing to students' own emotions, as well as by clearly linking grammatical structure and meaning, teachers foster students' understanding of how they might enhance their own writing with similar grammatical structures.

Experienced professional writers have internalized a wide variety of syntactical resources they select from to best convey their thoughts and ideas. Less experienced writers do not have such resources to draw upon. Examining sentences written by the best authors with teacher guidance supports their development. In sum, SC activities provide students with exposure to a variety of syntactical forms that they can ultimately utilize in their own speaking and writing (Saddler, 2012).

\section{Final Thoughts}


The controversies around grammar are very real, particularly given the deeply engrained emphasis on prescriptive grammar pedagogies that have traditionally plagued the grammar instruction enacted in schools. Specifically, it is important to remember that teaching SE is not to be belittled. Students need access to the grammatical forms that are associated with success in school and society. The problem is "the use of SE to beat little kids over the head... and to say to the child that his language, and the language of his family and friends, is 'not correct' and 'not good"' (Elgin, 1976, p. 32), a stance long associated with the prescriptive grammar tradition.

In 1990, Martha Kolln implored both scholars and teachers to ask themselves: "If this formal method of studying grammar doesn't work, then what will? What can we do to make the study of grammar useful?"' (p. 4). Hopefully, this article provides support as teachers move to implement grammar instruction "that affirms and builds up students, rather than putting them down” (Rickford \& Rickford, 2007, p. 284).

As a final caution, in the absence of strong grammatical knowledge, teachers are more likely to try to control students' language choices, rather than expanding them (Myhill, Jones, \& Watson, 2013). It is time for schools (and universities) to arm teachers with the necessary knowledge to foster active discussions about grammatical choice within highly integrated language arts curricula, enabling America's children to effectively employ grammar to their greatest benefit. 


\section{References}

Applegate, K. (2012). The one and only Ivan. New York: Harper Collins.

Beckham, C. (1938). The history of the teaching of high school English from 1870 to 1900 (Unpublished doctoral dissertation). Stanford University, Califonia.

Cheatham, G. A., Armstrong, J., \& Santos, R. M. (2009). “Y'all listenin?”: Assessing children's dialects in preschool. Young Exceptional Children, 12(4), 2-14. DOI:

$10.1177 / 1096250609337588$

Chubb, P. (1902) The teaching of English in the elementary and secondary School. New York: Macmillan.

Clark, U. (2010). Grammar in the curriculum for English: What's next? Changing English: Studies in Culture and Education, 17(2), 189-200. DOI: 10.1080/13586841003787332

Common Core State Standards Initiative. (n.d.). College and career readiness anchor standards for language. Retrieved from http://www.corestandards.org/ELA-Literacy/CCRA/L/

Corson, D. (2001). Language diversity and education. Mahwah, NJ: Lawrence Erlbaum.

Derewianka, B. (2011). A new grammar companion for teachers. Sydney: Primary English Teaching Association Australia (PETAA).

Dons, U. (2004). Descriptive adequacy of early modern English grammars. Berlin: Walter de Gruyter.

Elgin, S. H. (1976). Why" Newsweek" can't tell us why Johnny can't write. English Journal, $65(7), 29-35$.

Fogel, H., \& Ehri, L. C. (2006). Teaching African American English forms to Standard American English-speaking teachers: Effects on acquisition, attitudes, and responses to student use. Journal of Teacher Education, 57(5), 464-480. DOI:10.1006/ceps.1999.1002 
Gartland, L., \& Smolkin, L. (2014). Highlighted History of Grammar Instruction: What Lessons Can We Learn Moving Forward? Manuscript in preparation.

Gartland, L., \& Smolkin, L. (2013). “It just flows”: Preservice teachers grapple with academic language. Submitted for publication.

Glenn, C. (1995). When grammar was a language art. In S. Hunter \& R. Wallace (Eds.) The place of grammar in writing instruction: Past, present, and future (pp. 9-29). Portsmouth, NH: Heinemann.

Haussamen, B. (Ed.) (2003). Grammar alive: A guide for teachers. Urbana, IL: National Council of Teachers of English.

Huddleson, R. D., \& Pullum, G. K. (2005). A Student's introduction to English grammar. Cambridge, England: Cambridge University Press.

Jonson, B. (1909). The English grammar. In A. Waite (Ed. \& Trans.), Ben Jonson: The English Grammar. Retrieved from: http://babel.hathitrust.org/cgi/pt?id=njp.32101017209345;view=1up;seq=9 (Original work published 1640).

Killgallon, D., \& Killgallon, J. (2000). Sentence composing for elementary school: A worktext to build better sentences. Portsmouth, NH: Heinemann.

Killgallon, D., \& Killgallon, J. (n.d.) Sentence composing: Frequently asked questions [blog post]. Retrieved from http://userpages.umbc.edu/ killgall/

Kolln, M. (1990). The future of grammar in American schools. In E. Vavra \& M. Kolln (Eds.) The future of grammar in American schools. Paper presented at Assembly for the Teaching of Grammar (ATEG), Shenandoah College, Winchester, VA, 3-7.

Kolln, M., \& Hancock, C. (2005). The story of English grammar in United States schools. 
English Teaching: Practice \& Critique, 4(3), 11-31. Retrieved from https:/education.waikato.ac.nz/research/files/etpc/2005v4n3art1.pdf

Lado, R. (1957). Linguistics across cultures: Applied linguistics for language teachers. Ann Arbor, MI: University of Michigan Press.

Lowth, R. (1762). A short introduction to English grammar. Retrieved from http://find.galegroup.com/ecco/infomark.do?\&source=gale\&prodId=ECCO\&userGroupN ame $=$ viva_uva\&tabID $=$ T001\&docId $=$ CW111946769\&type $=$ multipage $\&$ contentSet $=\mathrm{ECC}$ OArticles\&version $=1.0 \&$ docLevel=FASCIMILE

Murphy, J. (2012). Roman writing instruction as described by Quintilian. In J. Murphy (Ed.) $A$ Short History of Writing Instruction: From Ancient Greece to Contemporary America. New York, NY: Routledge.

Myhill, D., Jones, S., \& Watson, A. (2013). Grammar matters: How teachers' grammatical knowledge impacts on the teaching of writing. Teaching and Teacher Education, 36, 7791. Retrieved from http://dx.doi.org/10.1016/j.tate.2013.07.005

Myhill, D., Jones, S., Watson, A., \& Lines, H. (2013). Playful explicitness with grammar: a pedagogy for writing. Literacy, 47(2), 103-111. DOI: 10.1111/j.1741-4369.2012.00674.x Myhill, D., \& Watson, A. (2014). The role of grammar in the writing curriculum: A review of the literature. Child Language Teaching and Therapy, 30(1), 41-62. DOI: $10.1177 / 0265659013514070$

National Governors Association Center for Best Practices \& Council of Chief State School Officers. (2010). Common Core State Standards for English language arts \& literacy in history/social studies, and technical subjects. Washington, DC: Authors. Retrieved from http://www.corestandards.org/ELA-Literacy/ 
Rickford, A. E., \& Rickford, J. R. (2007). Variation, versatility, and contrastive analysis in the classroom. In R. Bayley and C. Lucas (Eds). Sociolinguistic variation (pp. 276-296). Cambridge, England: Cambridge University Press.

Rose, S. K. (1983). Down from the haymow: One hundred years of sentence-combining. College English, 45 (5), 483-491.

Rumberger, R., \& Scarcella, R. (2000). Academic English. Linguistic Minority Research Institute Newsletter, 1, 1-2. Santa Barbara, CA: University of California.

Saddler, B. (2012). Teacher's guide to effective sentence writing. New York, NY: Guilford.

Schleppegrell, M. J., \& Colombi, M. C. (2002). Developing advanced literacy in first and second languages: Meaning with power. New York, NY: Routledge.

Troia, G. A., \& Olinghouse, N. G. (2013). The Common Core State Standards and evidencebased educational practices: The case of writing. School Psychology Review, 42(3), 343357.

Watson, A. (2013). Conceptualizations of 'grammar teaching': L1 English teachers' beliefs about teaching grammar for writing. Language Awareness. 1-15. DOI: $10.1080 / 09658416.2013 .828736$

Wheeler, R. S., \& Cartwright, K. B., Swords, R. (2012). Factoring AAVE into reading assessment and instruction. The Reading Teacher, 65(5), pp. 416-425. DOI:10.1002/TRTR.01063

Wheeler, R. S., \& Swords, R. (2010). Code-switching: Teaching standard English in urban classrooms. Urbana, IL: NCTE.

White, E. B. (1952). Charlotte's web. New York, NY: Harper and Bros. 
Table 1

Sources for Growing Your Own Grammar Knowledge

Resources for developing grammar knowledge

Adger, C. T., Snow, C., \& Christian, D. (Eds.). (2002). What teachers need to know about language. McHenry, IL: Delta Systems

Anderson, J., \& Spandel, V. (2005). Mechanically inclined. Portland, Maine: Stenhouse.

Killgallon, \& Killgallon, J. (2007). Grammar for high school: A student worktext. Portsmouth, NH: Heinemann.

Kolln, M.. \& Gray, L. (2012). Rhetorical grammar: Grammatical choices, rhetorical effects $\left(7^{\text {th }}\right.$ edition). Longman.

Resources for understanding linguistic diversity

Alvarez, L., \& Kolker, A. (Producer/Director). (1987). American tongues. [Motion picture]. New York, NY: Center for New American Studies.

PBS series, Do you speak American? http://www.pbs.org/speak/

Understanding Language: Language, Literacy and Learning in the Content Areas http://ell.stanford.edu/teaching_resources 
Table 2

Objectives for Teaching Grammar

We learn about grammar to:

1. Be able to reflect on how the English language works

2. Be able to use language effectively, appropriately and accurately

3. Understand how different kinds of meaning are created through the use of different grammatical forms so that we can control and shape those meanings more skillfully and effectively ourselves

4. Critically analyze texts so we can understand how grammar has been used to achieve certain effects

5. Examine patterns of language and word choices so that we can appreciate, interpret, and create well-constructed texts

6. Have a shared language for teaching and learning about the main features of the English language

Note: from Derewianka (2011), p. 1 
Table 3

New Ways of Talking about Language: From "Error" to "Pattern"

\begin{tabular}{|c|c|}
\hline Instead of & Try this \\
\hline $\begin{array}{l}\text { Thinking in terms of } \\
\text { - } \text { proper or improper } \\
\text { - good or bad }\end{array}$ & $\begin{array}{l}\text { See language as } \\
\text { - } \text { appropriate or inappropriate } \\
\text { - effective or ineffective in a specific } \\
\text { setting }\end{array}$ \\
\hline $\begin{array}{l}\text { Talking about } \\
\text { - } \text { right or wrong } \\
\text { - } \text { correct or incorrect }\end{array}$ & $\begin{array}{l}\text { Talk about } \\
\text { - } \text { patterns } \\
\text { - } \text { how language varies by setting }\end{array}$ \\
\hline $\begin{array}{l}\text { Thinking that students } \\
\text { - make mistakes, errors } \\
\text { - } \text { have problems with plurals, } \\
\text { possessives, tenses, etc. } \\
\text { - leave off an -s, -'s, -ed }\end{array}$ & $\begin{array}{l}\text { See your students as } \\
\text { - following the grammar patterns of their } \\
\text { home language }\end{array}$ \\
\hline $\begin{array}{l}\text { Saying to students } \\
\text { - "should have," "are supposed to," } \\
\text { "need to", "should correct" }\end{array}$ & $\begin{array}{l}\text { Invite students to } \\
\text { - code-switch (choose the language } \\
\text { pattern to fit the setting }\end{array}$ \\
\hline $\begin{array}{l}\text { Red notes in the margin } \\
\text { - correcting students' grammar }\end{array}$ & $\begin{array}{l}\text { Lead students to } \\
\text { - } \quad \text { compare and contrast language } \\
\text { - } \text { build on existing knowledge to add new } \\
\text { knowledge - standard English } \\
\text { - code-switch to fit the setting }\end{array}$ \\
\hline
\end{tabular}

Note: from Wheeler \& Swords, 2010, p. xvii 
Table 4

Sample Children's Literature for Linguistic Diversity Appreciation

Table 5. Children's Literature to Encourage an Appreciation of Linguistic Diversity

Compton, J.. (1994) Asphet: An Appalachian Tale. New York, NY: Holiday House.

Giovanni, N. (Ed.) (2008). Hip hop speaks to children: A celebration of poetry with a beat.

Naperville, IL: Sourcebook.

Herron, C. (1997). Nappy Hair. New York, NY: Alfred A. Knopf.

McKissack, P. (1986). Flossie and the Fox. New York: Dial Books

Note: adapted from Cheatham et al., (2009); Wheeler, Cartwright, \& Swords, (2012) 
Table 5

Informal versus Formal Language Use

\begin{tabular}{l|l}
\hline Informal use & Formal use
\end{tabular}

We went to my aunt house.

We went to my aunt's house.

The pattern

The pattern

Owner + what is owned

Owner +'s + what is owned

Note: Adapted from Wheeler \& Swords (2010)

Additional Requirements for submission to The Reading Teacher:

Pause and Ponder

1. How is this grammar instruction different from your current practice?

2. How might you implement some of these ideas into your own teaching?

\section{Take Action!}

1. Based on observations of your students' work, determine an appropriate grammatical feature to focus on. For example, you might determine that discussing the use of adverbial clauses to enhance students' written work would be a good use of your time.

2. Develop your students' understanding of the grammatical form you have chosen to highlight, thinking carefully about how you will also explain the feature through the use of examples and patterns.

3. After identifying the grammatical form (e.g., adverbial clauses) in multiple quality works in high quality children's literature, create a discussion about how this grammatical structure enhances the author's message.

4. Create scaffolded opportunities for students to practice adding adverbial clauses to their own writing. For example, after reading Applegate's (2012) The One and Only Ivan, teachers might encourage students to create a sentence that includes an adverbial clause to describe some aspects of Ivan's existence in his cage, with E.B.White's sentences as a model. This work might begin with students working in small, collaborative peer groups before their own independent efforts. 